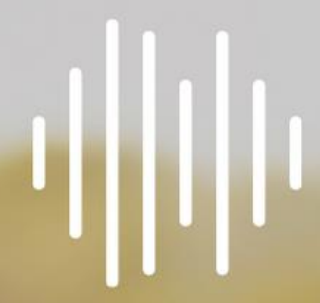

PRÁTICAS EM

SANEAMENTO

CLIMA

\title{
MEIO AMBIENTE
}

GIOVANNI CHAVES PENNER
Editora Poisson

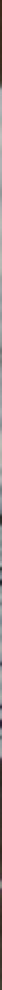

ORGANIZADOR 


\title{
Práticas em Saneamento, Clima e Meio Ambiente
}

\author{
Volume 1
}

1므 Ediçao

Belo Horizonte

Poisson

2020 
Editor Chefe: Dr. Darly Fernando Andrade

\section{Conselho Editorial}

Dr. Antônio Artur de Souza - Universidade Federal de Minas Gerais

Msc. Davilson Eduardo Andrade

Dra. Elizângela de Jesus Oliveira - Universidade Federal do Amazonas Msc. Fabiane dos Santos

Dr. José Eduardo Ferreira Lopes - Universidade Federal de Uberlândia Dr. Otaviano Francisco Neves - Pontifícia Universidade Católica de Minas Gerais

Dr. Luiz Cláudio de Lima - Universidade FUMEC

Dr. Nelson Ferreira Filho - Faculdades Kennedy

Msc. Valdiney Alves de Oliveira - Universidade Federal de Uberlândia

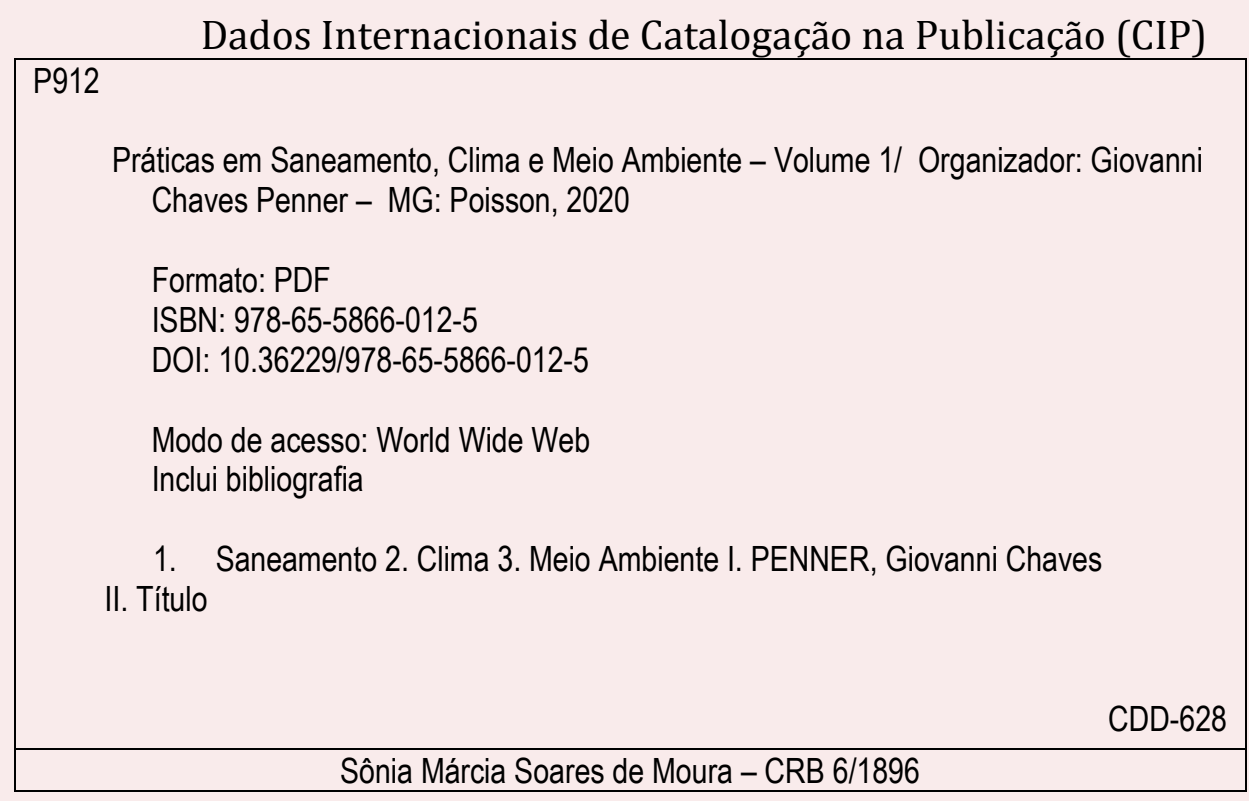

O conteúdo dos artigos e seus dados em sua forma, correção e confiabilidade são de responsabilidade exclusiva dos seus respectivos autores.

www.poisson.com.br

contato@poisson.com.br 


\section{SOBRE OS AUTORES}

\section{KATIUCIA NASCIMENTO ADAM}

Engenheira sanitarista (UFPA) Doutora em Recursos Hídricos e Saneamento Ambiental (UFRGS/IPH). Atuando principalmente nos seguintes temas: recursos hídricos, simulação hidrológica e mudanças climáticas. Atualmente docente da Faculdade de Engenharia Sanitária e Ambiental (FAESA/UFPA).

\section{LUIZA CARLA GIRARD MENDES TEIXEIRA}

Possui graduação em Engenharia Civil pela Universidade Federal do Pará (1993), mestrado em Engenharia Civil (Saneamento) pela Escola Politécnica da Universidade de São Paulo (1999), doutorado em Desenvolvimento Sustentável do Trópico Úmido pela Universidade Federal do Pará (2003) e pósdoutorado em Tratamento Avançado de Esgotos Domésticos no Departamento de engenharia Química e Tecnologia de Meio Ambiente da Universidade de Valladolid-Espanha (2010). Foi professora do CEFET/PA do curso técnico em Saneamento entre 1998 e 2003, tendo atuado como coordenadora do curso entre 1998 e 2002 . Foi presidente da Associação Brasileira de Engenharia Sanitária e Ambiental (ABES) - Seção Pará nos anos de 2008-2009. Desde 2003 é professora do quadro efetivo da Universidade Federal do Pará, tendo lecionado nos cursos de graduação em Engenharia Civil, Arquitetura e Engenharia Sanitária e Ambiental; nos programas de pós-graduação de Engenharia Civil-PPGEC e em Gestão de Recursos Naturais e Desenvolvimento Local - PPGEDAM. Atualmente é professora titular da UFPA e vice-coordenadora do Programa de pós-graduação em Engenharia Sanitária e Ambiental - PPGESA, tendo publicado mais de 30 artigos em periódicos internacionais e nacionais, além de diversos trabalhos em anais de eventos e capítulos de livros. É editora associada da revista Engenharia Sanitária e Ambiental da ABES. Tem experiência na área de Engenharia Civil, com ênfase em Saneamento Básico, atuando principalmente nos seguintes temas: lodo, qualidade da água e sistema de abastecimento de água.

\section{MARCIA REGINA UCHÔA MATOS}

Possui graduação em engenharia sanitária pela Universidade Federal do Pará (2010) e mestrado em engenharia civil (linha de pesquisa: saneamento ambiental e infraestrutura urbana) pela Universidade Federal do Pará (2014). Trabalhou na empresa Contécnica como consultora técnica no setor de projetos na Companhia de Saneamento do Pará (COSANPA). Foi Professora substituta da Universidade do Estado do Pará em 2015 e 2016 (Centro de Ciências Naturais e Tecnológico no Departamento de Engenharia Ambiental) e da Universidade Federal do Pará no ano de 2017 (Faculdade de Engenharia Sanitária e Ambiental). Atualmente presta serviço de consultoria em saneamento e meio ambiente e ministra disciplinas como professora horista na Universidade do Estado do Pará.

\section{CARLOS RODRIGO TANAJURA CALDEIRA.}

Formado em Engenharia Cartográfica pela Universidade Estadual Paulista Júlio de Mesquita Filho (2013). Em 2016 se tornou mestre em Ciências Cartográficas, na área de pesquisa em AQUISIÇÃO, ANÁLISE E REPRESENTAÇÃO DE INFORMAÇOES ESPACIAIS pela Universidade Estadual Paulista, Júlio de Mesquita Fillho. Em seu currículo Lattes os termos mais frequentes na contextualização da produção científica e tecnológica são temas relacionados a detecção de mudanças a partir de imagens orbitais temporais, assim como calibração de câmaras aéreas e processamento de imagens. Atualmente é docente em tempo integral junto ao Instituto Ciber Espacial da UFRA (Universidade Federal Rural da Amazônia) onde atua na área de Geociências/Fotogrametria, em temas ligados a Fotogrametria, Visão Computacional, Ajustamento de Observações, Projeções Cartográficas, tendo interesse também por tópicos como Cartografia Matemática, Temática, Digital e Processamento de Imagens. Atualmente atua como Vice - Coordenador do curso de Engenharia Cartográfica e de Agrimensura. 


\section{JORGE FERNANDO HUMGRIA FERREIRA}

Engenheiro Sanitarista e Ambiental (UFPA). Mestre e doutorando em Engenharia Civil na área de Recursos Hídricos e Saneamento Ambiental (UFPA). Vinculado ao Laboratório de Eficiência Energética e Hidráulica em Saneamento (LENHS/UFPA).

\section{GIOVANNI CHAVES PENNER}

Mestrado e doutorado em Hidráulica e Saneamento pela Escola de Engenharia de São Carlos-Universidade de São Paulo. Visitante na Agência de Proteção Ambiental dos Estados Unidos de Athens-GA em 2004. Sólida experiência com diagnóstico e remediação em área contaminadas. Atendimento ao monitoramento ambiental de diversos aterros sanitários. Professor doutor desde 2005 em cursos de Engenharia Civil e Ambiental. Desde 2016, professor adjunto na Universidade Federal do Pará, lecionando Hidrologia, Gestão de Recursos Hídricos e Impacto Ambiental. Membro do Conselho Estadual de Recursos Hídricos representando a UFPA. Coordenador do Programa de Pós-Graduação em Engenharia Sanitária e Ambiental da UFPA.

\section{HÉLIO DA SILVA ALMEIDA}

Possui graduação em Engenharia Sanitária pela Universidade Federal do Pará (1999), Mestrado em Engenharia Civil -área de concentração- Hidráulica e Saneamento pela EESC/USP(2000), Bacharel em gestão de riscos coletivos em Curso de Formação de Oficial Bombeiro Militar pelo Instituto de Ensino de Segurança do Pará (2003) e Doutorado em Engenharia de Recursos Naturais da Amazônia pela Universidade Federal do Pará (2015). É oficial da reserva do Corpo de Bombeiros Militar do Pará, no posto de Capitão e Graduando em Engenharia Mecânica pela UFPA.

\section{JOSÉ ALMIR RODRIGUES PEREIRA}

Engenheiro Sanitarista (UFPA). Mestre em Recursos Hídricos - Saneamento (UFPB) e Doutor em Engenharia Hidráulica e Saneamento (EESC-USP). Foi funcionário da Companhia de Saneamento do Pará de 1983 a 1996 e é professor da Universidade Federal do Pará - UFPA desde 1996. Atualmente é Professor Titular da UFPA, coordenando o Grupo de Pesquisa Hidráulica e Saneamento (GPHS) e o Laboratório de Eficiência Energética e Hidráulica em Saneamento (LENHS).

\section{MAYARA COBACHO ORTEGA CALDEIRA}

Engenheira Cartografa pela Universidade Estadual Paulista Júlio de Mesquita Filho (2013). Mestre em Ciências Cartográficas, na área de pesquisa em Posicionamento Geodésico pela Universidade Estadual Paulista, Júlio de Mesquita Fillho (2016), Bolsista FAPESP. Atualmente é professora da Universidade Federal Rural da Amazônia, atuando como docente das disciplinas de Cartografia I e II, Geodésia Espacial, Geodésia Física, Levantamentos Geodésicos, Topografia II, Astronomia de Posição e Laboratório Integrado I. Além disso, colabora com o Instituto de Pós-Graduação e Cursos - IPGC. Sendo que em 2013 foi Pesquisadora/bolsista CNPq, em projeto de pesquisa com estudos direcionados ao impacto da cintilação ionosférica e efeitos ionosféricos no posicionamento baseado em redes, com ênfase para posicionamento RTK empregando-se o conceito de VRS (Virtual Reference Station). Neste mesmo ano realizou estágio na empresa ENGEFOTO e na Prefeitura de Presidente Prudente, no departamento de cadastro. Em seu currículo Lattes os termos mais frequentes na contextualização da produção científica e tecnológica são temas relacionados a posicionamento GNSS, estudo dos efeitos da ionosfera, multicaminho, Levantamento Topográfico, Acessibilidade, entre outros. 


\section{NEYSON MARTINS MENDONÇA}

Engenheiro Sanitarista UFPA (1995). Mestre (1999) e Doutor (2004) em Hidráulica e Saneamento pela Escola de Engenharia de São Carlos-Universidade de São Paulo (USP). Professor do curso de Engenharia Sanitária e Ambiental (2008). Foi Diretor Técnico da Associação Brasileira de Engenharia Sanitária e Ambiental (ABES) - Seção Pará nos anos de 2008-2009. Desde 2011 é chefe do Laboratório de Instalações Piloto em Tratabilidade de Águas e Lodo da Faculdade de Engenharia Sanitária e Ambiental (FAESA), atualmente é membro do Programa de Pós-Graduação em Engenharia Sanitária e Ambiental (PPGESA). Atuou em projetos de pesquisa e extensão realizando coordenação e participação em mais de 12 projetos relativos a saneamento básico e ambiental.

\section{SILVANA VELOSO}

Graduada em Química Industrial pela Universidade Federal do Pará, Especialista e Gestão Ambiental e Licenciada Plena em Química pela Universidade Federal do Amapá, Mestre em Ciências Ambientais pela Universidade Federal do Pará, Doutora em Geoquímica Ambiental pelo Programa de Pós-graduação em Geologia e Geoquímica da Universidade Federal do Pará; Professora Adjunta classe C do Instituto Sócio Ambiental e de Recursos Hídricos da Universidade Federal Rural da Amazônia, atualmente Subcoordenadora do Curso de Engenharia Ambiental e Energias Renováveis e Conselheira titular no Conselho Estadual de Recursos Hídricos da Secretaria Estadual de Meio Ambiente e Sustentabilidade do Pará (SEMAS/PA); Com experiência na área de Química Ambiental com ênfase em qualidade da água; Gestão de bacias Hidrográficas e Geoquímica Ambiental.

Endereço para acessar este CV: http://lattes.cnpq.br/1148508546704346 


\section{PREFÁCIO}

O presente livro é o primeiro volume de uma série intitulada "Práticas em Saneamento, Clima e Meio Ambiente" publicado pela Editora Poisson, apresentando métodos práticos para aulas em campo e laboratório considerando a importância do ensino aplicado em engenharia e áreas afins.

o objetivo central deste livro foi apresentar a aplicação de diversos aspectos metodológicos para obtenção de dados primários em campo e laboratório, os quais são úteis para subsidiar acadêmicos, pesquisadores, engenheiros e técnicos da Região Amazônica.

Assim, em razão da escassez de informações práticas que se tem nessa região e sabendo o quão importante é a divulgação científica, evidencia-se a necessidade de promover, na forma de coletânea técnica, a elaboração de dez capítulos, os quais são descritos a seguir:

Capítulo 1. Aula prática: medição de vazão;

Capítulo 2. Aula prática: medição de vazão usando drones;

Capítulo 3. Aula prática: infiltração da água no solo;

Capítulo 4. Aula prática: hidrologia estatística;

Capítulo 5. Aula prática: detecção de mudanças a partir de série temporal de imagens orbitais utilizando os métodos diferença de NDVI e RCEN modificada;

Capítulo 6. Aula prática: nivelamento geométrico, determinação de desníveis e altitudes;

Capítulo 7. Aula prática: sistema de recalque levantamento da curva de uma bomba centrífuga;

Capítulo 8. Aula prática: carga fixa-poluição;

Capítulo 9. Aula prática: ensaio de adensamento por gravidade em batelada de lodo de ETA;

Capítulo 10. Aula prática: determinação de oxigênio dissolvido em águas, método químico.

A disseminação dessa coletânea técnico acadêmica, realizada arduamente com as experiências práticas e acadêmicas dos diversos professores que contribuíram em cada capítulo, desenvolvida de maneira detalhada e didática, para que possa ser replicada em outras instituições de ensino, bem como ser usada como ferramenta para obtenção de dados de práticos, propiciando assim à transferência dos conhecimentos e resultados não somente na Região Norte, mas em todo o Brasil. 


\section{SUMÁRIO}

Capítulo 1. Aula prática: medição de vazão. 09

Giovanni Chaves Penner, Katiucia Nascimento Adam DOI: 10.36229/978-65-5866-012-5.CAP.01

Capítulo 2. Aula prática: medição de vazão usando drones. 16

Katiucia Nascimento Adam, Giovanni Chaves Penner

DOI: 10.36229/978-65-5866-012-5.CAP.02

Capítulo 3. Aula prática: infiltração da água no solo 20

Giovanni Chaves Penner, Katiucia Nascimento Adam DOI: 10.36229/978-65-5866-012-5.CAP.03

Capítulo 4. Aula prática: hidrologia estatística 31

Giovanni Chaves Penner, Katiucia Nascimento Adam

DOI: 10.36229/978-65-5866-012-5.CAP.04

Capítulo 5. Aula prática: detecção de mudanças a partir de série temporal de imagens orbitais utilizando os métodos diferença de NDVI e RCEN modificada 50

Carlos Rodrigo Tanajura Caldeira, Mayara Cobacho Ortega Caldeira, Lucas Daniel Noronha Ferreira DOI: 10.36229/978-65-5866-012-5.CAP.05

Capítulo 6. Aula prática: nivelamento geométrico, determinação de desníveis e altitudes 61

Mayara Cobacho Ortega Caldeira, Carlos Rodrigo Tanajura Caldeira, Lucas Daniel Noronha Ferreira DOI: 10.36229/978-65-5866-012-5.CAP.06

Capítulo 7. Aula prática: sistema de recalque levantamento da curva de uma bomba centrífuga 73 Hélio da Silva Almeida, José Almir Rodrigues Pereira, Jorge Fernando Hungria Ferreira DOI: 10.36229/978-65-5866-012-5.CAP.07

Capítulo 8. Aula prática: carga fixa-poluição 81

Neyson Martins Mendonça

DOI: 10.36229/978-65-5866-012-5.CAP.08

Capítulo 9. Aula prática: ensaio de adensamento por gravidade em batelada de lodo de ETA...... 91

Luiza Girard Teixeira, Marcia Uchôa Matos

DOI: 10.36229/978-65-5866-012-5.CAP.09

Capítulo 10. Aula prática: determinação de oxigênio dissolvido em águas, método químico. 99

Silvana Carvalho Veloso

DOI: 10.36229/978-65-5866-012-5.CAP.10 


\section{Capítulo 1}

\section{Aula prática: Medição de vazão}

Giovanni Chaves Penner

Katiucia Nascimento Adam 


\subsection{OBJETIVOS INSTRUCIONAIS}

Ao final desta aula prática de medição de vazão em pequenos cursos d'água você deverá ser capaz de:

- $\quad$ Enunciar três possíveis métodos aplicáveis a medição de vazão em pequenos cursos d'água;

- Conceituar batimetria, molinete e traçador;

- Operacionalizar a medição de vazão um pequeno curso d'água;

- Identificar as incertezas do método de medição de vazão empregado;

- Comparar os resultados obtidos por diferentes métodos de medição de vazão identificando resultados anômalos.

\subsection{MEDIÇÃO DE VAZÃO EM HIDROLOGIA}

A visão de engenharia dada a nossa disciplina de Hidrologia e Climatologia foca no o ciclo hidrológico do ponto de vista quantitativo. Uma informação deveras solicitada em várias aplicações práticas em Hidrologia é "qual a vazão". Outra dúvida frequente associada ao tema: existe variação significativa da vazão ao longo do ano que comprometa um dado uso? Para responder, muitas vezes, faz-se necessário medir a vazão do curso d'água de interesse, criando-se séries históricas que são extremamente úteis para diversos estudos e projetos de Engenharia.

Desta forma mede-se vazão para se ter valores de referência para a tomada de decisão. Em muitos casos uma única medida não suficiente, daí a necessidade de séries históricas diárias, mensais e anuais. Eventualmente, em condições com as da cidade de Belém-PA, são necessárias medições horárias devido aos efeitos da maré.

\subsection{MÉTODOS DE MEDIÇÃO DE VAZÃO EM PEQUENOS CURSOS D'ÁGUA}

Como foi apresentado em sala de aula há diversos métodos para medir vazão em cursos d'água, cada um com condições de aplicação e ferramental específico. Como o foco da nossa aula prática é para pequenos cursos d'água serão considerados os métodos descritos a seguir.

\subsubsection{FLUTUADOR}

O método consiste em determinar a velocidade de deslocamento de um objeto flutuante, medindo o tempo utilizado para o seu deslocamento num determinado trecho de rio de comprimento conhecido (SANTOS et al., 2001). O flutuador de superfície pode ser uma boia, uma fruta, uma garrafa plástica, ou qualquer outro dispositivo. Um flutuador de superfície move-se com a mesma velocidade da superfície da água, e se for muito leve pode sofrer a influência do vento. Por outro lado, como o flutuador indica apenas a velocidade da superfície da água, é necessário aplicar um coeficiente redutor para obter a velocidade média na seção (SANTOS et al., 2001). A literatura (AZEVEDO NETTO et al., 1998) recomenda que a velocidade média seja obtida multiplicando-se a velocidade superficial por um coeficiente entre 0,8 e $0,9(0,8$ para rios com fundo pedregoso ou 0,9 para rios com fundo barrento). Todavia existem casos que indicam valores distintos e essa pode ser uma das conclusões desta aula prática. Com a velocidade média determinada fazse a batimetria da seção para que seja determinada a área de escoamento da água. Pelo produto da velocidade média pela área da seção de escoamento tem-se a vazão.

\subsubsection{MOLINETE}

Mais um método que determina a vazão pelo produto da velocidade do escoamento pela área da seção transversal.

Molinete são pequenas hélices que giram impulsionados pela passagem da água. Os molinetes são instrumentos projetados para girar em velocidades diferentes de acordo com a velocidade da água. 
Em cursos d'água naturais, a velocidade da água, em geral, é maior no centro de um rio do que junto às margens. Adicionalmente, a velocidade da água é mais baixa junto ao fundo do rio do que junto à superfície. Em função desta variação da velocidade nos diferentes pontos da seção transversal, utilizar apenas uma medição de velocidade pode resultar em uma estimativa errada da velocidade média.

Para obter uma boa estimativa da velocidade média é necessário medir em várias verticais, e em vários pontos ao longo das verticais conforme descrito nos slides da aula e na apostila de apoio. Lembrando que cada vertical de medição de velocidade da água terá uma velocidade média e estará associada a uma área de escoamento. A soma das vazões associada a cada vertical fornecerá a vazão total.

\subsubsection{DILUIÇÃO QUÍMICA OU TRAÇADOR SALINO}

Segundo Silva et al., (2009) traçador é qualquer substância, ou partícula/entidade (química ou biológica), que pode ser usada para seguir, quer pontualmente ou de forma contínua, o comportamento de um determinado sistema ou de um componente, tal como velocidade da água ou vazão.

Pelo exposto a medição da vazão pelo método de diluição usa um traçador. Tal técnica se aplica a pequenos cursos da água, porém, a velocidade e a irregularidade do leito devem ser suficientes para sua mistura até o ponto de determinação da concentração. Aplica-se também onde não é possível instalar calhas e vertedores devido ao custo ou acessibilidade, como presença de cachoeiras. Consiste em lançar no curso em estudo uma vazão de uma solução que não seja encontrada em grande quantidade nessas águas e, a jusante, medir a concentração dessa solução comparando-a com a concentração natural do curso (COLLISCHONN et al., 2015; PORTO et al., 2001).

Os produtos a serem empregados como traçadores devem apresentar certas qualidades essenciais como: elevada solubilidade na água, presença nula ou apenas traços em águas naturais, ser atóxico e não corrosivo para não causar danos ao ambiente, equipamentos e nem as pessoas que o manipulam. Sua concentração não deve se alterar sob influência da luz, bactérias, matéria orgânica, sedimentos em suspensão ou outras substancias solúveis presentes no curso d'água. Não é aconselhável o uso de elementos químicos radioativos como traçadores, que embora apresentem maior precisão, causam danos ao ambiente (HINDI et al., 1998).

Dentre os produtos mais utilizados como traçadores tem-se o Cloreto de Sódio (NaCl), Cloreto de Potássio $(\mathrm{NaK})$, Nitrito de Sódio $\left(\mathrm{NaNO}_{2}\right)$, Sulfato de Manganês $\left(\mathrm{MnSO}_{4}\right)$, Rodamina $\left(\mathrm{C}_{10} \mathrm{H}_{21} \mathrm{ClO}_{3} \mathrm{~N}_{2}\right)$ e Bicromato de Sódio $\left(\mathrm{Na}_{2} \mathrm{Cr}_{2} \mathrm{H}_{7} \mathrm{O}\right)$. $\mathrm{O}$ cloreto de sódio, popularmente conhecido como sal de cozinha refinado, além de ser inofensivo à ecologia, também possui a propriedade de aumentar a condutância específica da água, numa razão proporcional a concentração do mesmo. Tal fato permite medir a condutividade elétrica ao invés de se medir a concentração do sal, o que facilita e agiliza o trabalho de medição da vazão (HINDI et al., 1998).

Para a aplicação deste método existem duas condições fundamentais citadas por Hindi et al. (1998):

1) A homogeneidade do sistema água-traçador deve ser constante para qualquer ponto da seção de medição: em situação de escoamento turbulento esta homogeneidade se dá em distância muito mais curta quando comparadas a aquelas necessárias para rios com escoamento lento e tranquilo.

2) Conservação da matéria: não deverá ocorrer perda de massa do traçador entre os pontos de lançamento e de medição. Para isso é necessário determinar uma distância mínima (L), também chamada na literatura especializada de comprimento de mistura, entre estes dois pontos que seja suficiente para garantir a homogeneidade da solução e satisfazer a condição anterior. Esta distância depende da velocidade da água no rio, da turbulência do escoamento, da presença de obstáculos e do modo de injeção do sal.

Qualquer que seja o traçador empregado existe dois processos distintos para medir a vazão por este método, o processo por injeção a vazão constante e por volume instantâneo (integração). A principal diferença entre eles é que o primeiro processo se trata da injeção do traçador a uma vazão constante, enquanto que no segundo, a injeção é instantânea. A vantagem do processo por integração é não precisar controlar a vazão de injeção da solução no rio, o que torna mais fácil a aplicação do método (KILPATRICK et al., 1985). Moore (2005) indica que o processo por injeção constante seja aplicado em pequenos córregos com vazão menor do que $100 \mathrm{~L} / \mathrm{s}$ e para maiores vazões, de até $10.000 \mathrm{~L} / \mathrm{s}$, seja aplicado o processo de injeção instantânea. 


\subsection{PRÁTICA EM CAMPO}

Nossa aula prática acontecerá em campo fazendo medições reais, por diferentes métodos e com possibilidade de comparação dos métodos e resultados.

\subsubsection{SELEÇÃO DO LOCAL}

O local escolhido deve atender aos critérios apresentados em sala de aula. De forma resumida tem-se: o trecho escolhido para medição da vazão deve ser retilíneo (sem curvas), ter no mínimo $15 \mathrm{~cm}$ de profundidade e não ser uma área de águas lentas. Corredeiras desobstruídas são ideais. 0 comprimento deste trecho deve algo entre 10 e 20 metros para que as medições sejam realizadas com facilidade, todavia em casos reais deve-se trabalhar com o trecho mais retilíneo e uniforme disponível.

Para facilitar nossa atividade foi escolhido o canal que passa na lateral do prédio da Faculdade de Engenharia Naval, no Setor Saúde, da Cidade Universitária Prof. José da Silveira Netto da Universidade Federal do Pará em Belém.

Nas Fotos 1 e 2 é indicada a localização do canal para a realização da aula prática.

Foto 1 - Identificação do canal de drenagem na lateral do prédio da Faculdade de Engenharia Naval.

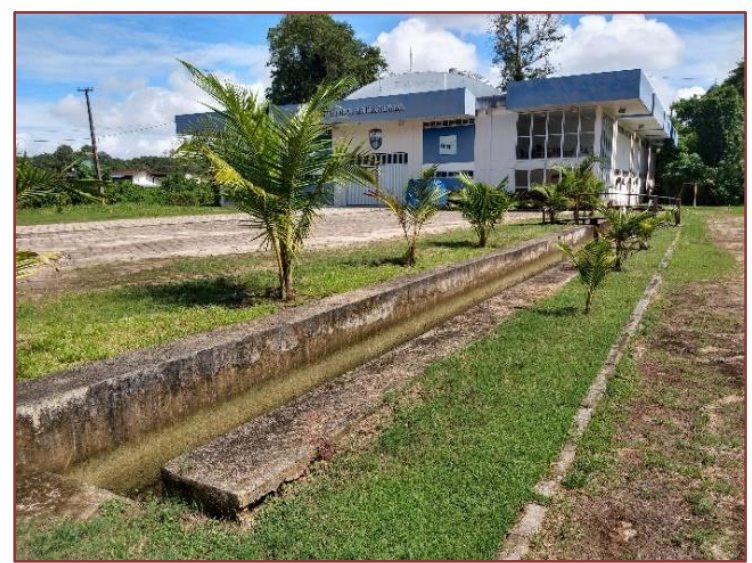

Foto 2 - Detalhe do canal e ponte de travessia que pode ser usado com auxiliar.

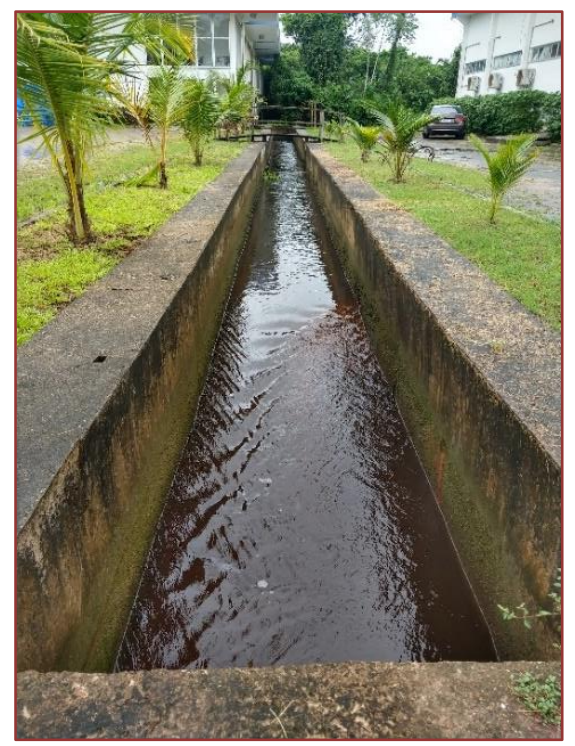




\subsubsection{ANTES DA MEDIÇÃO}

Separar os seguintes materiais antes de se deslocar para o local de medição:

1) Protetor solar;

2) Tenda ou guarda sol e cadeiras;

3) Trenas de 3 e 50 metros;

4) Cronômetro;

5) Planilha de campo (Apêndice 1), prancheta, caneta e lapiseira;

6) Sensor de Condutividade Elétrica e Molinete com sistema de aquisição de dados LabQuest 2, marca Vernier;

7) Balde graduado;

8) Frasco de Mariotte;

9) 5 quilos de sal de cozinha (cloreto de sódio);

10) Garrafa e/ou boia flutuadora;

11) Macacão de borracha.

Não esqueça de estar vestido adequadamente de calça, botas, camisa confortável, óculos de proteção solar e chapéu/boné. Também fiquem atentos para fazer registros fotográficos em todas as etapas.

\subsubsection{ATIVIDADES EM CAMPO}

Em grupos de 5 alunos nesta atividade de campo serão testados os três métodos de medição de vazão citados. Inicialmente um grupo fará a primeira medição usando o primeiro método, em seguida outro grupo fará a medição usando o segundo método e assim por diante. Caso haja tempo disponível todos os grupos farão a medição dos seus próprios dados, caso contrário os dados medidos por cada grupo deveram ser compartilhados com os demais grupos para a elaboração do seu respectivo relatório. Os métodos usados em campo seguirão a seguinte ordem:

Primeiro, usando o flutuador superficial, testando diferentes flutuadores (garrafas e bola de isopor). Comece medindo com a trena a distância entre o ponto onde será lançado o flutuador e o ponto onde será registrado o tempo. Um aluno será o responsável pelo lançamento e outro pelo registro do tempo, o procedimento deve ser repetido três vezes. Calcule a velocidade superficial para cada lançamento feito. Faça a batimetria da seção de escoamento da água.

Segundo, usando o molinete, conforme a largura e profundidade da lâmina d'água defina em quantas verticais e quantas profundidas diferentes em cada vertical precisa ser medida a velocidade de escoamento da água. Faça as medições das velocidades. Determine as dimensões da seção de escoamento da água para ser calculada a área referente a cada vertical.

Por fim, o terceiro, usando a diluição química com traçador salino. A primeira tentativa será usando um pulso, isto é, tomando aproximadamente $18 \mathrm{~L}$ de água do próprio curso d'água acrescente um $1 \mathrm{~kg}$ de sal, misture bem até não ter sal precipitado no fundo do balde. Meça a condutividade elétrica da solução contida no balde. Um aluno irá derramar a solução salina num ponto a montante, e outro fará os registros contínuos de condutividade elétrica, identificando o pulso das leituras, a uma distância que seja suficiente para que ocorra a mistura completa da solução salina. Configure o Labquest 2 para fazer registros a cada 2 segundos e defina o tempo total do experimento usando a informação do ensaio com o flutuador.

0 método da diluição química pode ser repetido seguindo parte do procedimento acima, todavia usando a vazão constante. Neste caso um frasco de Mariotte fornecerá uma vazão constante da solução salina. Devese preparar a solução salina como descrito anteriormente e introduzido no frasco de Mariotte. Determinada a condutividade elétrica inicial. Daí o procedimento de medição da condutividade elétrica é exatamente o mesmo do já descrito. 


\subsubsection{TRATAMENTO DOS DADOS OBTIDOS EM CAMPO}

Todos os dados devem ser organizados em planilha eletrônica Excel ou equivalente e trabalhados para a determinação da vazão. Fiquem atento com a condição de maré, pois se as medições levarem muito tempo podem haver variações nas condições de escoamento e consequentemente na vazão.

\section{Método do Flutuador:}

1. Calcule as três vezes a velocidade superficial;

2. Faça a média das velocidades superficiais;

3. Usando os coeficientes de correção da velocidade superficial com a velocidade média e determine o intervalo da velocidade média;

4. Calcule a área da seção de escoamento;

5. $\quad$ Determine a vazão.

Método do Molinete:

1. Determine a velocidade média em cada seção considerada;

2. Calcule a área de influência de cada seção;

3. Ache a vazão que passa por cada seção e a vazão total.

Método da Diluição Química:

Com os registros de concentração em função do tempo, volume de solução salina e concentração da solução salina, usado a equação vista em sala, é possível determinar a vazão - $Q=\frac{\left(c_{i}-c_{b}\right) \cdot V_{i}}{\int_{0}^{\infty}\left(c(t)-c_{b}\right) d t}$

\subsubsection{COMPARAÇÃO DOS RESULTADOS}

Como serão usados métodos diferentes com variados procedimentos, fora a comparação direta dos resultados, também deve ser considerado a precisão entre as medidas, a reprodutibilidade entre os ensaios, as incertezas das medidas e aplicabilidades de cada método.

Discutir as vantagens e desvantagens de cada método.

\section{BIBLIOGRAFIA}

[1] AZEVEDo NETO, J. M.; FERnANDEZ, M. F.; ARAUJO, A. E. ITO R. Manual de Hidráulica. São Paulo, Edigar Blucher, $19988^{\mathrm{a}}$ ed. 669p.

[2] COLLISCHONN, W.; DORNELlES, F. Hidrologia para engenharia e ciências ambientais. Porto Alegre: Associação Brasileira de Recursos Hídricos (ABRH). 336 p.: II. 2015.

[3] HINDI, E.C.; ROSA FILHO, E.F.; BITENCOURT, A.V.; GIUSTI, D. A. Determinação da descarga de rios por diluição de cloreto de sódio (método de integração). Boletim Paranaense de Geociências, 46: 151-161. 1998.

[4] KILPATRICK, F. A.; COBB, E. D.; Measurement of discharge using tracers. USA: USGS. 63p. 1985.

[5] MOORE, R. D. Slug Injection Using Salt in Solution. Streamline Watershed Management Bulletin Vol. 8/No. 2 Spring 2005, Victoria, B.C.

[6] PINEDA, L. A. C. Estudo observacional e de modelagem hidrológica de uma microbacia em floresta não perturbada na Amazônia Central. São José dos Campos: INPE, 2008. 236p.

[7] PORTO R. L. L.; FILHO, K. Z.; SILVA, R. M. Medição de vazão e curva chave - PHD - 307 Hidrologia Aplicada Escola Politécnica da Universidade de São Paulo - Departamento de Engenharia Hidráulica e Sanitária (Apostila - São Paulo 2001).

[8] SANTOS, I. DOS; FILL, H.D.; SUGAI, M.R.V.B..; BUBA, H. KISHI, R.T.; MARONE, E. E LAUTERT, L.F. Hidrometria Aplicada. Curitiba: Instituto de Tecnologia para o desenvolvimento - LACTEC, 372p. Curitiba - Paraná. 2001.

[9] SILVA, L. L. DA; DONNICI, C. L.; AYALA, J. D.; FREITAS, C. H. DE; MOREIRA, R. M.; PINTO, A. M. F. Traçadores: o uso de agentes químicos para estudos hidrológicos, ambientais, petroquímicos e biológicos. Química Nova. v.32, n.6, São Paulo. 2009. 


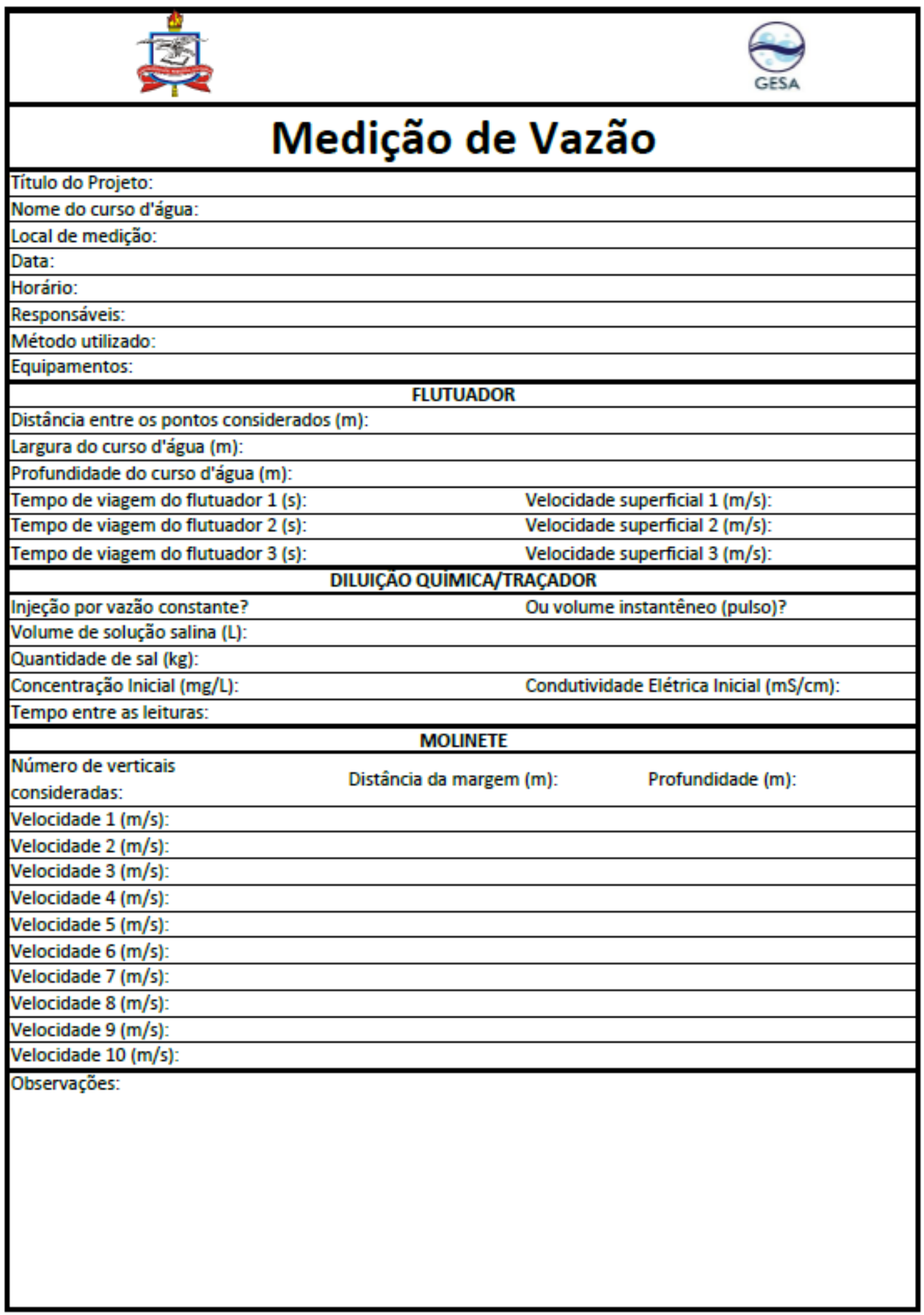




\section{Capítulo 2}

\section{Aula prática: Medição de vazão usando drones}

\section{Katiucia Nascimento Adam}

Giovanni Chaves Penner 


\subsection{OBJETIVOS}

Esta aula tem por objetivo apresentar uma nova possibilidade para medição de vazão a partir de imagens: o uso de drones.

Ao final da aula os alunos devem ter noção sobre os equipamentos e metodologia de medição aplicada durante a atividade desenvolvida.

\subsection{MEDIÇÃO DE VAZÃO E O USO DE DRONES}

Estudos envolvendo a utilização de Veículos Aéreos Não Tripulados (VANTs) ou drones para medição de vazão vêm surgindo nos últimos anos como uma alternativa de medição remota em ambientes de difícil acesso e em condições de eventos hidro-meteorológicos adversos. As principais aplicações envolvem a medição de velocidades superficiais de rios por meio de técnicas baseadas em imagens, como, por exemplo, velocimetria de imagem de partículas em grande escala (LSPIV), velocimetria de rastreamento de partículas (PTV) e a velocimetria de imagens espaço-temporais (STIV) (LÜKŐ, 2016). Estes métodos são baseados na análise de gravações de vídeo da superfície da água, para as quais a contribuição dos VANTs tem se mostrado essencial (e.g TAURO ET AL., 2016; DETERT \& WEITBRECHT, 2015; PERKS ET AL., 2016; SILVA ET AL., 2019).

Para que seja possível captar e coletar imagens para posterior medição de vazão são imprescindíveis requisitos como:

- Determinação de Pontos de Controle e Posicionamento: obtenção por GPS de três pontos de controle no terreno, constituídos por qualquer objeto na imagem cujas coordenadas $\mathrm{X}, \mathrm{Y}, \mathrm{Z}$ no terreno sejam conhecidas. Os pontos de controle devem ser bem distribuídos na imagem de modo a formar um triângulo e não uma linha reta.

- Planejamento de Voo: esta etapa é fundamental para a adequada captação de imagens da área em estuda. A partir desta é possível estipular altitude de voo; número de linhas de voo necessárias; distância entre as linhas de voo; distância no terreno entre exposições; número total de exposições requeridas.

Ainda nesta etapa é importante verificar a velocidade do vento. Ventos fortes podem causar vários problemas indesejados, como exemplo o desvio do drone da rota planejada, prejudicando a captura de imagens e posterior processamento das mesmas.

- Execução do Voo e Processamento das Fotografias

De modo geral os processamentos realizados com as fotografias correspondem a sequência: avaliação das imagens obtidas, alinhamento das fotos, construção da nuvem de pontos, construção da malha, construção do ortomosaico. Para esta etapa softwares devem ser utilizados.

\subsection{PRÁTICA EM CAMPO}

0 método de medição de vazão proposto consiste em uma adaptação e aprimoramento do método do flutuador proposto por PALHARES et al. (2007). Neste caso deve ser estabelecido o tipo de flutuador usado na prática de medição. Nesta aula prática será usada serragem como flutuador. Recomenda-se a leituras dos trabalhos de avaliação de traçadores em estudos hidráulicos (PAULO, 2015; SILVA et at., 2019).

O local escolhido para aplicação deve ser um trecho retilíneo do rio e com informações pertinentes à seção, tais como medições da seção transversal e estação linimétrica. 0 local deve ainda oferecer base para os experimentos e alocação de pontos de controle (PC).

Para esta aula prática serão utilizados os seguintes recursos e equipamentos:

- Dispositivo móvel com GPS (determinação dos pontos de controle);

- $\quad$ Molinete (medição de velocidade e posterior comparação);

- $\quad$ Serragem; 
VANT DJI Mavic PRO.

É necessário que o drone esteja com o GPS calibrado para o local de voo.

As medições de vazão no rio são realizadas através levantamentos aerofotogramétricos com o drone (DJI Mavic PRO) na região a jusante da do ponto de lançamento da serragem. Os passos adotados para o processo do levantamento aerofotogramétrico, seguindo metodologia proposta por Silva et. al., 2019, são descritos a seguir:

a) disposição do objeto de escala e dos pontos de controle dentro do campo de visão do local de medição do VANT;

b) posicionamento do VANT sobre do rio, com a câmera disposta em um ângulo perpendicular ao fluxo do escoamento com altura suficiente para captura de imagens entre as duas margens do curso d'água;

c) lançamento da serragem;

d) Gravação de vídeo (câmera do drone) acompanhando o lançamento da serragem, de modo a registrar o avanço das partículas ao longo da superfície no rio;

Feita a gravação, a vazão, posteriormente, deve ser estimada por meio da análise das velocidades das partículas em um processo de integração com a área da seção transversal do trecho do rio avaliado (ver item 2.6).

\subsection{PROCESSAMENTO DE DADOS}

O processamento de dados segue metodologia proposta por Silva et. al., 2019. Para avaliação da velocidade superficial das partículas, primeiramente deve ser realizada a conversão dos vídeos em imagens sequencias por meio da utilização do software livre Video To JPG Converter (https://www.dvdvideosoft.com/pt/products/dvd/Free-Video-to-JPG-Converter.htm) e após, a seleção das fotos de modo a se obter fotos com intervalos de 1 segundo. A avaliação das imagens pode ser realizada com o software Arcgis.

A análise da velocidade superficial por meio de linhas permite demarcar a frente das plumas de traçadores com linhas, buscando aproximar-se de um traçado de perfil de velocidade superficial. Esta metodologia consiste em acompanhar, junto das regiões mais relevantes (centro, margem esquerda e margem direita), o movimento das frentes de aglomerados de serragem. Posteriormente, junto da referência de escala e o conhecimento do tempo decorrido foi possível determinar a velocidade superficial instantânea média entre duas imagens por meio da Equação 1 . A vazão da seção, por fim, é determinada com a multiplicação da velocidade média da seção com a área da seção transversal e, quando necessário, com um coeficiente de ajuste (Equação 2).

$$
v=\frac{d\left(\frac{L r}{L f}\right)}{\Delta t}
$$

Onde: v é velocidade do traçador $(\mathrm{m} / \mathrm{s})$; d é distância percorrida pelo traçador, entre duas imagens, na escala da imagem (m); Lr é o comprimento real do objeto de escala (m); Lf é o comprimento do objeto na escala da imagem (m); e $\Delta$ t é o tempo transcorrido entre as duas imagens analisadas.

$$
Q=C * v * A
$$

Onde: C é o coeficiente de ajuste da velocidade média superficial em velocidade média da seção do rio; v é a velocidade do traçador (m/s); e A é a área da seção transversal analisada $\left(\mathrm{m}^{2}\right)$. 


\section{BIBLIOGRAFIA}

[1] DETERT, M.; WEITBRECHT, V. A low-cost airborne velocimetry system: Proof of concept. Journal of Hydraulic Research, v. 53, n. 4, pp. 532-539, 2015.

[2] LÜKŐ, G.Analysis of UAV-based topography and river flow measurements. [s. l.], 2016.

[3] PALhareS, J.C. P. et al. Medição da Vazão em Rios pelo Método do Flutuador. Comunicado Técnico -

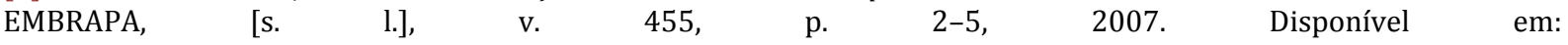
https://ainfo.cnptia.embrapa.br/digital/bitstream/item/58075/1/CUsersPiazzonDocuments455.pdf. Acesso em $31 / 08 / 2020$.

[4] PAULO, F.A.; BORGES, A.L.O. Visualização do Escoamento e Perfis de Velocidade em Curva de Sistema de Conduto de Drenagem Pluvial Urbana. Porto Alegre, IPH - Instituto de Pesquisas Hidráulicas, 2018.

[5] PERKS, M.T.; RUSSELL, A.J.; LARGE, A.R.G. Technical Note: Advances in flash flood monitoring using unmanned aerial vehicles (UAVS). Hydrology and Earth System Sciences, v. 20, n. 10, pp. 4005-4015, 2016.

[6] TAURO, F.; PORFIRI, M.; GRIMALDI, S. Surface flow measurements from drones. Journal of Hydrology, [s. l.], v. 540, pp.240-245, 2016. Disponível em: http://dx.doi.org/10.1016/j.jhydrol.2016.06.012

[7] SILVA, T.Z;; FAN, F.M.; TSCHIEDEL, A.F.; ADAM, K.N.; PAIXÃO, M. Utilização de vants para medição de vazão em cursos d’água. In:XXIII Simpósio Brasileiro de Recursos Hídricos. Foz do Iguaçu, 2019. 


\section{Capítulo 3}

\section{Aula prática: Infiltração da água no solo}

Giovanni Chaves Penner

Katiucia Nascimento Adam 


\subsection{OBJETIVOS INSTRUCIONAIS}

Ao final desta aula prática de infiltração da água no solo você deverá ser capaz de:

- Enunciar quatro possíveis métodos aplicáveis a determinação da taxa de infiltração da água no solo;

- Realizar a medição da taxa de infiltração em campo por um dos métodos testados na prática de campo;

- Identificar as diferenças e aplicabilidades de cada método;

- Comparar os resultados obtidos por diferentes métodos identificando suas aplicabilidades.

\subsection{INFILTRAÇÃO DA ÁGUA NA HIDROLOGIA}

Como comentado a visão de engenharia dada a nossa disciplina de Hidrologia e Climatologia foca o ciclo hidrológico do ponto de vista quantitativo. 0 conhecimento da taxa de infiltração da água no solo em hidrologia é fundamental para aplicar técnicas de conservação do solo, planejamento e dimensionamento de estruturas de infiltração e de drenagem, tal conhecimento aplicado ao planejamento urbano é extremamente útil no zoneamento municipal.

Assim, para se dispor de valores de referência é fundamental o conhecimento dos métodos de medição e a espacialização dos dados como auxiliar à tomada de decisão. Em muitos casos o mapeamento dos diferentes tipos de solo associados a sua respectiva taxa de infiltração e as condições de saturação do solo são suficientes para tal aplicação. Portanto o conhecimento e da taxa de infiltração e seus interferentes é uma ferramenta extremamente útil na Engenharia Sanitária e Ambiental. Belém e em boa parte do Estado do Pará há uma peculiaridade que é a grande quantidade de sistemas de infiltração de efluentes, sendo a taxa de infiltração uma variável de interesse poucas vezes determinada.

\subsection{MÉTODOS DE MEDIÇÃO DE INFILTRAÇÃO DA ÁGUA NO SOLO}

Como discutido em sala de aula há diversos métodos para determinar a taxa de infiltração da água no solo, cada um com condições de operacionalização e ferramental específico, bem como diversas aplicabilidades com ênfase na área agrícola e zoneamento dos espaços urbanos. Como o foco da nossa aula é prático serão considerados os métodos descritos a seguir por se dispor de ferramental para sua execução.

Os métodos de determinação da infiltração de água no solo são simples e capazes de representar adequadamente as condições do solo (PRUSKI et al., 1997).

\subsubsection{IFILTRÔMETRO DE ANÉIS CONCÊNTRICOS}

Para determinação da infiltração de água no solo o método mais conhecido é o infiltrômetro de anel (ou anéis concêntricos), onde a infiltração se processa apenas na vertical. Este consiste em dois anéis concêntricos (com 2 diferentes diâmetros), ambos de mesma altura, que são inseridos no solo até a profundidade de $0,15 \mathrm{~m}$, com auxílio de marreta, na Figura 1 pode-se observar os componentes do infiltrômetro de anel, composto por 2 cilindros: $\emptyset 500$ x $250 \mathrm{~mm}$ e $\emptyset 250 \times 250 \mathrm{~mm}$, espessura de $3 \mathrm{~mm}$. Flutuador tipo boia com escala, suporte do flutuador, cruzeta em aço para cravação, nível tipo bolha, cronômetro digital portátil, marreta com pontas de Nylon e par de alças para extração. Sendo de suma importância que as bordas inferiores dos anéis sejam finas e apresentem corte em forma de bisel, para melhor introdução destes no solo. 
Figura 1 - Componentes do infiltrômetro de anel.

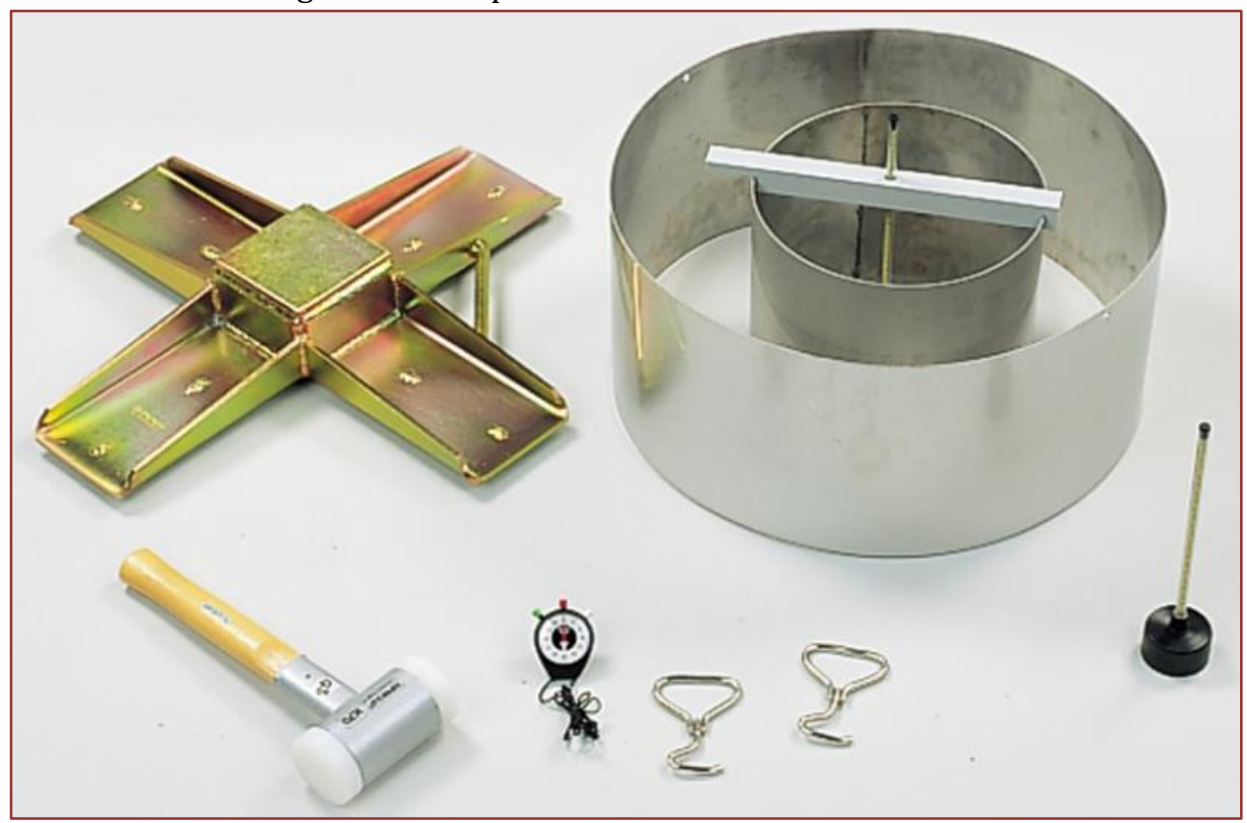

Fonte: https://en.eijkelkamp.com/products/field-measurement-equipment/double-ringinfiltrometer.html

Vale ressaltar que o ensaio de infiltração pode ser realizado na superfície do solo, como o que faremos, entretanto, pode acontecer em profundidades diferentes como mostrado na Figura 2.

Figura 2 - Ensaio de infiltração com anéis concêntricos sendo realizado a um metro de profundidade da superfície do solo.

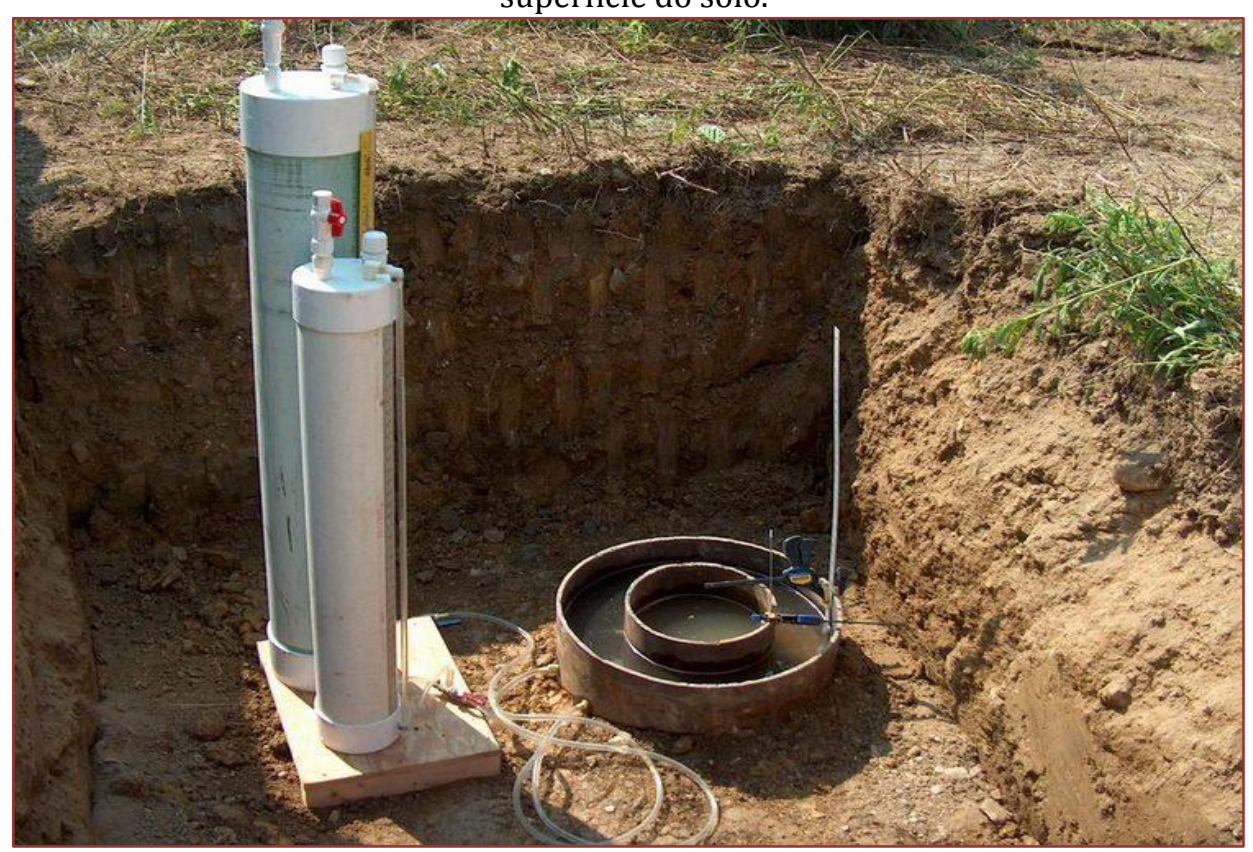

Fonte: http://earthy-moony.blogspot.com/2011/02/measurement-of-infiltration-rate.html.

No caso do dimensionamento de sumidouros como dispositivo de infiltração de efluentes deve-se garantir que a profundidade investigada seja representativa da profundidade onde se assentará a base de infiltração do sumidouro. A título de curiosidade, os dois recipientes de PVC da Figura 2 são frascos de Mariotte usados para manter o nível da água constante, isto é, mesma carga hidráulica. 


\subsubsection{ENSAIO DE INFILTRAÇÃO ABGE (1996)}

O método padronizado mais simples disponível para ensaios de infiltração é o recomendado pela Associação Brasileira de Geologia de Engenharia (ABGE) em 1996.

0 teste consiste em realizar um furo de sondagem com geometria cilíndrica no solo com o auxílio de uma cavadeira articulada. 0 furo precisa ficar com circunferência uniforme que pode ser $20 \mathrm{~cm}$ de diâmetro e atingir uma profundidade de $30 \mathrm{~cm}$ aproximadamente. 0 furo deve ser totalmente preenchido com água por 10 min garantindo que o solo ao redor esteja saturado, se necessário deve ser feita a reposição da água.

Após os 10 min iniciais o ensaio pode começar. Neste momento efetua-se a contagem do tempo das medições de rebaixamento do nível d'água no furo, onde a mensuração do nível de água no furo de sondagem foi feita, ver Figura 3. Os intervalos, em minutos, pré-determinados e consecutivos sugeridos são: 0,$5 ; 1 ; 1,5 ; 2 ; 2,5 ; 3 ; 3,5 ; 4 ; 5 ; 6 ; 7 ; 8 ; 10 ; 12 ; 14 ; 16 ; 18 ; 20$ e 22 - período do ensaio geralmente previsto, procedendo-se as respectivas anotações em planilha (Apêndice 1), com o registro do decréscimo do nível d'água no furo, a cada intervalo de tempo informado. 0 ensaio pode ser encerrado quando o rebaixamento atingiu $20 \%$ da carga inicial ou $30 \mathrm{~min}$.

Figura 3 - Ilustração do ensaio de infiltração indicado por ABGE (1996)

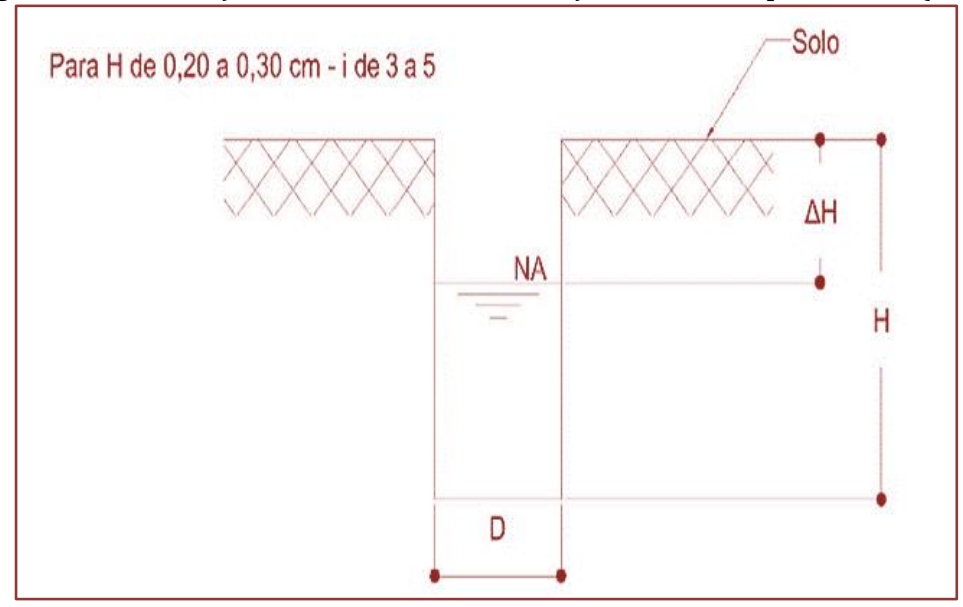

A equação a seguir é utilizada para a determinação da condutividade hidráulica de acordo com o método ABGE (1996):

$$
\mathrm{K}=\frac{\Delta \mathrm{H}}{\Delta \mathrm{t}} \cdot \frac{1}{\mathrm{i} \cdot\left(\frac{2 \cdot \mathrm{H}}{\mathrm{r}}+1\right)}
$$

Onde $\mathrm{K}(\mathrm{cm} / \mathrm{s})$, é a condutividade hidráulica, $\Delta \mathrm{H}(\mathrm{cm})$ é a variação do nível de carga hidráulica, $\Delta \mathrm{t}$ é a variação do tempo (s), H é a profundidade do poço $(\mathrm{cm}), \mathrm{r}$ é o raio do furo do poço $(\mathrm{cm})$ e i é adimensional variando de 3 a 5 (quando a geometria do furo é cilíndrica adota-se 5).

\subsubsection{MÉTODO OPEN END HOLE}

O método Open end Hole ou "Ensaio de Ponta Aberta" consiste na utilização de um furo de sondagem revestido com tubo de PVC, do topo até a sua base, para a obtenção do coeficiente de condutividade hidráulica vertical de uma determinada profundidade de solo (FIORI, 2010). Na Figura 4 apresenta-se as variáveis utilizadas para o ensaio. 
Figura 4 - Ilustração do ensaio Open end Hole

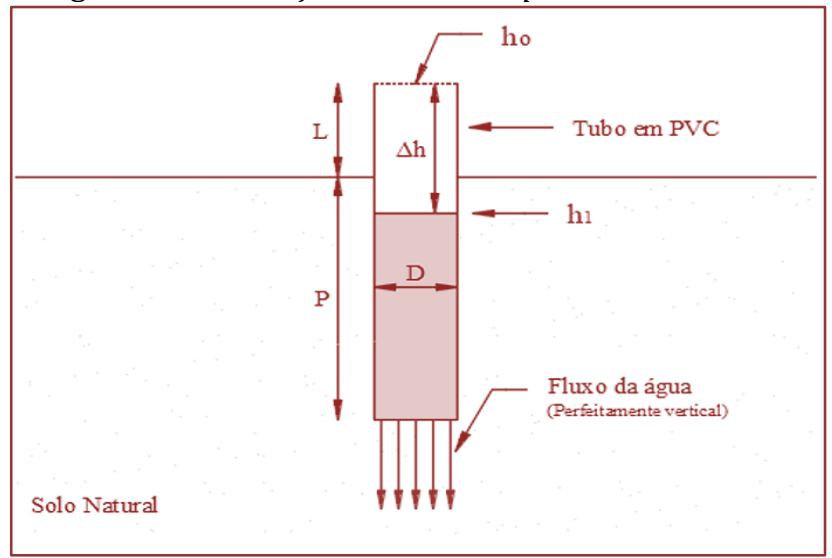

A carga hidráulica $\left(\mathrm{h}_{0}\right)$ é o comprimento do tubo, do topo até a base do tubo e é dado pela expressão $\mathrm{h}_{0}=\mathrm{P}$ + L. 0 método consiste na avaliação da infiltração vertical carga hidráulica e/ou nível de água variável. Essa variação do nível de água $(\Delta \mathrm{h})$ é dada em função do tempo, sendo assim $\mathrm{h}_{\mathrm{o}}$ representa o nível de água inicial e $h_{1}$ representa o nível de água final. Onde $h_{1}$ é dado pela relação: $h_{1}=h_{0}+\Delta h$. Considerando, ainda, o raio do tubo de $\mathrm{PVC}(\mathrm{R}=\mathrm{D} / 2)$ e representa a condutividade hidráulica vertical:

$$
\mathrm{K}_{\mathrm{v}}=2,303 \cdot\left(\frac{\mathrm{R}}{4 \cdot \Delta \mathrm{t}}\right) \cdot\left[\log \left(\frac{\mathrm{h}_{\mathrm{o}}}{\mathrm{h}_{1}}\right)\right]
$$

Onde Kv é a condutividade hidráulica vertical, $\mathrm{R}$ é raio, $\Delta \mathrm{t}$ é a variação do tempo, $\mathrm{h}_{\mathrm{o}}$ é a carga hidráulica inicial e $\mathrm{h}_{1}$ é a carga hidráulica final.

0 ensaio é realizado em três pontos distintos espacializados de forma triangular (equilátera) distanciados em aproximadamente 1,5 $\mathrm{m}$ (Figura 5). Os furos de sondagem precisam ficar em diferentes profundidades 0,5; 1,0 e 1,5 metros. Em locais onde a zona saturada é superficial, como Belém, atenção deve ser dada se fluirá água natural ao furo. Caso ocorra água, deve-se descartar o ponto e fazer o ensaio com os três furos, no entanto, com duas profundidades distintas $(0,5$ e $1,0 \mathrm{~m})$, em caso de a um metro de profundidade também for observada a presença de água deve-se adotar três furos com a mesma profundidade $(0,5 \mathrm{~m})$. Em caso de ainda assim for constatada a presença de água com a 0,5 m então este ponto deve ser descartado e selecionado outro ponto para a realização do ensaio. Note que as profundidades 0,$5 ; 1,0$ e 1,5 m não são obrigatórias e poderia ser adotado outro conjunto, por exemplo, 0,2; 0,4 e 0,6 m.

Figura 5 - Disposição dos furos de sondagem para o ensaio Open end Hole

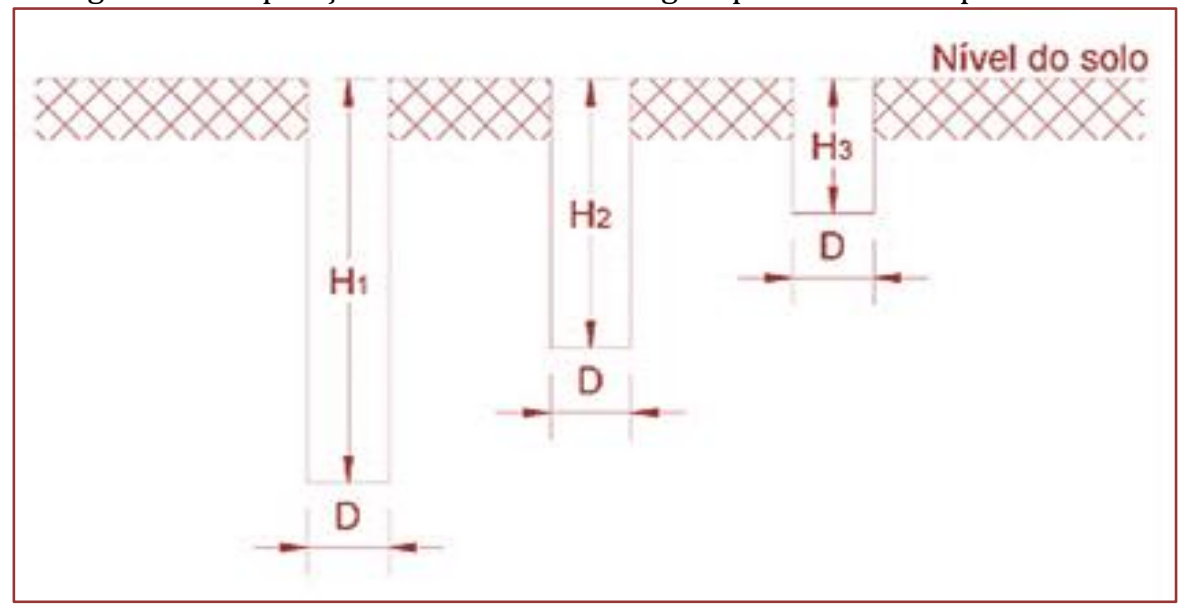


Um dos cuidados executivos para a realização do ensaio é que o tubo em PVC seja de diâmetro adequado para o furo de sondagem evitando caminho preferencial entre o a parede do tubo de PVC e a parede do furo de sondagem.

\subsection{PRÁTICA EM CAMPO}

Nossa aula prática acontecerá em campo fazendo medições reais, por diferentes métodos e com possibilidade de comparação dos métodos e resultados.

\subsubsection{SELEÇÃO DO LOCAL}

Para nossa aula de campo não há critérios específicos para a seleção do local de ensaio, pois trata-se apenas de uma aplicação prática. Todavia em aplicações na área agrícola deve ser usado algum critério para a divisão da área de interesse em subárea; em aplicações de zoneamento urbano deve ser identificados os tipos de solo e sua distribuição espacial, bem como evitar ensaios em locais de deposição de aterro; para o caso de infiltração de efluentes deve-se considerar a profundidade da zona saturada e a profundidade que se pretende posicionar o sumidouro.

Para facilitar nossa atividade foi escolhida a lateral do prédio do Laboratório de Engenharia Sanitária e Ambiental (LAESA), no Setor Profissional, da Cidade Universitária Prof. José da Silveira Netto da Universidade Federal do Pará em Belém. Na Figura 6 é indicada a localização da lateral do prédio LAESA para a realização da aula prática. Na referida aparecem troco de tubo em amarelo que são as tampas de poços de monitoramento da água subterrânea, trata-se de estrutura de pesquisa e não deve ser usado como apoio ou para sentar!

Figura 6 - Identificação da lateral do prédio da Faculdade de Engenharia Sanitária e Ambiental.

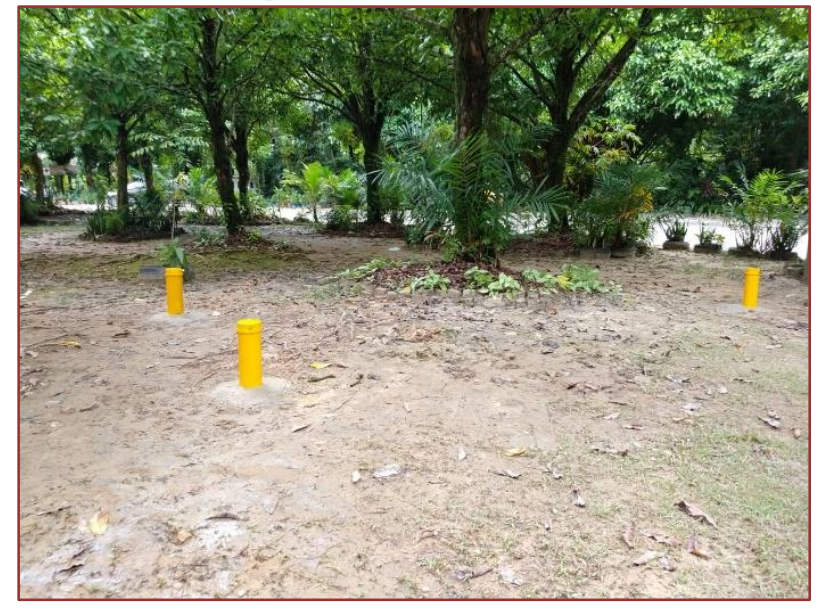

\subsubsection{ANTES DA MEDIÇÃO}

Separar os seguintes materiais antes de se deslocar para o local de medição:

12) Protetor solar;

13) Tenda ou guarda sol e cadeiras;

14) Trenas de 3 e 50 metros;

15) Medidor de nível d'água eletrônico;

16) Planilhas de campo (Apêndice 1), prancheta, caneta e lapiseira;

17) Caixa com todo o conjunto do infiltrômetro de duplo anel;

18) Cavadeira articulada e cavadeira simples;

19) Tubos de PVC de 100 mm, em 3 tamanhos; 


\section{0) Régua metálica.}

Não esqueça de estar vestido adequadamente de calça, botas, camisa confortável, óculos de proteção solar e chapéu/boné. Também fiquem atentos para fazer registros fotográficos em todas as etapas.

\subsubsection{ATIVIDADES EM CAMPO}

Em grupos de 5 alunos nesta atividade de campo serão testados os três métodos de medição da taxa de infiltração e consequente condutividade hidráulica do solo.

Inicialmente um grupo fará medição usando o primeiro método, concomitante em seguida outro dois grupos farão a medição usando o segundo e terceiro métodos. Caso haja tempo disponível todos os grupos farão a medição dos seus próprios dados, caso contrário os dados medidos por cada grupo deveram ser compartilhados com os demais grupos para a elaboração do seu respectivo relatório.

Os ensaios podem ser iniciados ao mesmo tempo em pontos distintos guardando alguma distância para não atrapalhar a outra equipe sendo:

1) Método ABGE (1996): aqui será considerado o Ensaio em Poço, sem revestimento e acima do nível d'água. Usando a cavadeira articulada faça um furo de aproximadamente $30 \mathrm{~cm}$ de profundidade. Meça o diâmetro aproximado do furo e a profundidade que ficou. Sature o furo com água até a superfície por 10 mim. Passados os 10 min complete o furo com água e comece a fazer os registros da variação do nível da água com auxílio de uma régua que deve ficar dentro do furo, considerando os intervalos indicados na planilha (Apêndice 1). Segundo ABGE (1996) o ensaio pode ser encerrado quando o rebaixamento atingiu $20 \%$ da carga inicial ou $30 \mathrm{~min}$.

2) Infiltrômetro de duplo anel: abra a caixa de transporte do equipamento e retire os anéis, cuidado com o peso da caixa e dos anéis. Posicione os anéis metálicos na área de interesse, lembrando de colocar a lateral mais fina de cada anel para baixo. Ajuste a posição dos anéis com a ferramenta de ajuste no formato de uma cruzeta. Use marreta da caixa para fazer a cravação de aproximadamente $10 \mathrm{~cm}$ dos anéis no solo. Consulte se estão nivelados com a régua de nível, faça eventuais ajustes. Coloque inicialmente água no anel externo até aproximadamente formar uma lâmina de $10 \mathrm{~cm}$. Posicione o suporte e a régua do cilindro central. Acrescente água até formar uma lâmina de $10 \mathrm{~cm}$. Marque o nível inicial e comece a contagem do tempo. Faça a anotação dos registros de altura da lâmina d'água nos intervalos de tempo indicados na planilha de campo (Apêndice 1), caso o nível rebaixe mais que dois centímetros faça a reposição da água nos anéis. Siga a orientação das colunas da planilha de campo. Depois de duas leituras de rebaixamento é possível calcular demais colunas, sendo a terceira coluna a diferença entre as medidas, a quarta coluna os infiltrados acumulados e a quinta coluna a velocidade de infiltração, atenção as velocidades de infiltração são em $\mathrm{mm} / \mathrm{h}$, então será necessário multiplicar o tempo medido em minutos por 60 . 0 ensaio continua até que sejam atingidas três velocidades de infiltração iguais de forma consecutiva.

3) Método Open end hole: o ensaio será realizado em 3 profundidades distintas, sendo elas: 0,3; 0,6 e 0,9 m. Faça 3 furos com cavadeira articulada ou trado helicoidal nas profundidades indicadas, seguindo uma forma triangular (equilátera), com lado de 1,5 metros. Encaixe os tubos de PVC em cada um dos respectivos furos, lembre-se que o furo precisa estar ajustado ao tubo para não escapar água entre o furo e o tubo de revestimento. Faça leituras regulares do nível d'água a cada 5 min por um intervalo de ao menos 40 min. Preencha as informações da planilha de campo (Apêndice 1).

\subsubsection{TRATAMENTO DOS DADOS OBTIDOS EM CAMPO}

Todos os dados devem ser organizados em planilha eletrônica Excel ou equivalente e trabalhados para o cálculo da taxa de infiltração e da condutividade hidráulica.

Método ABGE (1996):

6. Calcule as taxas de infiltração;

7. Faça gráficos da variação do nível d'água e da taxa de infiltração em função do tempo; 
8. Com a equação fornecida calcule a condutividade hidráulica da zona não saturada do solo.

Infiltrômetro de duplo anel:

4. $\quad$ Calcule as taxas de infiltração;

5. Faça gráficos da variação do nível d'água e da taxa de infiltração em função do tempo.

\section{Método Open end hole:}

1. Calcule as taxas de infiltração;

2. Faça gráficos da variação do nível d'água e da taxa de infiltração em função do tempo;

3. Com a equação fornecida calcule a condutividade hidráulica vertical da zona não saturada do solo.

\subsubsection{COMPARAÇÃO DOS RESULTADOS}

Como serão usados métodos diferentes com variados procedimentos, fora a comparação direta dos resultados, também deve ser considerado a precisão entre as medidas, a reprodutibilidade entre os ensaios, as incertezas das medidas e aplicabilidades de cada método.

Discutir as vantagens e desvantagens de cada método.

Apresente uma aplicação prática dos resultados para o dimensionamento de uma trincheira de infiltração de água da chuva da cobertura de uma casa ou prédio e para um sumidouro que infiltrará efluentes tratados de uma casa ou qualquer outro empreendimento.

\section{BIBLIOGRAFIA}

[1] AGÊNCIA NACIONAL DE ÁGUAS - ANA. Estudos hidrogeológicos para a gestão das águas subterrâneas da região de Belém/PA: Relatório Final - Volume 2 (TOMO I: resultados em hidrogeologia). Brasília: ANA, 2018.

[2] ASSOCIAÇÃO BRASILEIRA DE GEOLOGIA DE ENGENHARIA - ABGE. Ensaio de Permeabilidade em Solos: Orientações para sua execução no campo. 3.ed. Boletim 4. São Paulo, 1996.

[3] ASSOCIAÇÃo BRASILEIRA DE GEOLOGIA DE ENGENHARIA - ABGE. Ensaio de Permeabilidade em Solos: Orientações para sua execução no campo. 4.ed. São Paulo, 2013.

[4] FAGUNDES, E. A. A. et al. Determinação da infiltração e velocidade de infiltração de água pelo método de infiltrômetro de anel em solo de cerrado no município de Rondonópolis-MT. Enciclopédia Biosfera, Goiânia, v. 8, n. 14, p. 369-378, 2012.

[5] FIORI, Joyce Pinheiro de Oliveira. Avaliação de métodos de campo para a determinação de condutividade hidráulica em meios saturados e não saturados. 2010. 110 f. Dissertação (Mestrado em Área de concentração: Hidrogeologia e Meio Ambiente) - Instituto de Geociência, Universidade de Brasília, Brasília, 2010.

[6] PRUSKI, F.F.; VENDRAME, V.; OLIVEIRA E.F.; BALBINO, L.C.; FERREIRA, P.A.; WERLANG, L.; CARVALHO, L.T. Infiltração de água no Latossolo Roxo. Pesquisa Agropecuária Brasileira, v. 32, n. 1, p.77-84, 1997.

[7] SOTO, M. A. A. Estudo da Condutividade Hidráulica em Solos não Saturados. 1996, 136 p. Dissertação (Mestrado em Engenharia Civil) - Escola de Engenharia de São Carlos, Universidade de São Paulo, São Carlos, 1996. 


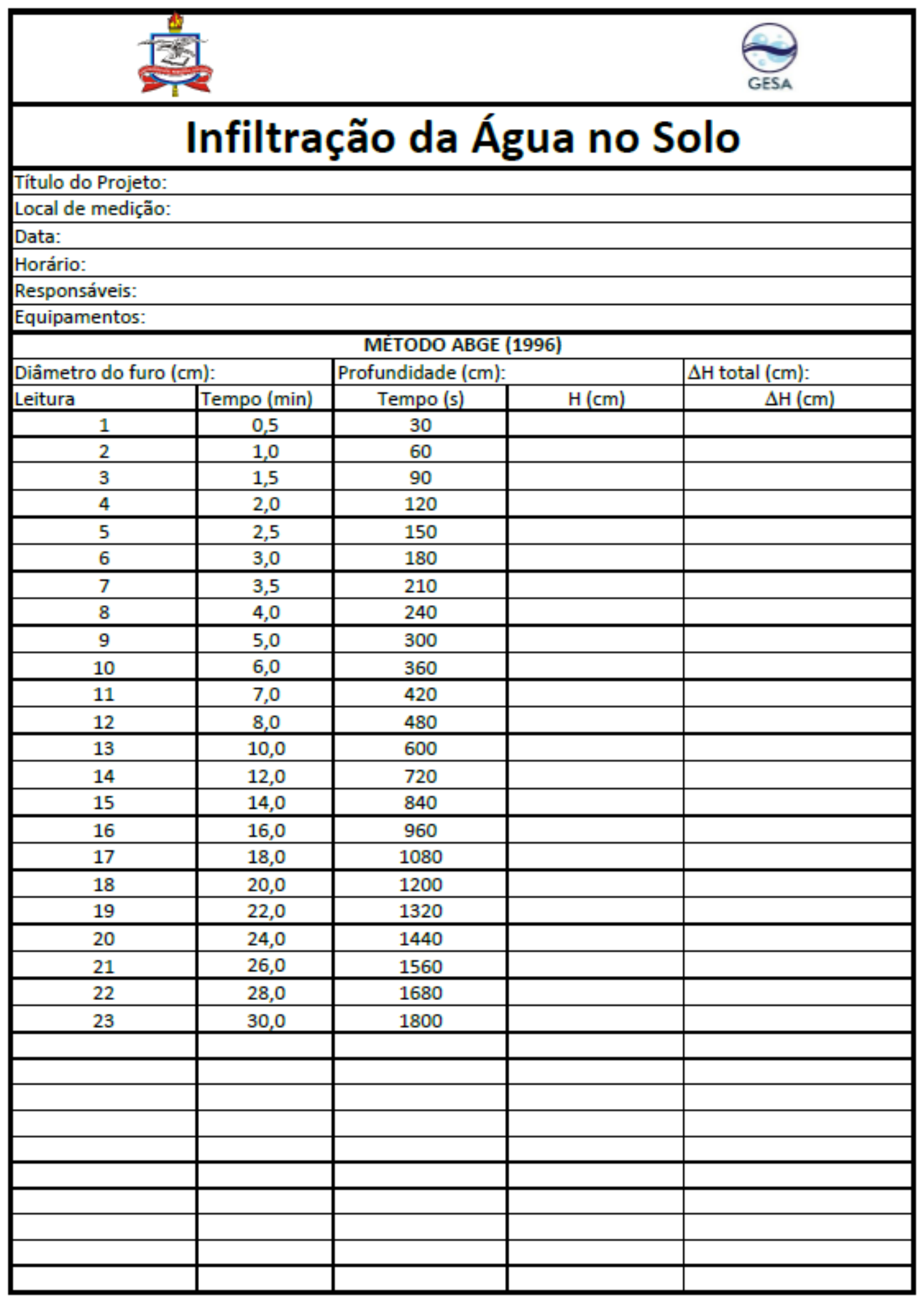




\begin{tabular}{|c|c|c|c|c|}
\hline \multicolumn{5}{|l|}{ Título do Projeto: } \\
\hline \multicolumn{5}{|l|}{ Local de medição: } \\
\hline \multicolumn{5}{|l|}{ Data: } \\
\hline \multicolumn{5}{|l|}{ Horário: } \\
\hline \multicolumn{5}{|l|}{ Responsáveis: } \\
\hline \multicolumn{5}{|l|}{ Equipamentos: } \\
\hline \multicolumn{5}{|c|}{ INFILTRÓMETRO DE ANEIS CONCÉNTRICOS } \\
\hline \multirow{2}{*}{ Tempo (min) } & \multicolumn{2}{|c|}{ Régua } & \multirow{2}{*}{$\begin{array}{c}\text { Infiltração } \\
\text { Acumulada }(\mathrm{cm}) \\
\end{array}$} & \multirow{2}{*}{$\begin{array}{c}\text { Velocidade de Infiltração } \\
(\mathrm{cm} / \mathrm{h})\end{array}$} \\
\hline & Leitura $(\mathrm{cm})$ & Diferença $(\mathrm{cm})$ & & \\
\hline \multicolumn{5}{|c|}{ 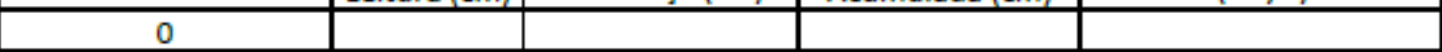 } \\
\hline \multicolumn{5}{|l|}{1} \\
\hline \multicolumn{5}{|l|}{3} \\
\hline \multicolumn{5}{|l|}{5} \\
\hline \multicolumn{5}{|l|}{10} \\
\hline \multicolumn{5}{|l|}{15} \\
\hline \multicolumn{5}{|l|}{20} \\
\hline \multicolumn{5}{|l|}{25} \\
\hline \multicolumn{5}{|l|}{30} \\
\hline \multicolumn{5}{|l|}{40} \\
\hline \multicolumn{5}{|l|}{50} \\
\hline \multicolumn{5}{|l|}{60} \\
\hline \multicolumn{5}{|l|}{75} \\
\hline \multicolumn{5}{|l|}{90} \\
\hline \multicolumn{5}{|l|}{120} \\
\hline \multicolumn{5}{|l|}{150} \\
\hline 180 & & & & \\
\hline
\end{tabular}




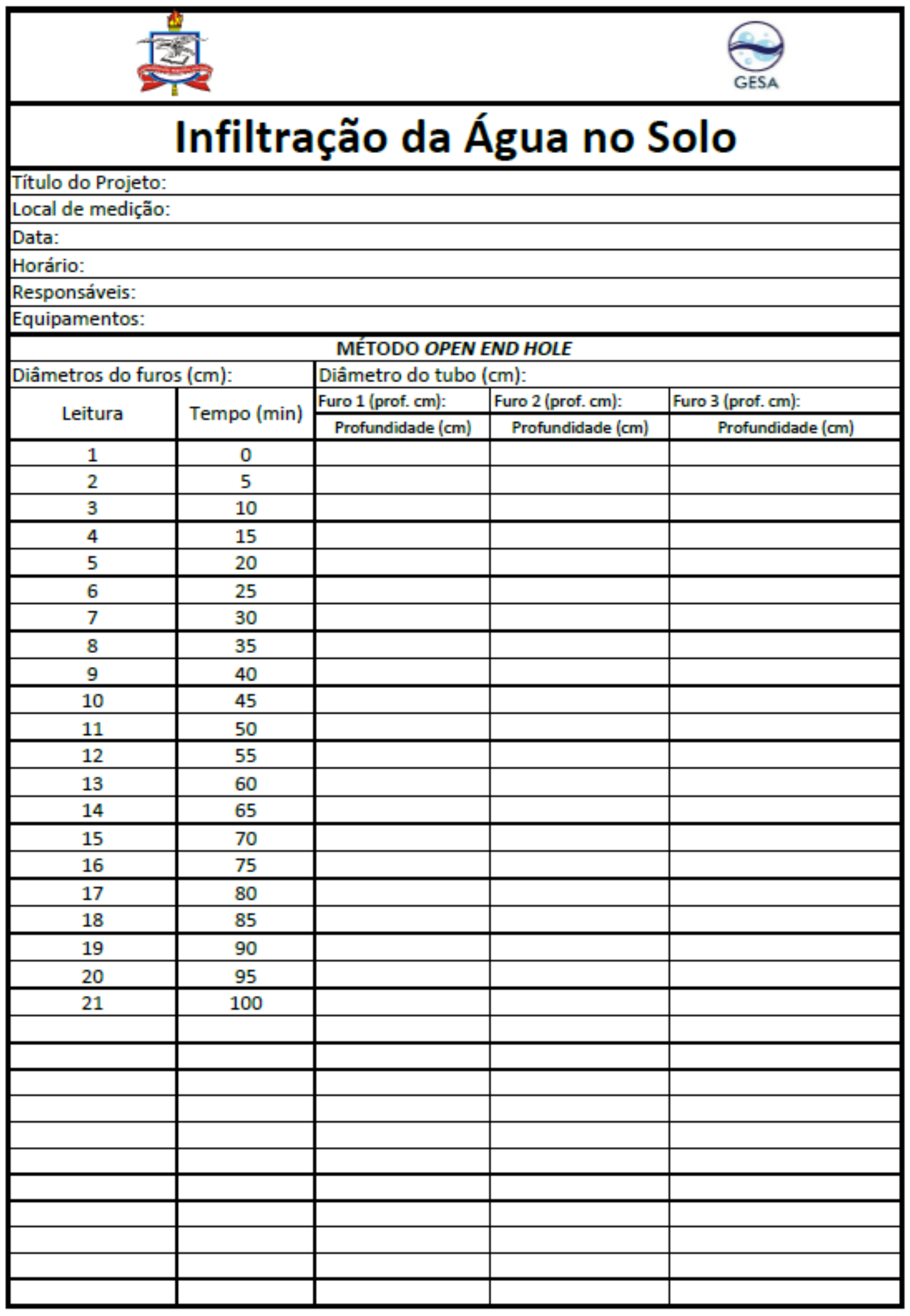




\section{Capítulo 4}

\section{Aula prática: Hidrologia estatística}

Giovanni Chaves Penner

Katiucia Nascimento Adam 


\subsection{OBJETIVOS INSTRUCIONAIS}

Ao final desta aula prática de Estatística Aplicada à Hidrologia você deverá ser capaz de:

- Acessar ao sítio da Agência Nacional de Águas para localizar e copiar dados hidrológicos;

- Enunciar quatro distribuições probabilísticas aplicadas frequentemente em Hidrologia;

- Testar a aderência das diferentes distribuições probabilísticas a dados medidos usando planilha eletrônica Excel;

- Identificar que tipo de programa específico pode ser utilizado na análise de frequência.

\subsection{ESTATÍSTICA APLICADA A HIDROLOGIA}

Séries de variáveis hidrológicas como precipitações, vazões, nível d'água, evaporação e outras, quando observadas ao longo do tempo, apresentam variações sazonais. Estas variações não são regulares, isto é, ocorrem anos com valores máximos bem acentuados e outros anos com valores reduzidos. A observação de séries longas de dados hidrológicos revelará a ocorrência de extremos (máximos e mínimos) e diferentes sequências de valores, que caracterizam as variáveis hidrológicas como aleatórias. Variáveis hidrológicas estarão sempre associadas, portanto a uma probabilidade de ocorrência. Consequentemente as obras hidráulicas devem sempre ser dimensionadas para um determinado "risco" de falha.

Neste caso o objetivo da estatística é o de extrair informações significativas de uma dada massa de dados. As técnicas utilizadas em estatística aplicadas à hidrologia permitem avaliar a probabilidade de ocorrência de um fenômeno hidrológico com determinada magnitude.

\subsection{EXTREMOS MÁXIMOS: PREVISÃO DE ENCHENTES}

Quando se trabalha com valores máximos de uma dada variável hidrológica estão sendo considerados os extremos máximos. No caso da previsão de enchentes são trabalhadas as séries de dados de vazão, selecionando-se apenas as vazões máximas de cada ano em um determinado local. Neste caso é obtida a série de vazões máximas deste dado local e é possível realizar análises estatísticas relacionando vazão com sua probabilidade associada. As séries de vazões disponíveis na maior parte dos locais (postos fluviométricos) são relativamente curtas, não superando algumas dezenas de anos. Por outro lado, muitas vezes é necessário a estimativa de uma vazão para uma condição futura desconhecida, que pode estar associada uma centena de anos ou até século.

\subsection{LEVANTAMENTO DE DADOS}

A elaboração de projetos em Hidrologia e Recursos Hídricos, por vezes, requer o levantamento de informações. Tais informações podem ser obtidas em levantamentos em campo, que são demorados e apresentam um custo, mas de grande valia conforme a necessidade de detalhamento do projeto.

Outra fonte de informações com dados é Sistema Nacional de Informações sobre Recursos Hídricos (SNIRH), gerenciado pela Agência Nacional de Águas (ANA), é parte integrante dos instrumentos de gestão previsto na Política Nacional de Recursos Hídricos, instituída pela Lei no 9.433, de 08 de janeiro de 1997, conhecida como Lei das Águas. Trata-se de um amplo sistema de coleta, tratamento, armazenamento e recuperação de informações sobre recursos hídricos, bem como fatores intervenientes para sua gestão.

No presente material será considerado o uso de dados disponíveis no Portal HidroWeb que é uma ferramenta integrante do SNIRH e oferece o acesso ao banco de dados que contém todas as informações coletadas pela Rede Hidrometeorológica Nacional (RHN), reunindo dados de níveis fluviais, vazões, chuvas, climatologia, qualidade da água e sedimentos. 


\subsection{PRÁTICA EM LABORATÓRIO DE INFORMÁTICA}

Como dito os dados usados nesta prática serão obtidos do Sistema HIDROWEB gerenciado pela ANA. Para tanto acesse ao sítio:

- $\underline{\text { http://www.snirh.gov.br/hidroweb/apresentacao }}$

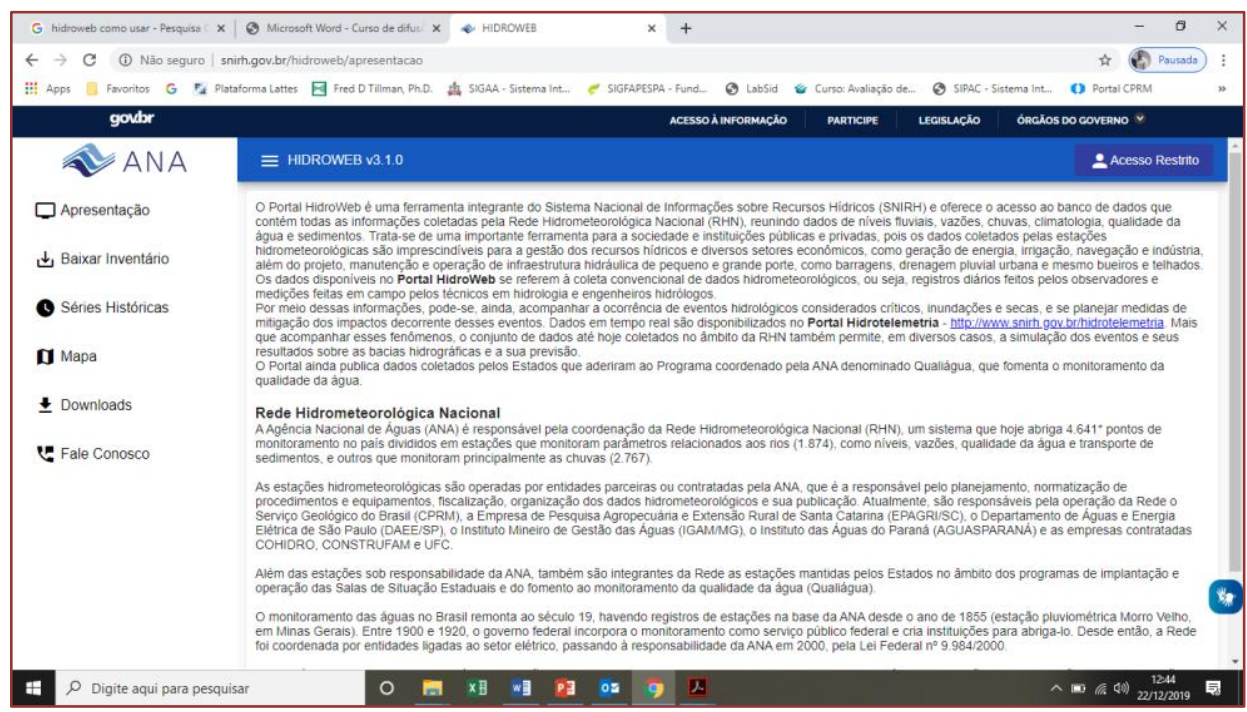

- Clique em "Séries Históricas"

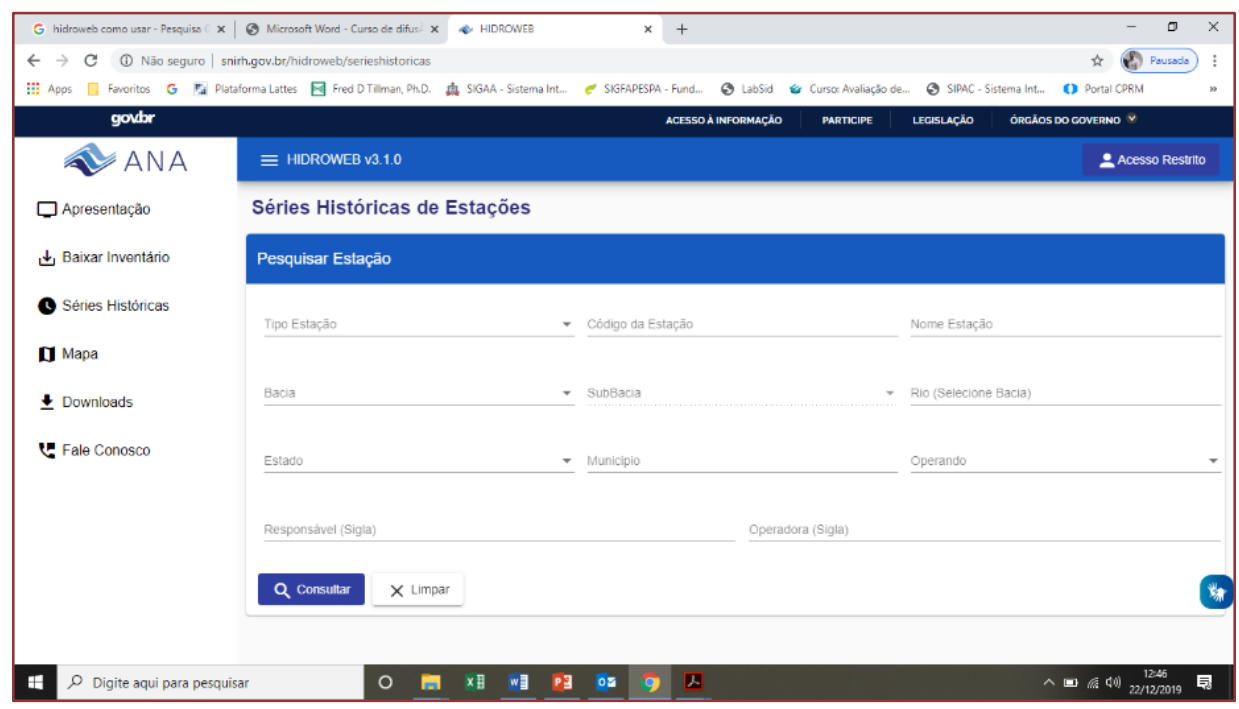

- Nesta nova página você poderá optar por inserir tipo de estação (pluviométrica ou fluviométrica ou ambas), o código da estação desejada, ou o nome da estação, ou o nome do rio (precisa selecionar a Bacia antes), da bacia hidrográfica, o Estado, etc... Não é necessário preencher todos os campos; somente um já lhe trará um resultado, que deverá ser analisado posteriormente. Digamos que você queira todas as estações da bacia do rio São Francisco. No campo "Bacia" escolha "4 - Rio São Francisco". Clique em "Consultar". Como resultados da consulta vão aparecer para todas as estações contidas na bacia selecionada. 
- No retorno da busca, parte de baixo da tela, é possível visualizar uma lista de estações, com o código, nome e tipo de estação.

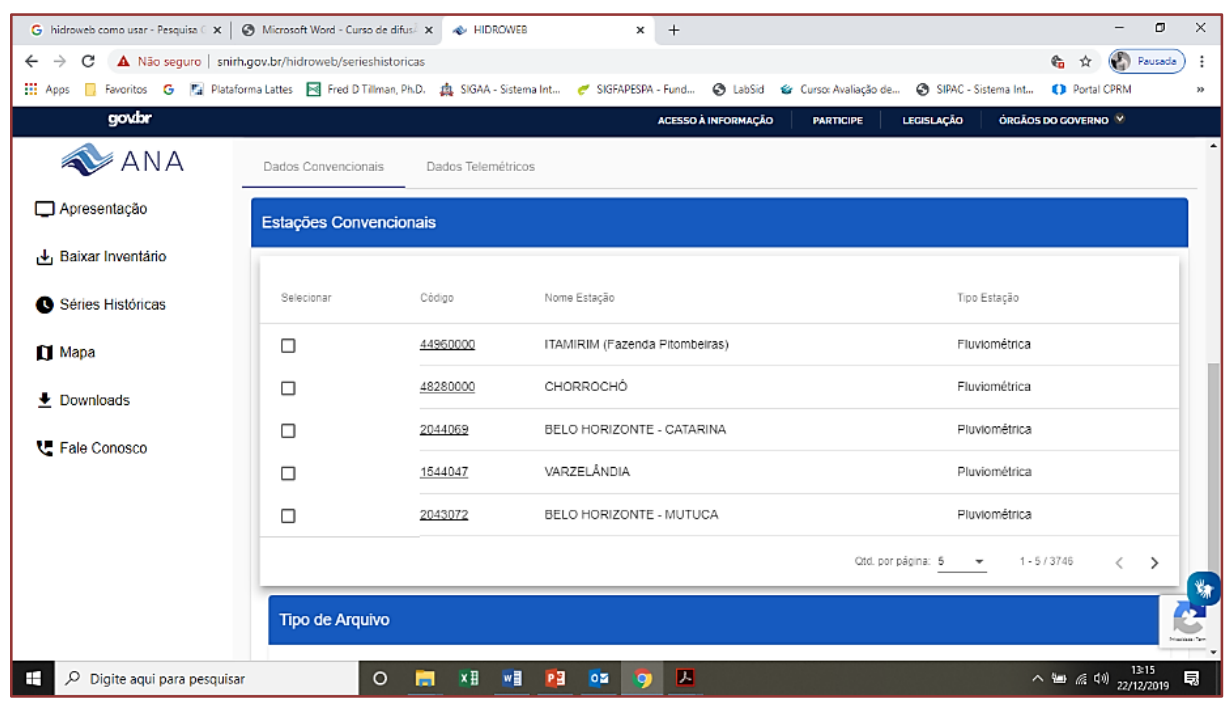

- Para as estações gerenciadas pela ANA o código das estações fluviométricas é composto por 8 dígitos, sendo:

1 dígito: indica a qualidade da estação, ou seja, se está "fora do curso d'água", representada pelo valor "0" (válido para estações pluviométricas) e se está "nos cursos d'água" (no caso das estações fluviométricas), recebe valores de 1 a 9 , sendo:

Bacia 1 - Bacia do rio Amazonas

Bacia 2 - Bacia do rio Tocantins

Bacia 3 - Bacia do Atlântico - Trecho Norte/Nordeste

Bacia 4 - Bacia do rio São Francisco

Bacia 5 - Bacia do Atlântico - Trecho Leste

Bacia 6 - Bacia do rio Paraná

Bacia 7 - Bacia do rio Uruguai

Bacia 8 - Bacia do Atlântico - Trecho Sudeste

Por continuidade atribui-se a denominação de Bacia 9 à área de drenagem de qualquer bacia hidrográfica da América do Sul que não tenha interferência na rede potamográfica brasileira.

$2^{\circ}$ dígito - representa uma das sub-bacias que compõem a bacia identificada pelo primeiro dígito (valores de 0 a 9 );

3ำ 4o e 5o dígitos - representam o número arbitrado à estação obedecendo ao seguinte critério: o a numeração é crescente, com intervalos variáveis, ao longo do curso d'água e seus afluentes; a sequência das estações no curso d'água será de montante para jusante; ao encontrar-se um afluente, as estações nele situadas, serão numeradas, também, de montante para jusante, antes de continuar o processo com o rio principal; o mesmo se fará para o afluente do afluente, e assim por diante.

6ํㅜ 7ํㅡ e 8o dígitos - representam a previsão quanto à possibilidade de uma futura expansão da rede, quando serão identificadas novas estações. No estágio atual de desenvolvimento da rede de monitoramento, a grande maioria dos campos é constituída por zeros (000). 
- Daí é só você localizar a estação do seu interesse, no campo "Tipo de arquivo" marcar um dos três formatos e clicar em "BaixarArquivo" que o download será iniciado.

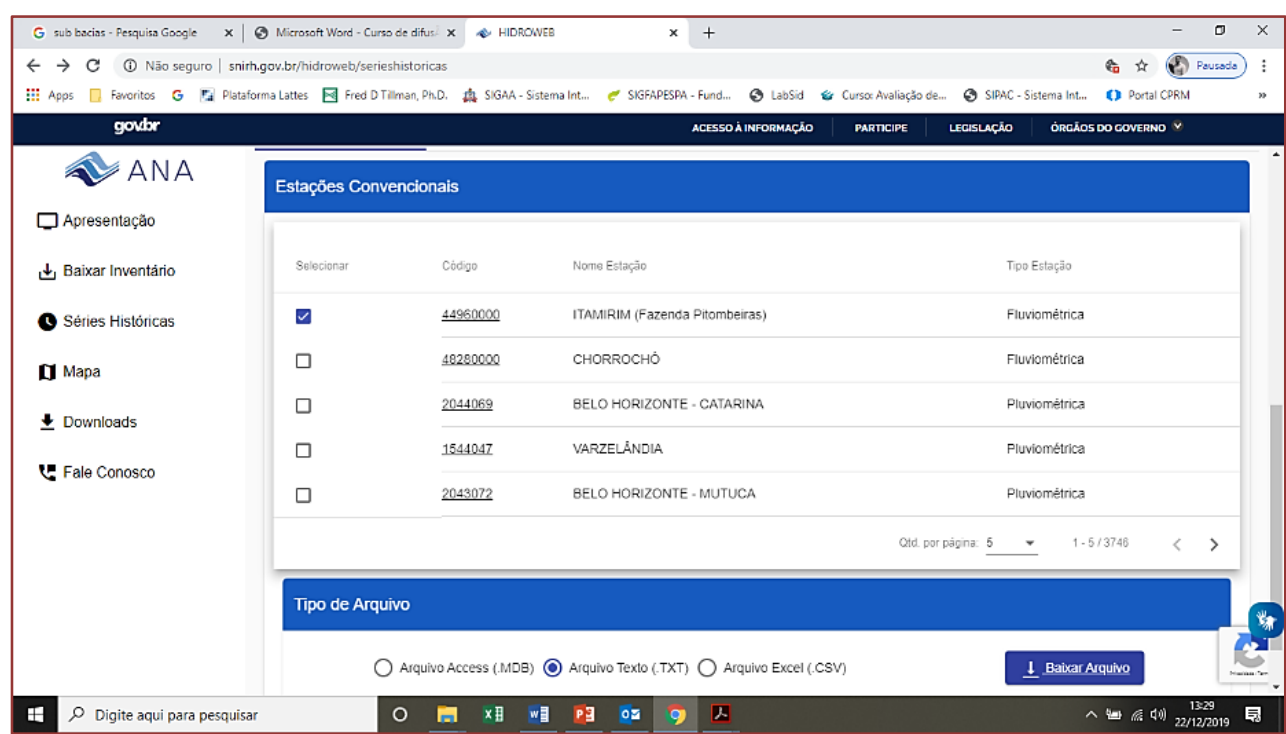

- 0 arquivo virá compactado, neste caso você precisa usar um descompactador para visualizar o arquivo em TXT. Assim, será somente dar dois cliques no arquivo para abrir em um editor de textos.

- Para abrir no software Microsoft Excel basta salvar o arquivo .TXT e, com o Excel aberto, clicar no menu Arquivo, desça até a opção Abrir, vá em procurar e localize a pasta onde o arquivo .TXT está armazenado, escolha a opção todos os arquivos, daí é só marcar o arquivo e clicar em Abrir, veja as Figuras abaixo.

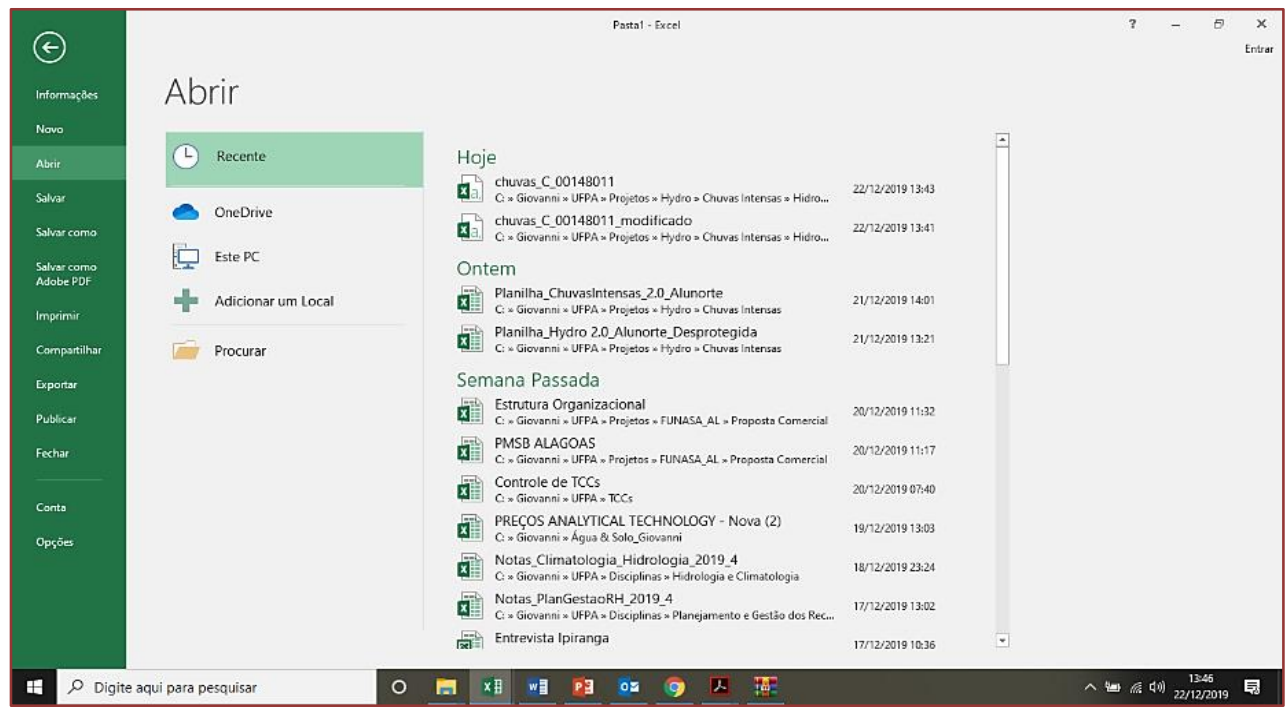


- Seu arquivo de dados está pronto para ser trabalhado.

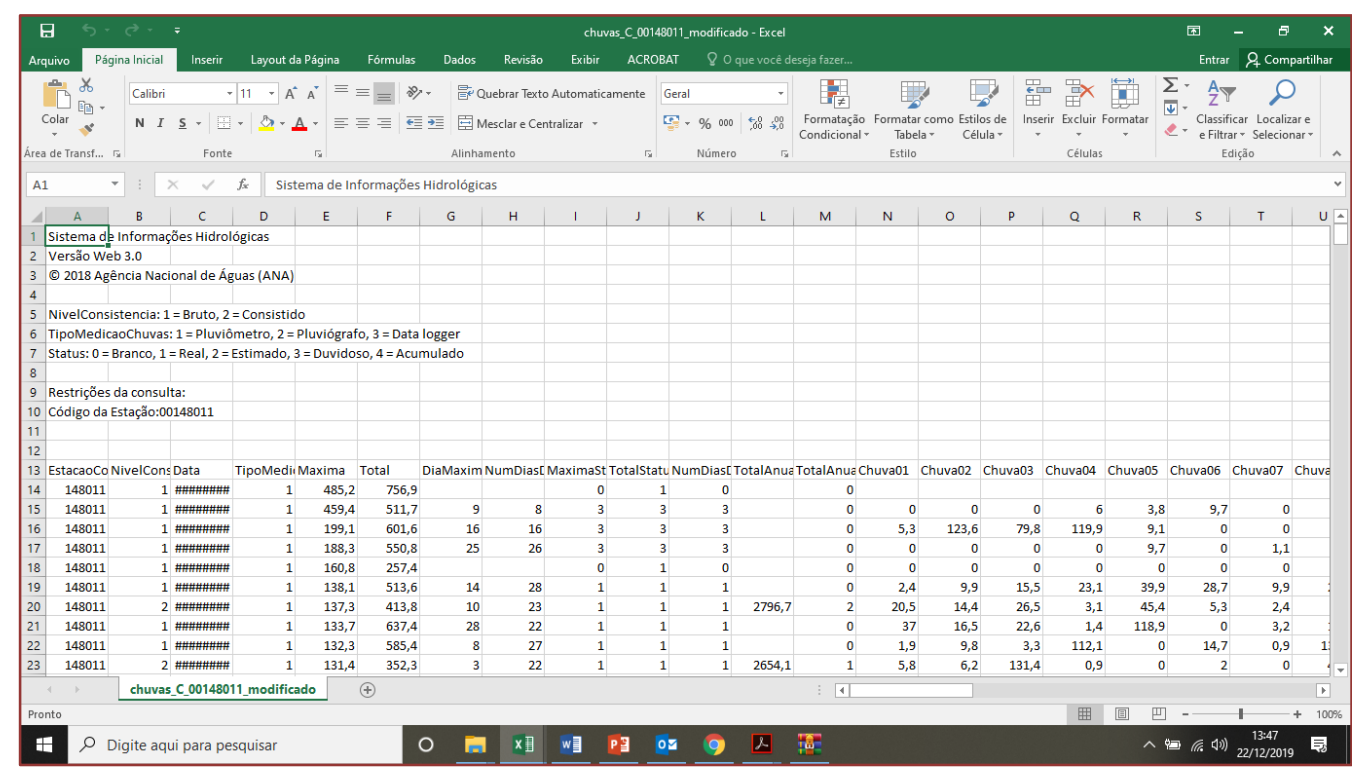

\subsubsection{PREPARAÇ̃̃O DOS DADOS}

Nesta disciplina nos interessamos em separar as maiores vazões de cada ano. Desta forma você precisará separar as maiores vazões de cada ano.

Como exemplo iremos usar as vazões máximas anuais do rio Guaporé, no posto fluviométrico (86560000) Linha Colombo (RS), que já foram separados e organizados e são apresentados na Tabela 1, a seguir.

Tabela 1 - Vazões máximas anuais do posto fluviométrico (86560000) Linha Colombo (RS)

\begin{tabular}{|c|c|c|c|c|c|}
\hline Ano & $\begin{array}{l}\text { Vazão Máxima } \\
\qquad\left(\mathrm{m}^{3} / \mathrm{s}\right)\end{array}$ & Ano & Vazão Máxima $\left(\mathrm{m}^{3} / \mathrm{s}\right)$ & Ano & $\begin{array}{l}\text { Vazão Máxima } \\
\qquad\left(\mathrm{m}^{3} / \mathrm{s}\right)\end{array}$ \\
\hline 1940 & 953 & 1958 & 646 & 1976 & Falha \\
\hline 1941 & 1171 & 1959 & 953 & 1977 & 673 \\
\hline 1942 & 723 & 1960 & falha & 1978 & 760 \\
\hline 1943 & 267 & 1961 & 718 & 1979 & 780 \\
\hline 1944 & 646 & 1962 & 503 & 1980 & 653 \\
\hline 1945 & 365 & 1963 & falha & 1981 & 537 \\
\hline 1946 & 1359 & 1964 & 457 & 1982 & 945 \\
\hline 1947 & 411 & 1965 & 915 & 1983 & 1650 \\
\hline 1948 & 480 & 1966 & 742 & 1984 & 1165 \\
\hline 1949 & 365 & 1967 & 840 & 1985 & 888 \\
\hline 1950 & 1192 & 1968 & 331 & 1986 & 728 \\
\hline 1951 & 356 & 1969 & 320 & 1987 & 809 \\
\hline 1952 & 246 & 1970 & 365 & 1988 & 945 \\
\hline 1953 & 1093 & 1971 & 671 & 1989 & 1380 \\
\hline 1954 & 840 & 1972 & 1785 & 1990 & Falha \\
\hline 1955 & 622 & 1973 & 726 & 1991 & Falha \\
\hline 1956 & falha & 1974 & 397 & 1992 & Falha \\
\hline 1957 & 598 & 1975 & 480 & 1993 & 639 \\
\hline
\end{tabular}

Vale ressaltar que todos os anos onde ocorram falhas foram desconsiderados. Todavia poderia ser usado algum critério de preenchimento de falha, porém não é o objetivo da presente aula. 


\subsubsection{DETERMINAÇÃO DE VALORES MÁXIMOS POR DIFERENTES DISTRIBUIÇÕES PROBABILÍSTICAS}

Todos os projetos de engenharia são planejados para o futuro, não havendo certeza absoluta das exatas condições de trabalho da obra. 0 engenheiro que atua com hidrologia e recursos hídricos não estará absolutamente certo da vazão ou precipitação que afetará o projeto. Contudo, deve estar consciente de que um erro acentuado de previsão das quantidades hidrológicas poderá causar efeitos destruidores indesejáveis, que podem inviabilizar economicamente todo o projeto.

Uma vez que o comportamento exato das vazões em anos futuros não pode ser absolutamente previsto, procura-se introduzir leis de probabilidade de modo a estabelecer as prováveis variações para permitir que o plano seja completado com base em um risco calculado. Recorre-se, pois, à análise estatística com o propósito de utilizar os eventos de descargas observadas (série histórica de vazões) num dado período, como meio de se efetuar a projeção para um período de tempo maior.

Na previsão de enchentes, ou seja, na determinação da magnitude das vazões de pico das cheias (que são as vazões críticas ou de projeto), recorre-se ao uso de modelos de probabilidade, a partir de um enfoque estatístico que consiste em definir a relação entre as descargas máximas e as correspondentes frequências de ocorrência, apoiando-se no estudo de uma série de dados observados. A suposição básica é que as cheias verificadas durante um determinado período possam ocorrer em um período futuro de características hidrológicas similares, isto é, com uma expectativa de repetição.

As funções matemáticas de distribuição de probabilidade mais utilizadas na análise de frequência das vazões de enchente são:

1) distribuição gama, também conhecida como distribuição Pearson tipo III;

2) transformação logarítmica da distribuição gama, também conhecida como distribuição log-Pearson tipo III;

3) distribuições exponenciais, também conhecidas como distribuições de valores extremos ou distribuições de Fisher-Tippett, que são de três tipos, sendo a mais frequente do tipo I, duplo exponencial, conhecida como distribuição Gumbel;

4) distribuição gaussiana (distribuição normal de probabilidade);

5) transformação logarítmica da distribuição normal, também conhecida como distribuição log-normal ou distribuição de Galton.

Ven Te Chow conseguiu comprovar que a maioria das distribuições de probabilidade usadas em Hidrologia por uma única equação geral, onde a variável de interesse (vazão, chuva, etc.) é expressa em função da média, do desvio padrão e do fator de frequência $K_{T r}$, conforme:

$$
x_{T r}=\bar{X}+K_{T r} \cdot s_{X}
$$

Onde:

$x_{T r}=$ variável de interesse (vazão, chuva, etc.) para o período de retorno Tr;

$\bar{X}=$ média aritmética do conjunto de dados;

$K_{T r}=$ fator de frequência associado a distribuição probabilística de interesse;

$S_{X}=$ desvio padrão do conjunto de dados.

Como visto na aula teórica em sala de aula, a média aritmética, o desvio padrão e coeficiente de assimetria são determinados diretamente da série histórica dos dados que pode ser determinado diretamente com calculadora, planilha eletrônica (função do Excel: "=média()", "=desvpad.a()" e "=distorção()") ou software específico. No caso das distribuições que trabalham com o logaritmo (log-normal, log-Pearson, etc.) é necessário antes de calcular a média aritmética, o desvio padrão e o coeficiente de assimetria determinar o logaritmo (pode ser logaritmo na base 10, log, ou logaritmo natural, ln, usaremos a segunda opção) de cada valor da variável de interesse (vazão, precipitação, etc.). 
O valor do fator de frequência pode ser obtido por tabela, como indicado na apostila e feito em sala de aula. Também pode ser usado o Excel, neste caso, para as distribuições Normal e log-Normal, o $\mathrm{K}_{\mathrm{Tr}}$, é dado por: "= INV.NORMP.N(1-(1/Tr); Média; Desvio Padrão)".

Para a distribuição Gumbel segue a mesma ideia usada em sala de aula, isto é, calcula-se a variável reduzida de Gumbel $\left(\mathrm{y}_{\mathrm{Tr}}\right)$ para cada período de retorno, em seguida determina-se a média e desvio padrão dos valores de "У ${ }_{\operatorname{Tr}}$ " e finalmente aplica-se a equação: $K_{T r_{G u m b e l}}=\frac{y_{T r}-y_{\text {médio }}}{y_{\text {desvio padrão }}}$

No caso das distribuições Pearson III e log-Pearson III, que são derivados da função Gama, usa-se a função do Excel "= INV.GAMA(1-(1/Tr); $\alpha ; \beta)$ ". Todavia precisa feito um ajuste na equação proposta pode Ven Te Chow.

Inicialmente, sendo o coeficiente de assimetria positivo ( $g_{x}>0$ ), os parâmetros " $\alpha$ e $\beta$ " da distribuição Gama são dados por:

$$
\alpha=\frac{4}{g_{x}^{2}}
$$

Onde: $g_{x}$ - coeficiente de assimetria da variável de interesse (vazão, chuva, etc.).

$$
\beta=\frac{S_{X}}{\sqrt{\alpha}}
$$

Onde: $S_{X}$ - desvio padrão da variável de interesse (vazão, chuva, etc.).

Para o Excel a equação da distribuição Pearson III fica no formato:

$$
x_{T r}=\bar{X}-\frac{2 \cdot S_{X}}{g}+I N V . G A M A\left(1-\frac{1}{T r} ; \alpha ; \beta\right)
$$

Caso o coeficiente de assimetria positivo $\left(g_{x}<0\right)$, os parâmetros “ $\alpha$ e $\beta$ ” da distribuição Gama são dados por:

$$
\begin{gathered}
\alpha=\frac{4}{g_{x}^{2}} \\
\beta=\left|\frac{S_{X}}{\sqrt{\alpha}}\right|
\end{gathered}
$$

Neste caso, para o Excel, a equação para a distribuição Pearson III fica no formato:

$$
x_{T r}=\bar{X}-\frac{2 \cdot S_{X}}{g}-I N V . G A M A\left(\frac{1}{T r} ; \alpha ; \beta\right)
$$

Para a distribuição log-Pearson III o procedimento é parecido com o anterior, lembrando que para todas as distribuições "log" inicialmente os valores da variável de interesse devem ser logaritmados na forma Y $=\ln (\mathrm{X})$, os coeficientes parâmetros $\alpha$ e $\beta$ precisarão ser novamente calculados, considerando a média aritmética, desvio padrão e coeficiente de assimetria dos $\ln (\mathrm{X})$. 
Para o Excel, caso gY>0, a equação da distribuição log-Pearson III fica no formato:

$$
x_{T r}=\exp \left\{\bar{Y}-\frac{2 \cdot S_{Y}}{g_{Y}}+\operatorname{INV} . \text { GAMA }\left(1-\frac{1}{\operatorname{Tr}} ; \alpha ; \beta\right)\right\}
$$

No caso de " $\mathrm{g}_{Y}<0$ " a equação da distribuição log-Pearson III fica no formato:

$$
x_{T r}=\exp \left\{\bar{Y}-\frac{2 \cdot S_{Y}}{g_{Y}}-I N V . G A M A\left(\frac{1}{T r} ; \alpha ; \beta\right)\right\}
$$

\subsubsection{POSIÇÃO DE PLOTAGEM PARA ANÁLISE DE FREQUÊNCIA}

Em hidrologia existem muitas vezes eventos extremos, tais como secas ou cheias. 0 valor de um acontecimento extremo é inversamente proporcional à sua frequência de ocorrência, isto é, um acontecimento extremo ocorre com menos frequência do que um evento moderado. Neste caso aplica-se a análise frequência em hidrologia para relacionar a magnitude dos valores extremos com a sua frequência de ocorrência, daí é possível comparar tais valores extremos com os determinados por distribuições probabilísticas e em seguida fazer previsões para caso mais extremos. Os resultados desta análise podem ser usados em vários problemas de engenharia, tais como, dimensionamento de barragens, pontes, estruturas de controlo de cheias, etc.

No caso de eventos máximos, que o objetivo deste material, a estimação da probabilidade empírica de excedência, associada a um certo ponto, é geralmente referida como a determinação da posição de plotagem, a qual pode ser expressa como uma fração entre 0 e 1 , ou como uma porcentagem entre 0 e 100 . No caso da população, a determinação da posição de plotagem é meramente um problema de determinação da "fração" da população cujos valores são maiores ou iguais ao valor em questão. Assim, para uma variável aleatória de máximos, o menor valor da população terá uma posição de plotagem igual a 1 (um) e o maior valor terá uma posição de plotagem igual a 0 (zero). A definição das posições de plotagem para dados amostrais não é tão direta como no caso populacional, uma vez que nunca haverá certeza de que a amostra contém o maior e/ou o menor valor da população. Assim, para dados amostrais, as posições de plotagem 0 e/ou 1 devem ser evitadas, à exceção dos casos em que existirem informações definitivas acerca dos limites populacionais (Naghettini e Pinto, 2007).

Em síntese, para o caso de máximos, uma fórmula para a estimação da posição de plotagem deve especificar a frequência com que um, entre $n$ valores ordenados de modo decrescente, será igualado ou superado.

As posições de plotagem mais usuais em Hidrologia são dadas na Tabela 2. Lembrando que $p=1 /$ Tr.

Tabela 2 - Equações para estimar a posição de plotagem

\begin{tabular}{|l|c|}
\hline \multicolumn{1}{|c|}{ Nome } & Equação \\
\hline Weibull & $p=\frac{m}{n+1}$ \\
\hline Mediana & $p=\frac{m-0,3175}{n+0,365}$ \\
\hline Hosking & $p=\frac{m-0,35}{n}$ \\
\hline Blom & $p=\frac{m-0,375}{n+0,25}$ \\
\hline Cunnane & $p=\frac{m-0,4}{n+0,2}$ \\
\hline Gringorten & $p=\frac{m-0,44}{n+0,12}$ \\
\hline Hazen & $p=\frac{m-0,5}{n}$ \\
\hline
\end{tabular}


Obs: quando os dados são ordenados em ordem decrescente o número de ordem "m" varia de 1, maior valor, até "n", que será o último valor.

Não existe uma posição de plotagem melhor ou pior, em geral observa-se a melhor disposição dos dados. A posição de Plotagem de Weibull é indicada pelo US Water Resources Council. Já a publicação britânica Flood Estimation Handbook, mencionada por Bayliss e Reed (2001), sugere a utilização da equação de Gringorten.

Aqui no nosso curso de Climatologia e Hidrologia da UFPA será usada a posição Weibull como referência.

\subsubsection{TESTE DE ADERÊNCIA}

Por hipótese assumimos que a distribuição populacional da variável de interesse (vazões, chuva, etc.) seja descrita por determinado modelo de distribuição de probabilidade (normal, log-normal, Gumbel, etc.). Testaremos se a hipótese verificando a aderência dos dados da amostra (série de vazões, chuva, etc.) ao modelo de distribuição de probabilidade. A hipótese de nulidade Ho é, sempre, que a distribuição teórica representa adequadamente a distribuição observada.

Neste momento vamos usar o teste Não Paramétrico de Hipótese de Kolmogorov-Smirnov para conferir a aderência das distribuições probabilística aos dados.

O Teste de Aderência de Kolmogorov-Smirnov permite verificar a significância das diferenças entre as frequências observadas e as frequências teóricas obtidas a partir de uma distribuição probabilística. Sendo aplicável para distribuições probabilísticas contínuas.

Definidas as funções probabilísticas acumuladas empírica $\mathrm{S}(\mathrm{x})$ (observadas, isto é, no nosso caso, dados copiados do Hidroweb associados a uma posição de plotagem) e teórica $\mathrm{F}(\mathrm{x})$ (hipotética, distribuições probabilísticas testadas no Excel), a estatística de teste é o máximo módulo da diferença das probabilidades acumuladas destas funções: $\mathrm{D}=$ máximo $|\mathrm{F}-\mathrm{S}|$, o valor de "D" é comparado com o valor de "D $\alpha$ " obtido da Tabela 3, sendo "N" o número de dados e " $\alpha$ " a significância. Se "D > D $\alpha$ " a hipótese da distribuição teórica representar a distribuição empírica é rejeitada ao nível de significância $\alpha$. Se "D $\alpha>\mathrm{D}$ " a hipótese da distribuição teórica representar a distribuição empírica não pode ser rejeitada ao nível de significância $\alpha$.

Tabela 3 - Valores críticos da estatística $\mathrm{D}_{\mathrm{N}, \alpha}$ do teste de aderência Kolmogorov-Smirnov

\begin{tabular}{|c|c|c|c|c|c|c|c|c|c|}
\hline $\mathrm{N}$ & $\mathrm{D}_{\mathrm{N}, 0,10}$ & $\mathrm{D}_{\mathrm{N}, 0,05}$ & $\mathrm{D}_{\mathrm{N}, 0,02}$ & $\mathrm{D}_{\mathrm{N}, 0,01}$ & $\mathrm{~N}$ & $\mathrm{D}_{\mathrm{N}, 0,10}$ & $\mathrm{D}_{\mathrm{N}, 0,05}$ & $D_{\mathrm{N}, 0,02}$ & $D_{\mathrm{N}, 0,01}$ \\
\hline 10 & 0,369 & 0,409 & 0,457 & 0,489 & 26 & 0,233 & 0,259 & 0,290 & 0,311 \\
\hline 11 & 0,352 & 0,391 & 0,437 & 0,468 & 27 & 0,229 & 0,254 & 0,284 & 0,305 \\
\hline 12 & 0,338 & 0,375 & 0,419 & 0,449 & 28 & 0,225 & 0,250 & 0,279 & 0,300 \\
\hline 13 & 0,325 & 0,361 & 0,404 & 0,432 & 29 & 0,221 & 0,246 & 0,275 & 0,295 \\
\hline 14 & 0,314 & 0,349 & 0,390 & 0,418 & 30 & 0,218 & 0,242 & 0,270 & 0,290 \\
\hline 15 & 0,304 & 0,338 & 0,377 & 0,404 & 31 & 0,214 & 0,238 & 0,266 & 0,285 \\
\hline 16 & 0,295 & 0,327 & 0,366 & 0,392 & 32 & 0,211 & 0,234 & 0,262 & 0,281 \\
\hline 17 & 0,286 & 0,318 & 0,355 & 0,381 & 33 & 0,208 & 0,231 & 0,258 & 0,277 \\
\hline 18 & 0,279 & 0,309 & 0,346 & 0,371 & 34 & 0,205 & 0,227 & 0,254 & 0,273 \\
\hline 19 & 0,271 & 0,301 & 0,337 & 0,361 & 35 & 0,202 & 0,224 & 0,251 & 0,269 \\
\hline 20 & 0,265 & 0,294 & 0,329 & 0,352 & 36 & 0,199 & 0,221 & 0,247 & 0,265 \\
\hline 21 & 0,259 & 0,287 & 0,321 & 0,344 & 37 & 0,196 & 0,218 & 0,244 & 0,262 \\
\hline 22 & 0,253 & 0,281 & 0,314 & 0,337 & 38 & 0,194 & 0,215 & 0,241 & 0,258 \\
\hline 23 & 0,247 & 0,275 & 0,307 & 0,330 & 39 & 0,191 & 0,213 & 0,238 & 0,255 \\
\hline 24 & 0,242 & 0,269 & 0,301 & 0,323 & 40 & 0,189 & 0,210 & 0,235 & 0,252 \\
\hline 25 & 0,238 & 0,264 & 0,295 & \multirow{2}{*}{0,317} & $>40$ & \multirow{2}{*}{$1,22 /$ raiz(N) } & $1,36 /$ raiz(N) & $1,52 /$ raiz(N) & $\begin{array}{c}1,63 / \text { raiz } \\
(\mathrm{N})\end{array}$ \\
\hline
\end{tabular}


No nosso curso iremos adotar um nível de significância " $\alpha$ " de $5 \%$ ou 0,05 . Tal valor é muito empregado na literatura sobre Estatística aplicada a Hidrologia.

0 teste Kolmogorov-Smirnov pode ser implementado em planilha eletrônica Excel com os seguintes passos:

1) Ordene os dados da sua variável de interesse do maior para o menor (considerando que estamos trabalhando com valores máximos), calcule o também os "ln" da variável de interesse, determinando a média aritmética, o desvio padrão e o coeficiente de assimentria;

2) Atribua um número de ordem " $m$ " variando de 1 associado ao maior valor da variável de interesse até "n" que está associado ao menor dos valores;

3) Usando a posição de plotagem de Weibull calcule o período de retorno associado aos dados. Em seguida calcule a probabilidade excedência fazendo " $\mathrm{p}_{\mathrm{exc}}=1 / \mathrm{Tr}$ ". Depois calcule a probabilidade de inexistência " $\mathrm{p}_{\text {inex }}=1-\mathrm{p}_{\text {exc }}$ ";

4) Como o teste de Kolmogorov-Smirnov pede que seja calculada diferença entre a probabilidade de inexistência da variável de interesse com probabilidade de inexistência de cada distribuição probabilística considerada:

a. Distribuição Normal: use a "=DIST.NORM.N (Variável de interesse; Média; Desvio Padrão; VERDADEIRO);

b. Distribuição log-Normal: use a "=DIST.LOGNORM.N ( $\ln ($ Variável de interesse); Média $\ln (\mathrm{x})$; Desvio Padrão $\ln (\mathrm{x})$; VERDADEIRO);

c. Distribuição Gumbel: calcule os parâmetros " $\mu=$ média $-0,577^{*} \alpha$ ", “ $\alpha=0,7797^{*} S x^{\prime \prime}$ e "=EXP($\operatorname{EXP}(($ O -Variável de interesse $) / \alpha)) " ;$

d. Distribuição Pearson III: calcule os parâmetros “ $\alpha=\left(2 / \mathrm{g}_{\mathrm{X}}\right)^{2 ”}$ ", " $\beta=\mathrm{S}_{\mathrm{X}} / \operatorname{raiz}(\alpha)^{\text {", " }} \gamma=\bar{X}-S_{X} \cdot \sqrt{\alpha}$ " e "=DIST.GAMA(Variável de interesse - $\gamma ; \alpha ; \beta$; VERDADEIRO)";

e. $\quad$ Distribuição log-Pearson III: calcule os parâmetros “ $\alpha=\left(2 / \mathrm{g}_{\mathrm{Y}}\right)^{2 ”}$, “ $\beta=\mathrm{S}_{\mathrm{Y}} / \operatorname{raiz}(\alpha)$ ”, “ $\gamma=\bar{Y}-S_{Y} \cdot \sqrt{\alpha}$ ” e "=DIST.GAMA(ln(Variável de interesse) - $\gamma ; \alpha$; $\beta$; VERDADEIRO)".

5) A diferença das probabilidades acumuladas para cada distribuição probabilística é calculada como: $\mathrm{D}=$ máximo $\mid \mathrm{p}_{\text {inex }}-\mathrm{p}_{\text {inex }}($ distribuição de interesse $) \mid$;

6) Todas as distribuições probabilísticas que satisfizerem a condição "D $\alpha>D$ " suportam a hipótese da distribuição teórica não pode ser rejeitada ao nível de significância considerado.

\subsubsection{SUA ATIVIDADE PRÁTICA}

1) Trabalhando em grupos de até 5 alunos;

2) Escolha uma estação, pode ser Pluviométrica ou Fluviométrica, contida no Sistema HIDROWEB gerenciado pela ANA que contenha pelo menos 20 anos de registros que podem ser contínuos ou descontínuos;

3) Identifique o nome e o número da estação considerada;

4) Separe os maiores valores da variável de interesse de cada ano;

5) Ordene os dados do maior para o menor valor;

6) Atribua um número de ordem, calcule a frequência (posição de plotagem de Weibull) e o período retorno;

7) Calcule o logaritmo neperiano de cada valor da variável de interesse;

8) Determine a média aritmética, o desvio padrão e coeficiente de assimetria da variável de interesse e dos respectivos logaritmos neperianos;

9) Faça o cálculo comparativo entre os valores da variável de interesse com os fornecidos pelas distribuições probabilísticas: Normal, log-Normal, Gumbel, Pearson III e log-Pearson III. Considerar os mesmos períodos de retorno já calculados; 
10) Faça um Gráfico comparativo entre os valores da variável de interesse com os fornecidos pelas distribuições probabilísticas em função dos respectivos períodos de retorno;

11) Por comparação gráfica indique qual distribuição probabilística apresenta a melhor aderência aos dados da variável de interesse;

12) Bônus para quem aceitar o desafio: aplique o teste de Kolmogorov-Smirnov e indique quais das distribuições probabilísticas testadas podem ser aceitas.

\subsubsection{USANDO O PROGRAMA SISTEMA ESPECIALISTA EM ANÁLISE DE FREQUÊNCIA}

Dentre as ferramentas disponíveis para a análise de frequência local, os sistemas especialistas computacionais, que emulam os princípios de raciocínio de um especialista humano ao selecionar uma distribuição de probabilidades, têm-se mostrado muito úteis. Um exemplo desse tipo de sistema é o SEAF (Sistema Especialista para Análise de Frequência local de eventos máximos anuais). Vamos testar o programa SEAF (Sistema Especialista em Análise de Frequência) 1.0, desenvolvido pelo Departamentos de Engenharia Sanitária e Ambiental e Engenharia Hidráulica e Recursos Hídricos da Universidade Federal de Minas Gerais, disponível na URL http://www.ehr.ufmg.br/downloads/.

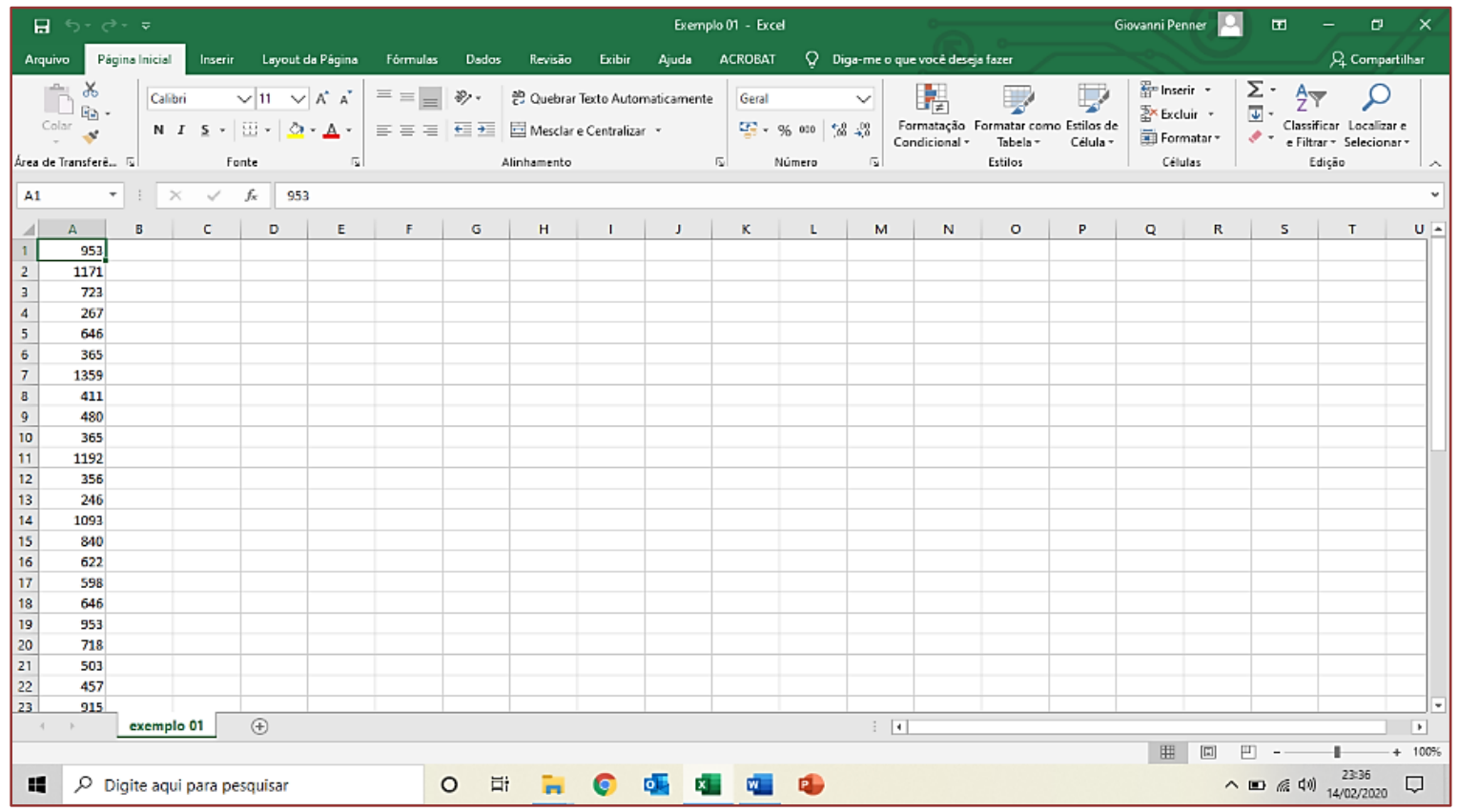

Basicamente os dados da variável de interesse só precisam ser colocados no formato que é lido pelo SEAF. Os dados devem estar em uma única coluna e salvos em .txt, tal operação pode ser facilmente realizada no Excel. Como mostrados nas Figuras abaixo. 


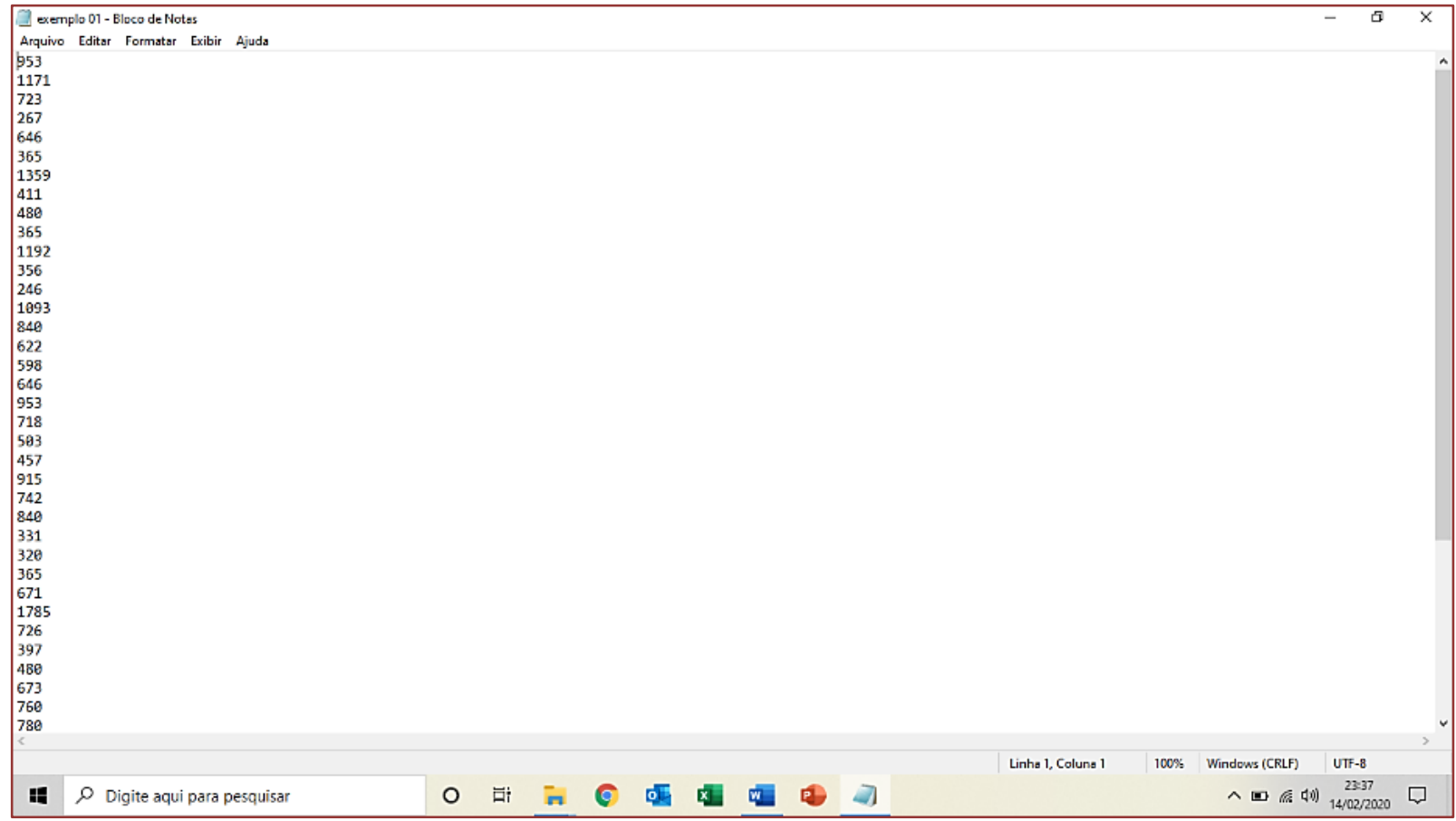

Em seguida o programa SEAF pode ser executado. No meu caso a versão do SEAF disponível não roda nas versões atuais do Windows, daí foi usada uma Máquina Virtual, Oracle VM VirtualBox, para rodar o Windows XP, conforme Figura a seguir.

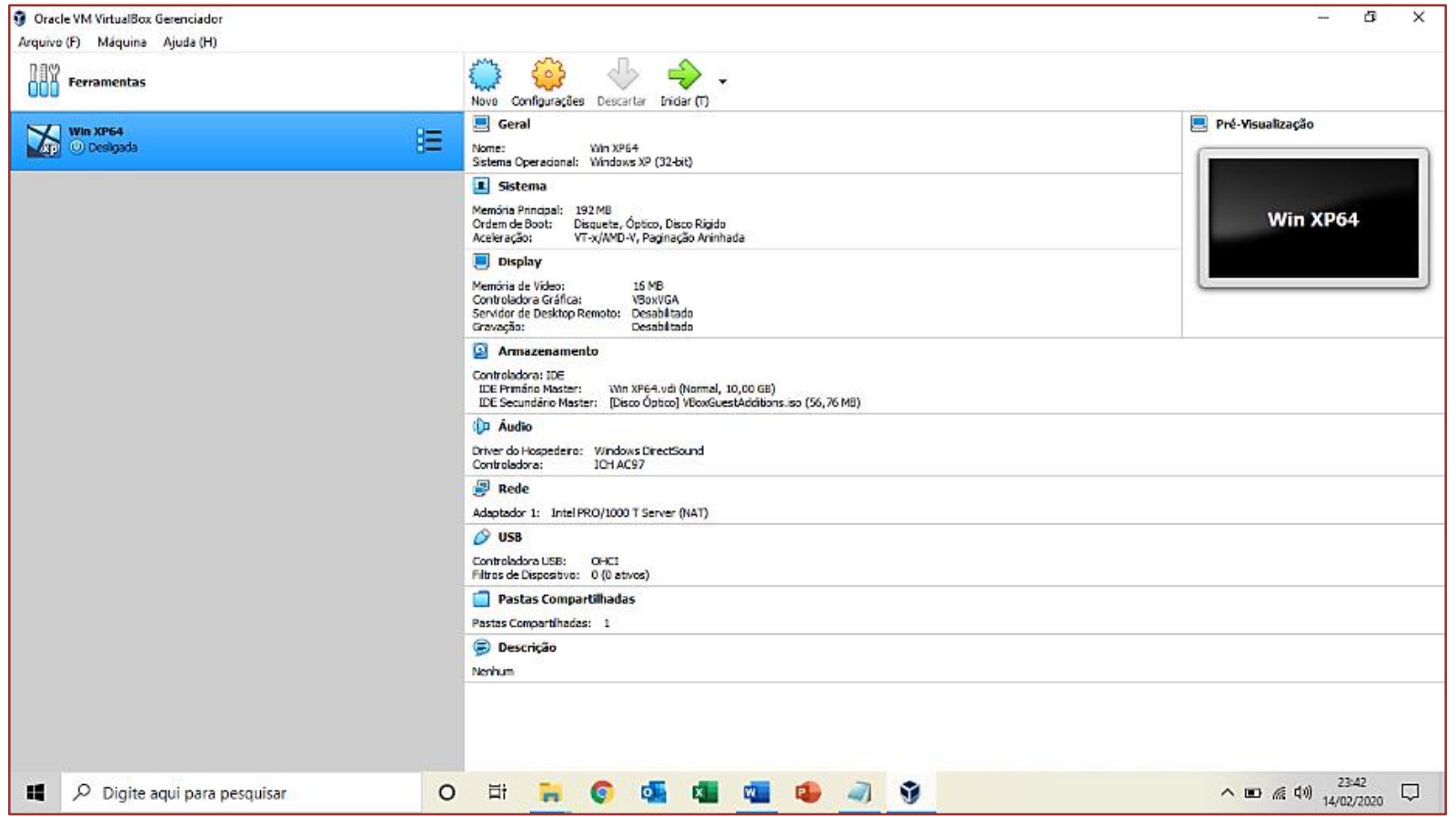

Agora é possível observar SEAF no Windows XP. 


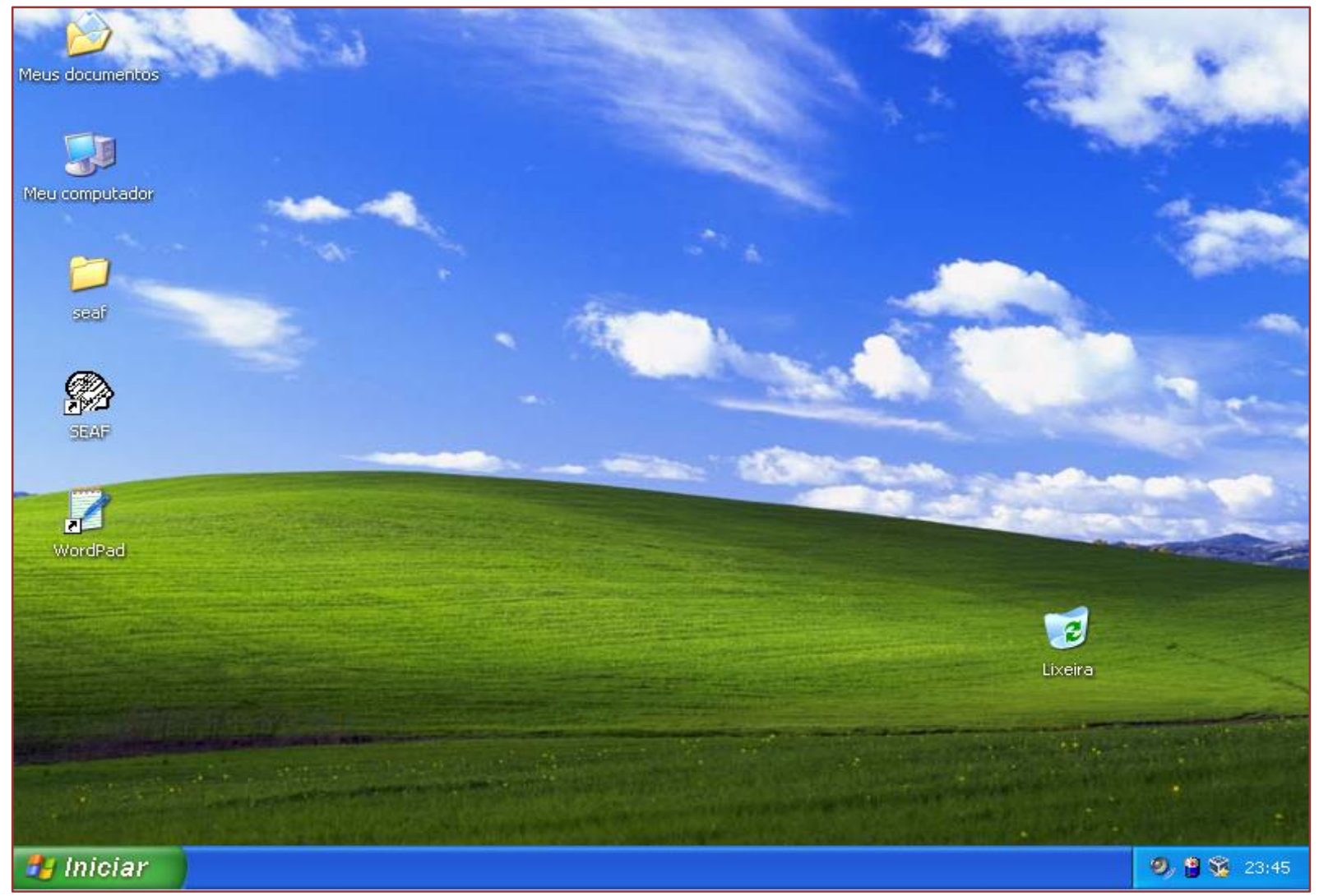

\section{SEAF iniciado.}

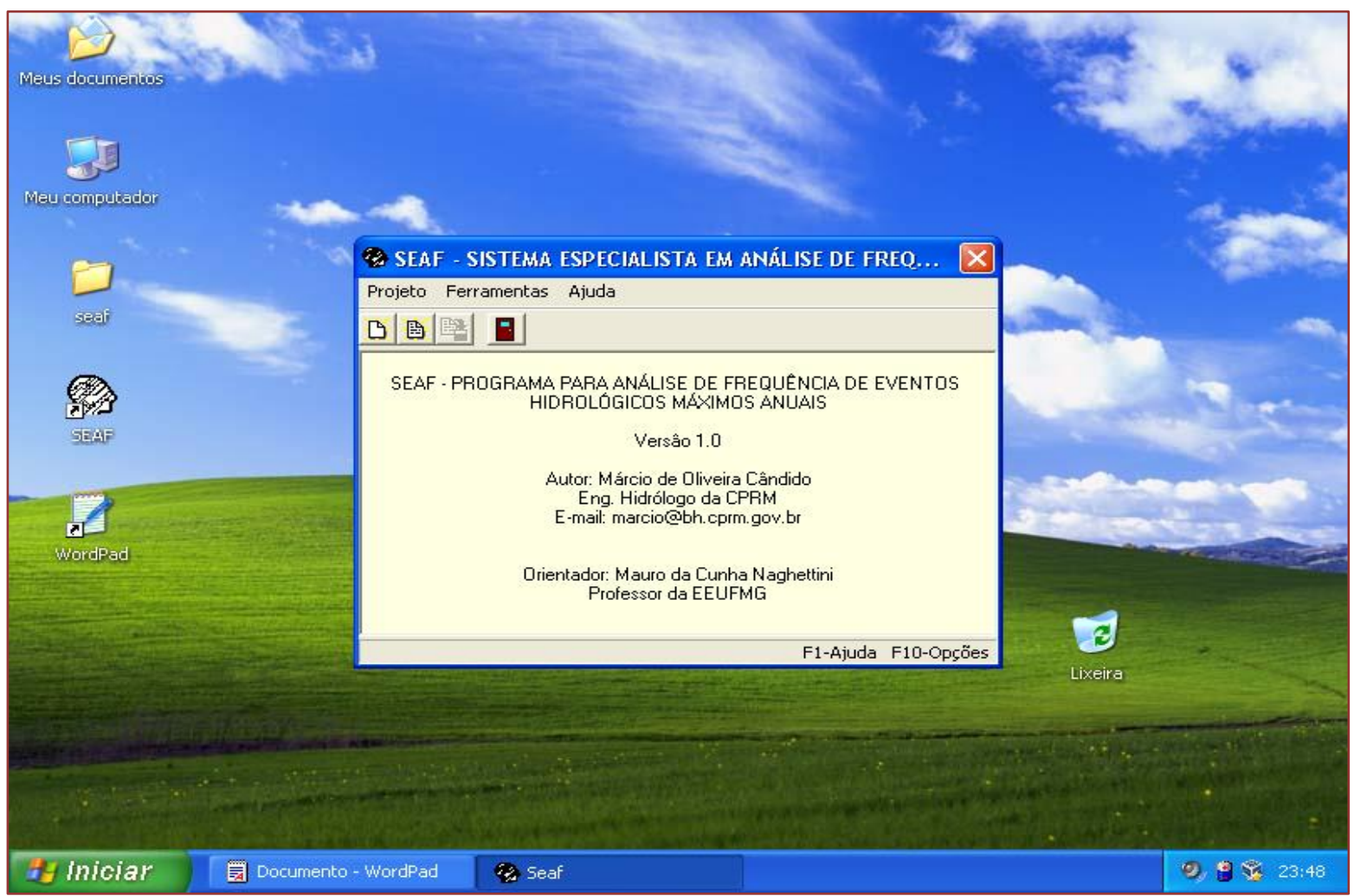

\section{Projeto sendo criado.}



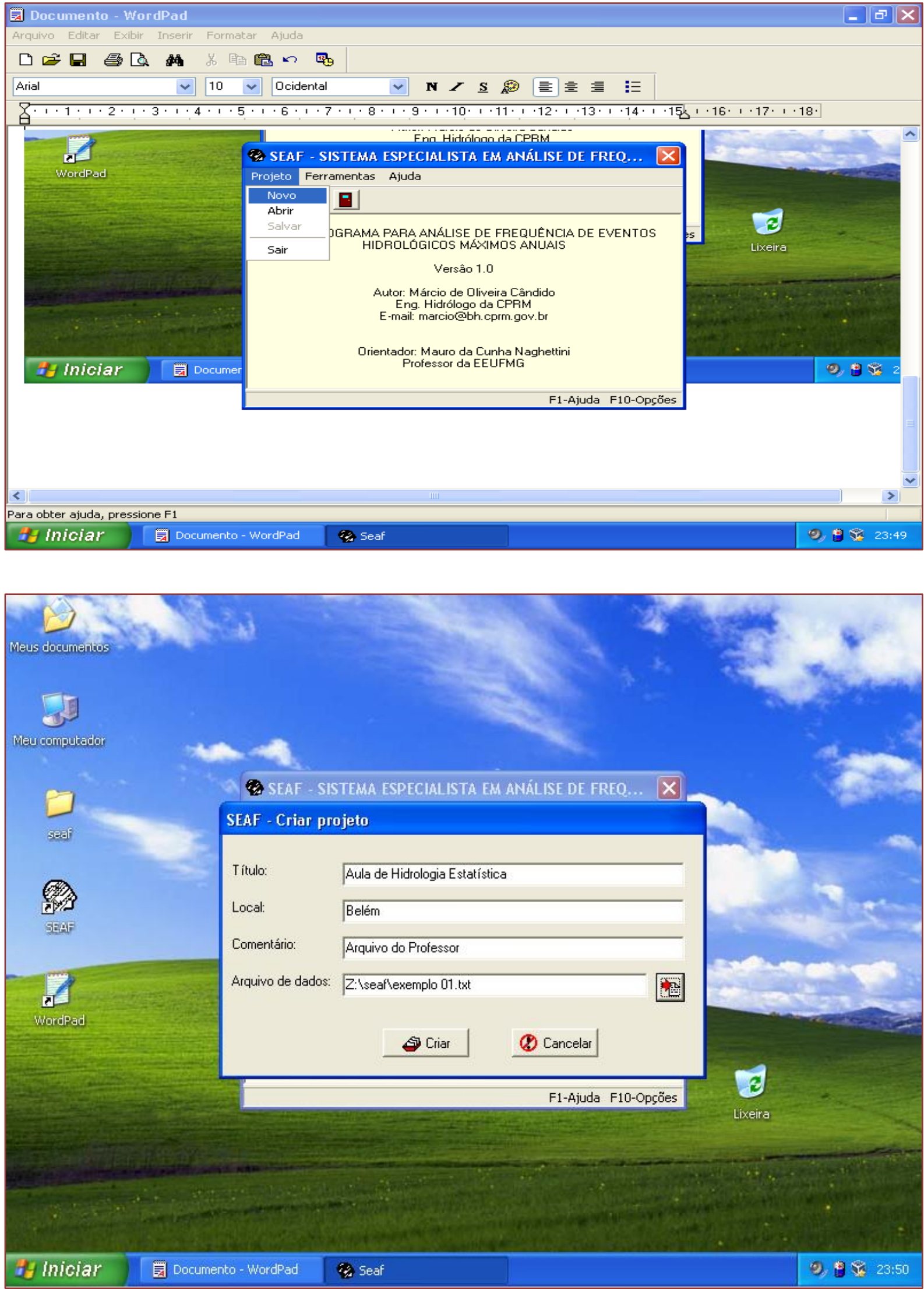
Depois dos dados lidos é só seguir pressionando a seta de execução que os resultados são apresentados. Ao final um arquivo ".txt" com os resultados é apresentado. 0 descritivo do arquivo ".txt" é apresentado a seguir:

\section{SEAF - SISTEMA ESPECIALISTA EM ANÁLISE DE FREQUÊNCIA}

TÍTULO: Aula de Hidrologia Estatística

LOCAL: Belém

COMENTÁRIO: Arquivo do Professor

ARQUIVO DE DADOS: Z: \seaf\exemplo 01.txt

\section{ESTATÍSTICAS DESCRITIVAS:}

**Tamanho da amostra: 47

Máximo: 1785.0000

Mínimo: 246.0000

Média: 746.5532

Desvio padrão: 350.7593

Assimetria: 0.9869

**Momentos-L:

11: 746.5532

12: 193.2720

t3: 0.1807

t4: 0.1535

**Logaritmos:

Máximo: 7.4872

Mínimo: 5.5053

Média: 6.5091

Desvio padrão: 0.4730

Assimetria: -0.1354

TESTES NÃO PARAMÉTRICOS:

**Teste de Kendall:

Coef. Corr. Kendall: 0.1198

Estatistica Z: 1.1650

Valor limiar de | Z |: 1.9600

Alfa: $5 \%$

$\mathrm{Z}<|\mathrm{Z}|=>$ dados independentes

**Teste de Mann-Kendall: 
Estatistica U: 1.6146

Valor limiar de | U |: 1.9600

Alfa: 5\%

$\mathrm{U}<|\mathrm{U}|=>$ dados homogeneos

**Teste Grubbs \& Beck:

*Limite superior:

LS: 2458.6931

Max: 1785.0000

Alfa: $5 \%$

Max $<$ LS => não há outlier

*Limite inferior:

LI: 183.2389

Min: 246.0000

Alfa: $5 \%$

Min > LI => não há outlier

**Teste da assimetria:

*Limite superior:

Não há outlier - a retirada do máximo amostral não resultou em uma mudança significativa da assimetria.

*Limite inferior:

Não há outlier - a retirada do mínimo amostral não resultou em uma mudança significativa da assimetria.

ESTIMAÇÃO DOS PARÂMETROS:

$\begin{array}{lccc}\text { Distribuição } & \text { Posição } & \text { Escala } & \text { Forma } \\ \text { Normal } & 746.5532 & 342.5656 & \\ \text { Log-Normal } & 6.5091 & 0.4801 & \\ \text { Gumbel } & 585.6067 & 278.8325 & \\ \text { Exponecial } & 360.0093 & 386.5439 & \\ \text { Pearson-III } & 746.5532 & 355.6089 & 1.0955 \\ \text { Log-Pearson-III } & 6.5091 & 0.4810 & -0.2474 \\ \text { GEV } & 583.5028 & 274.4976 & -0.0167 \\ \text { GPA } & 285.0576 & 640.4654 & 0.3878\end{array}$


TESTES DE AJUSTE:

${ }^{* *}$ Teste de Filliben

Distribuição $\quad$ R(90\%) R

Normal $\quad 0.9803 \quad 0.9655$

Log-Normal $\quad 0.9803 \quad 0.9933$

Gumbel $\quad 0.9704 \quad 0.9946$

Exponecial $\quad 0.9641 \quad 0.9810$

Pearson-III $\quad 0.9816 \quad 0.9949$

Log-Pearson-III $0.9850 \quad 0.9936$

$\begin{array}{lll}\text { GEV } & 0.9806 & 0.9948 \\ \text { GPA } & 0.9867 & 0.9879\end{array}$

**Teste da Variância

Distribuição $\quad|Z|$

Normal $\quad 2.7931$

Log-Normal 0.6232

Gumbel $\quad 0.1498$

Exponencial $\quad 2.0676$

Pearson-III 0.3719

Log-Pearson-III $\quad 0.1078$

GEV 0.0149

GPA $\quad 1.9071$

ESTIMAÇÃO DE QUANTIS:

\begin{tabular}{|c|c|c|c|c|c|c|c|}
\hline Distribuição & 2 & 5 & 10 & 50 & 100 & 200 & 1000 \\
\hline Normal & 746.553 & 1034.864 & 1185.569 & 1450.097 & 1543.480 & 1628.944 & 1805.161 \\
\hline Log-Normal & 671.214 & 1005.370 & 1241.779 & 1799.018 & 2050.539 & 2311.431 & 2958.870 \\
\hline Gumbel & 687.802 & 1003.839 & 1213.082 & 1673.594 & 1868.278 & 2062.251 & 2511.574 \\
\hline Exponencial & 627.941 & 982.128 & 1250.060 & 1872.178 & 2140.110 & 2408.042 & 3030.160 \\
\hline Pearson-III & 682.906 & 1.011 .811 & 1.223 .395 & 1665.060 & 1843.166 & 2016.593 & 2406.210 \\
\hline Log-Pearson-III & 684.645 & 1010.878 & 1225.789 & 1689.153 & 1881.607 & 2071.956 & 2509.553 \\
\hline GEV & 684.418 & 1000.434 & 1212.981 & 1690.254 & 1896.017 & 2103.431 & 2593.246 \\
\hline GPA & 674.334 & 1051.827 & 1260.369 & 1574.320 & 1659.706 & 1724.967 & 1823.213 \\
\hline
\end{tabular}




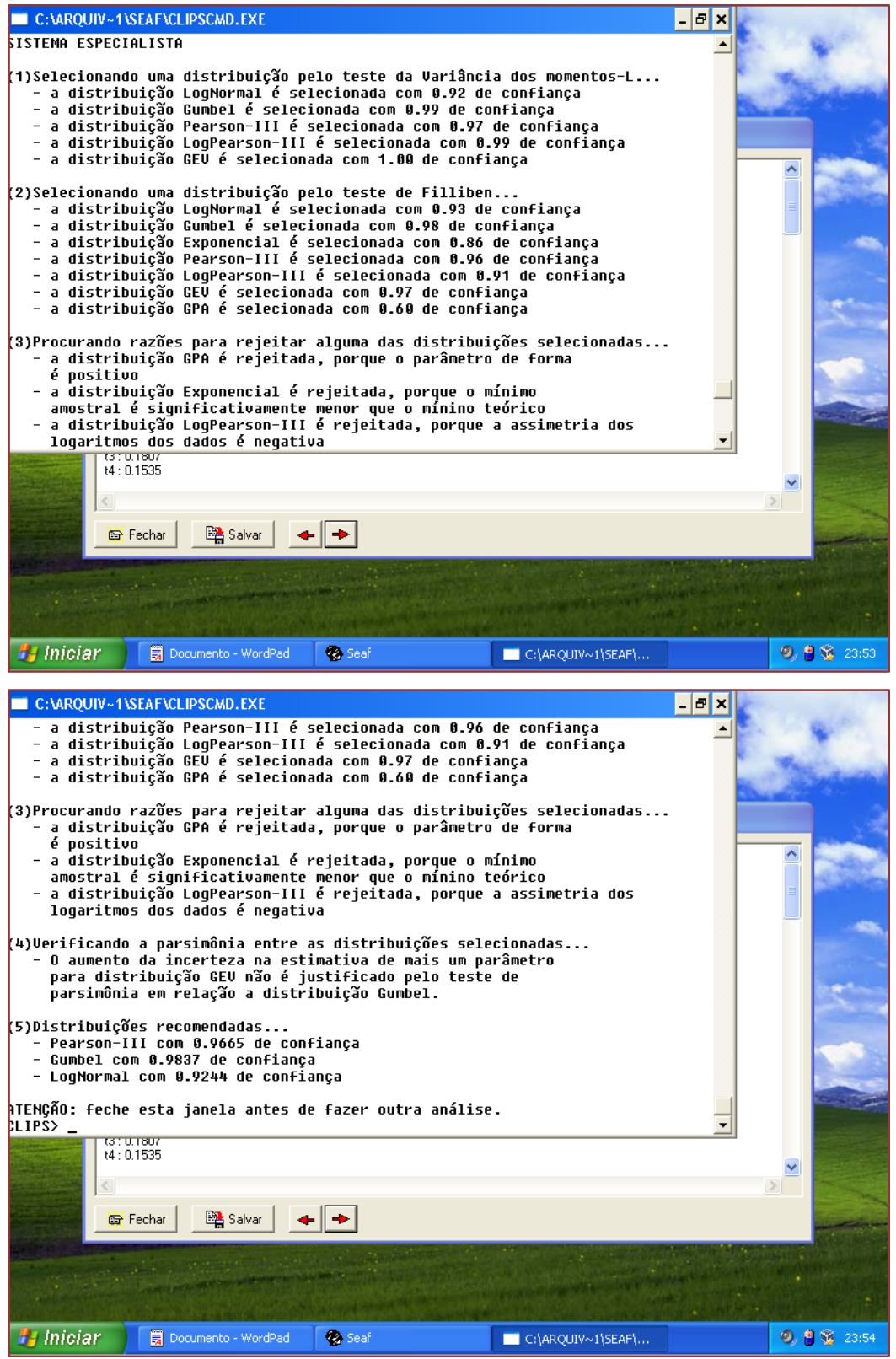

Pelo relatório final apresentado, ver item 5, as três melhores distribuições são: Pearson III, Gumbel e LogNormal, todavia a distribuição Gumbel apresentou coeficiente de ajuste mais próximo a 1, sendo a escolhida para fazer previsões futura.

Como pode-se observar a conclusão foi praticamente a mesma, entretanto o resultado é obtido de forma rápida e prática.

\section{BIBLIOGRAFIA}

[1] BARBOSA, A. R. J. Elementos de Hidrologia Aplicada. Apostila de curso. Escola de Minas, Universidade Federal de Ouro Preto. Ouro Preto, 2007.

[2] BAYLISS, A. C.; REED, D. W. The use of historical data in flood frequency estimation. Report to Ministry of Agriculture, Fisheries and Food. Centre for Ecology and Hydrology (www.ceh.ac.uk). United Kingdom. Mar., 2001.

[3] CÂNDIDO, M. O. SEAF - um protótipo de um sistema especialista para análise de frequência local de eventos hidrológicos máximos anuais. 2003. 174 f. Dissertação (Mestrado em Saneamento, Meio Ambiente e Recursos Hídricos) - Universidade Federal de Minas Gerais, Belo Horizonte, 2003.

[4] NAGHETTINI, M. C.; PINTO, E. J. A. Hidrologia Estatística. Belo Horizonte: CPRM, 552 p., 2007. 


\section{Capítulo 5}

Aula prática: Detecção de mudanças a partir de série temporal de imagens orbitais utilizando os métodos diferença de NDVI e RCEN modificada

Carlos Rodrigo Tanajura Caldeira Mayara Cobacho Ortega Caldeira Lucas Daniel Noronha Ferreira 


\subsection{OBJETIVOS INSTRUCIONAIS}

Ao final desta aula prática de Processamento Digital de Imagens você estará instruído para:

1) Enunciar dois possíveis métodos aplicáveis à detecção de mudanças a partir de série temporal de imagens orbitais;

2) Conceituar detecção de mudanças, NDVI (Índice de Vegetação por Diferença Normalizada) e RCEN (Radiometric Rotation Controlled by Nonchange axis) modificada e;

3) Comparar os resultados obtidos pelos diferentes métodos de detecção de mudanças.

\section{2.DETECÇÃO DE MUDANÇAS NO CONTEXTO DE SENSORIAMENTO REMOTO}

Realizar detecções de mudanças de características da superfície da Terra é importante para a compreensão tanto da dinâmica dos fenômenos quanto para a previsão dos impactos, bem como para o apoio na tomada de decisões.

Durante as últimas décadas foram desenvolvidas várias técnicas de detecção de mudanças a partir de imagens, dentre elas as baseadas em imagens de Sensoriamento Remoto. Em geral, a detecção de mudança envolve a utilização de um conjunto de dados multitemporais que permite a análise qualitativa e quantitativa do fenômeno em estudo (CALDEIRA, 2016).

Na prática, não é fácil selecionar um algoritmo adequado para um projeto de deteç̧ão de mudança, e por esta razão o conhecimento das técnicas de deteç̧ão de mudanças utilizados em pesquisas e aplicações anteriores é útil para entender como essas técnicas podem ser melhores exploradas e utilizadas na resolução de outros problemas. É relevante destacar que é necessário que estas mudanças sejam separáveis de outros fatores, como diferenças provocadas por condições atmosféricas, iluminação da cena, ângulos de visada do sensor, umidade do solo dentre outros. Visando isto, esta aula apresenta resultados da avaliação preliminar de duas abordagens de detecção de alterações. A primeira delas é feita a partir de uma modificação na técnica RCEN e a segunda baseada na diferença temporal entre imagens utilizando um índice de vegetação expressas pelo NDVI. Os dois métodos serão implementados e aplicados a um conjunto de imagens ortorretificadas, as quais foram tomadas em duas épocas distintas, ou seja, utilizando de série temporal.

\subsection{TÉCNICAS DE DETECÇÃO DE MUDANÇAS}

Como foi apresentado em sala de aula, há diversos métodos de detecção de mudanças, cada um com condições de aplicação específico. Vários autores resumiram algumas das técnicas mais utilizadas, com suas limitações e aplicações (SINGH, 1989; MOUAT et al., 1993; DEER, 1995; COPPIN e BAUER, 1996; JENSEN et al., 1997; SERPICO e BRUZZONE, 1999; LU et al., 2004, COPPIN et al., 2004; RADKE et al., 2005; THONFELD et al., 2005; WARNER et al., 2008; HUSSAIN et al., 2013; TEWKESBURY et al., 2015; MISHRA et al., 2017, ASOKAN e ANITHA, 2019).

O objetivo da detecção de alterações é comparar a representação espacial de dois pontos no tempo, controlando todas as variações causadas por diferenças nas variáveis que não são de interesse, a fim de monitorar as mudanças causadas por diferenças nas variáveis de interesse (GREEN; KEMPKA e LACKEY, 1994).

A premissa básica da utilização de dados de Sensoriamento Remoto na detecção de alterações é que as mudanças nos objetos de interesse resultam em variações nos valores de reflectância ou na textura local, mas essas análises podem ser separadas de mudanças causadas por outros fatores como diferenças nas condições atmosféricas, iluminação, ângulo de visada e umidade do solo (DEER, 1995).

Em sala de aula foi visto que alguns processamentos prévios são necessários para que a detecção de mudanças seja realizada de forma correta, são eles: Correção Geométrica, Radiométrica e Atmosférica.

Como o foco da nossa aula prática é a aplicação e comparação entre duas técnicas, já aplicado às correções necessárias previamente as imagens, serão considerados as técnicas descritas a seguir. 


\subsubsection{MÉTODO DE DETECÇÃO DE MUDANÇAS BASEADO NA DIFERENÇA TEMPORAL DE NDVI}

Para viabilizar a detecção de mudanças, segundo essa abordagem, é necessário realizar uma prévia normalização radiométrica nas bandas espectrais e imagens multitemporais envolvidas no processo, além da correção geométrica entre as bandas.

O Índice de Vegetação por Diferença Normalizada (NDVI) conforme (LEE et al., 2020), pode ser obtido a partir da normalização do índice de razão simples a partir da Equação (1). Ressalta-se, ainda, que o resultado dessa aplicação do NDVI será representado entre um intervalo de -1 a 1, ou seja, as análises que serão relacionadas aos parâmetros do NDVI deverão estar enquadradas neste intervalo. Os fatores que corresponderão a esses dois índices numéricos de representação estarão diretamente ligados ao quantitativo de vegetação presente na cena, uma vez que, segundo aborda LIU (2007), quanto mais densa estiver essa vegetação o valor se amostrará mais próximo de 1. Quanto ao contrário, ou seja, índices mais próximos de 0 , ter-se-ia esse valor quando não se apresenta uma presença expressiva de vegetação sendo, assim, representados por solo exposto, construções, áreas descampadas dentre outros. Tratando-se de valores negativos, ou seja, mais próximos de -1 estaria sendo representando corpos d'água e sombra.

$$
N D V I=\frac{\rho_{\text {nir }}-\rho_{\text {red }}}{\rho_{\text {nir }}+\rho_{\text {red }}}
$$

onde, $\rho_{\text {nir }}$ é o fluxo radiante refletido no infravermelho próximo e $\rho_{\text {red }}$ é o fluxo radiante refletido no vermelho da região do visível.

Com base nos valores de NDVI calculados para cada sensor é calculado o valor que deve indicar possíveis alterações, como visto na Equação (2).

$$
N D V I_{\text {detecção }}=N D V I_{D 2}-N D V I_{D 1}
$$

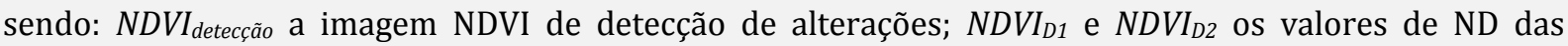
imagens NDVI de cada uma das datas.

\subsubsection{TÉCNICA RCEN (RADIOMETRIC ROTATION CONTROLLED BY NONCHANGED AXIS) MODIFICADA}

Essa categoria tem como referência a técnica de detecção de mudanças RCEN, a qual faz uma transformação representando uma similaridade entre a resposta espectral dos pixels de não mudança nas épocas em que se adotaram as coletas. A técnica de origem foi proposta por (MALDONADO; SANTOS; GRAÇA, 2007), e desse modo, aplicando-se no método original, as seguintes premissas são verdadeiras:

- A maior parte dos pixels entre dois rasters, presente em uma mesma região na banda espectral, em um curto período de tempo, não é alterado, principalmente se tratando de regiões monitoradas;

- $\quad 0$ eixo que representa a não mudança gera um ângulo $\theta$ indicando uma posição relativa que não sofre alteração;

- $\quad 0$ eixo que representa a não mudança pode ser obtido por uma regressão linear de valores radiométricos, os quais são coletados em locais onde não sofreram mudanças;

- As bandas espectrais corretas devem ser selecionadas conforme o alvo de interesse;

- A compatibilidade radiométrica entre as bandas envolvidas é garantida;

- A técnica é robusta até quando se compara dados de sensores diferentes.

Em concordância com os pressupostos destacados por (MALDONADO; SANTOS; GRAÇA, 2007), o resultado do processo de aplicação da técnica será o eixo de não mudança, sendo este obtido por meio de informações nas áreas onde não sofreram alterações. Desse modo, sendo assumido que o nível de 
alterações não é o predominante, ao se realizar a comparação das imagens dessas duas épocas, é possível conceituar que o eixo de não mudança pode ser de forma estimada a partir do raster de forma geral, ou seja, sem que seja realizada uma pré-seleção das áreas sem modificações.

Dessa forma, descreve-se o método de detecção denominado como RCEN modificado. 0 ângulo de rotação $\theta$ (calculado pelo eixo que representa a não mudança) pode ser obtido se aplicando uma regressão linear nos valores de ND (Nível Digital) das bandas espectrais correspondentes, sendo que variações mínimas na largura da banda ou na sua sensibilidade podem ser assimiladas pela transformação aplicada. Deste modo, tendo-se como sabe duas imagens em diferentes épocas, tem-se a Figura (1), a qual traz representações de os elementos essenciais para o desenvolvimento da equação que foi calculada.

Figura 1. Representação gráfica do eixo de não mudança e do valor de $\mathrm{I}_{\mathrm{INT}}$ (imagem intermediária)

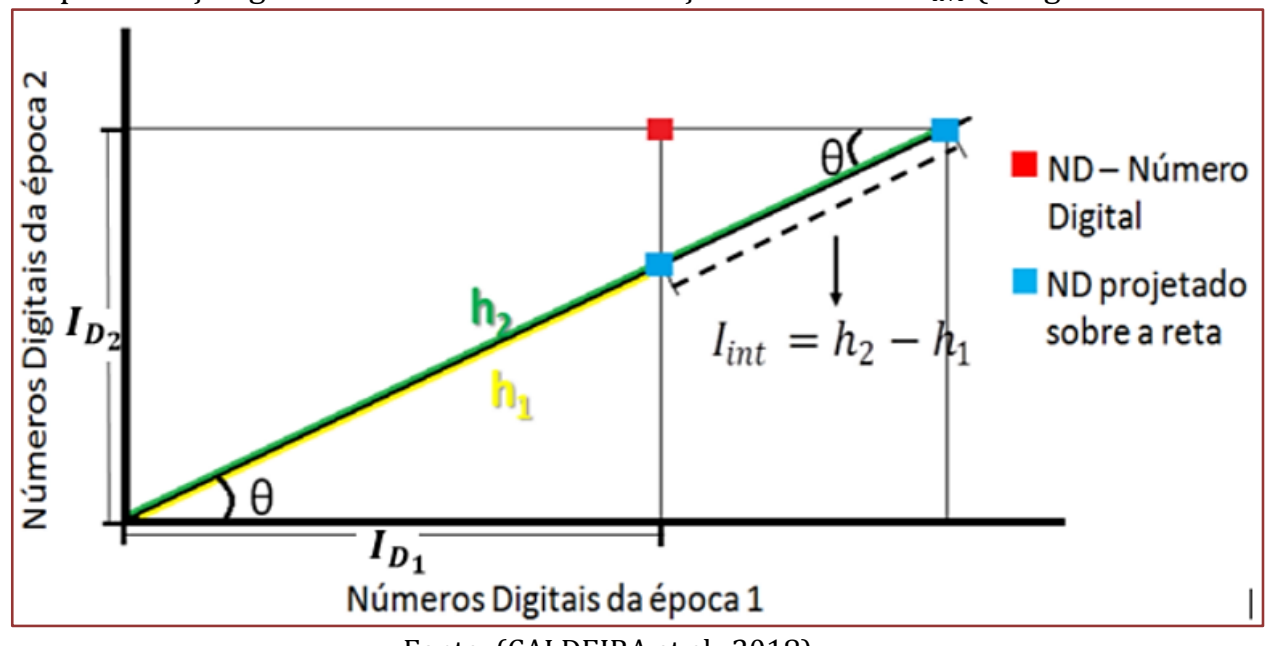

Fonte: (CALDEIRA et al., 2018)

Ao se considerar um pixel com valores determinados por $I_{D_{1}}$ e $I_{D_{2}}$, nos dois períodos - respectivamente, se este pixel estiver situado sobre a reta representada pelo coeficiente angular $\tan (\theta)$, isso nos direciona a interpretar que esse pixel não sofreu alterações. Se esse pixel estiver disposto como representado na Figura (1) (ponto em vermelho), a distância entre as projeções (representado em azul na figura) será um indicador de que este pixel sofreu modificações entre as épocas escolhidas.

Ou seja, o valor de $\mathrm{I}_{\mathrm{INT}}$, presente na Equação (3), será estimado por uma diferença entre as distâncias $\mathrm{h}_{2}$ $\mathrm{h}_{1}$. Dessa forma, ao se aplicar as funções trigonométricas adequadas para cada um dos triângulos, é viável se determinar os valores de $h_{1}$ e $h_{2}$ em função dos valores de $I_{D 1}, I_{D 2}, \theta$, bem como de $b$ (coeficiente linear da reta de não mudança). Ou seja:

$$
I_{I N T}=(\cos \theta)^{-1} * I_{D 1}-(\sin \theta)^{-1} *\left(I_{D 2}-b\right)
$$

A utilização do coeficiente linear (b), presente na Equação (3), pode ser justificada pela razão de que, na Figura (1), a reta passa pela origem, ou seja, apresentando um caso ideal. Se a reta não passar pela origem, será necessário realizar uma translação desta reta para a origem utilizando o coeficiente linear. Essa operação resulta em uma imagem intermediária ( $\left.\mathrm{I}_{\mathrm{INT}}\right)$ a qual se relaciona com as modificações ocorridas. Logo, quanto maior for a mudança, maior será o valor resultante.

Desse modo, pode-se notar, na Figura (1) conforme apresentada, que os pixels analisados podem ficar acima ou abaixo desta reta formada pelo coeficiente angular $\tan (\theta)$, resultando em valores os quais podem ser positivos e negativos para $\mathrm{I}_{\mathrm{INT}}$. 
Baseando-se em valores intermediários que foram calculados para cada banda espectral utilizadas nas duas épocas, em base da Equação (3), calcula-se o valor indicando possíveis alterações. Na Equação (4), pode-se obter o resultado com o índice de alteração $\mathrm{I}_{\text {detec }}$ calculado a partir de das bandas multiespectrais:

$$
I_{\text {detec }}=\sum_{n}^{i=1} I_{I N T, B i}
$$

sendo $\mathrm{I}_{\mathrm{INT}, \mathrm{Bi}}$, os valores intermediários para as bandas; i os índices das bandas e n o número de bandas.

Os valores obtidos pela Equação (3), para uma única banda, resultarão em um número pertencente ao conjunto dos reais. Consonante a isso, o resultado desses modelos matemáticos pode ser de variação positiva à negativa, o qual poderá indicar o aparecimento de "novos" alvos bem como o "desaparecimento" de alguns objetos na cobertura da terra. Para realçar as mudanças mais expressivas, pode ser adotado de um percentual, ou seja, de um limiar, o qual permitirá esse realce às mudanças de interesse.

\subsection{PRÁTICA}

Nossa aula prática será realizada em Laboratório, em virtude de sua estrutura a qual possui computadores e softwares específicos para a atividade.

\subsubsection{MATERIAIS}

Em síntese, os materiais que serão utilizados para esta aula prática serão:

- Imagens ortorretificadas orbitais do mesmo local, porém em diferentes épocas; e

- Um computador desktop.

\subsubsection{ANTES DA MEDIÇÃO}

Primeiramente, em aulas passadas, os pares de cenas do mesmo sensor, referentes às bandas correspondentes nas duas datas, foram co-registradas geometricamente utilizando o software ENVI $5.0 \mathrm{e}$ realizado a correção atmosférica antes de serem submetidas ao processamento de análise de alterações. Lembrando que a detecção de mudanças, utilizando as técnicas descritas, faz a comparação pixel a pixel, logo o tamanho do pixel terá que ser o mesmo para as duas imagens. Caso as imagens utilizadas forem de sensores diferentes, além do registro geométrico entre as imagens, também deverá haver uma reamostragem na imagem de maior resolução espacial de modo a compatibilizá-las. Um exemplo são os sensores SPOT-6, com GSD (Ground Sample Distance) igual a 6 metros e o WorldView-2 (GSD de 2 metros). A Figura (2) mostra um fluxograma do método proposto para se promover uma melhor compreensão dos procedimentos. 
Figura 2. Fluxograma do método proposto

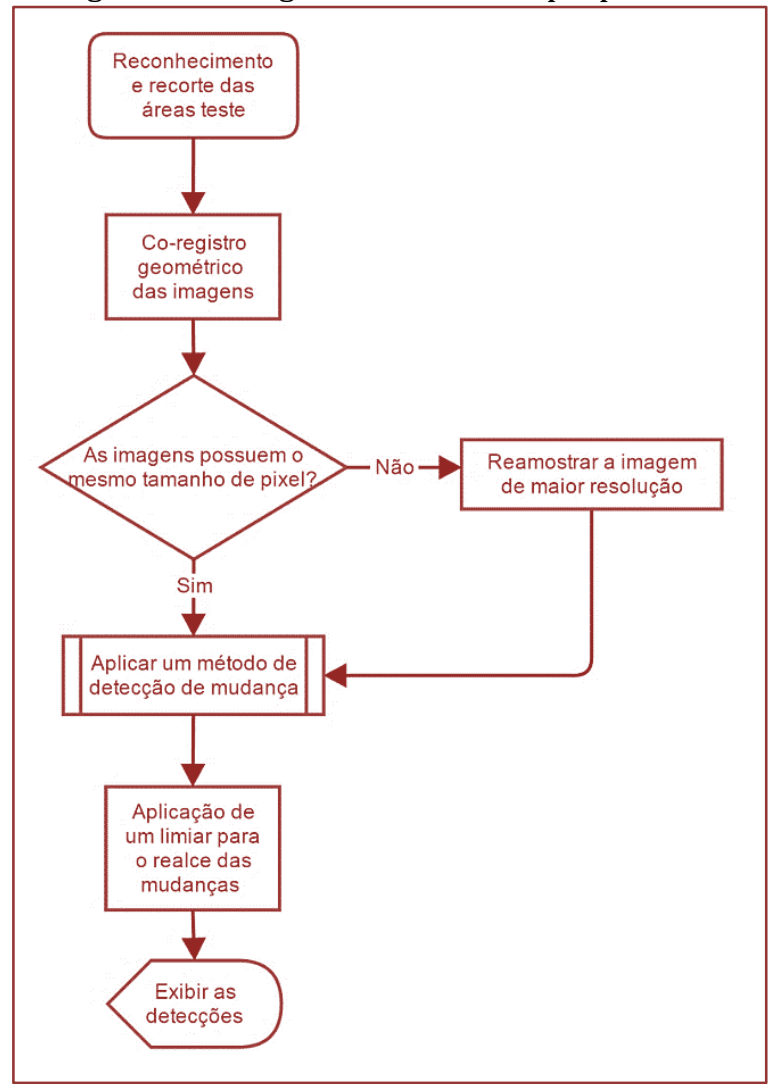

Fonte: Autores (2020)

Os segmentos de imagem devem possuir o mesmo tamanho, com a mesma área geográfica e mesmo tamanho do pixel, porém em diferentes datas para cada sistema imageador.

As Figuras (3) e (4) apresentam exemplos de recortes de imagens que representam áreas testes, na forma de composições coloridas RGB. As imagens indicadas pelas letras (a) e (b) em cada figura, diferenciam as cenas dos sensores WorldView-2 e Spot-6, respectivamente, nas quais se percebe com clareza o melhor detalhamento geométrico da imagem WorldView-2, definido pelo menor GSD desse sensor.

Figura 3. Área teste extraída de composição colorida normal (RGB) das imagens: (a) WordView-2 de 29/07/2010; (b) Spot-6 de 22/04/2013.

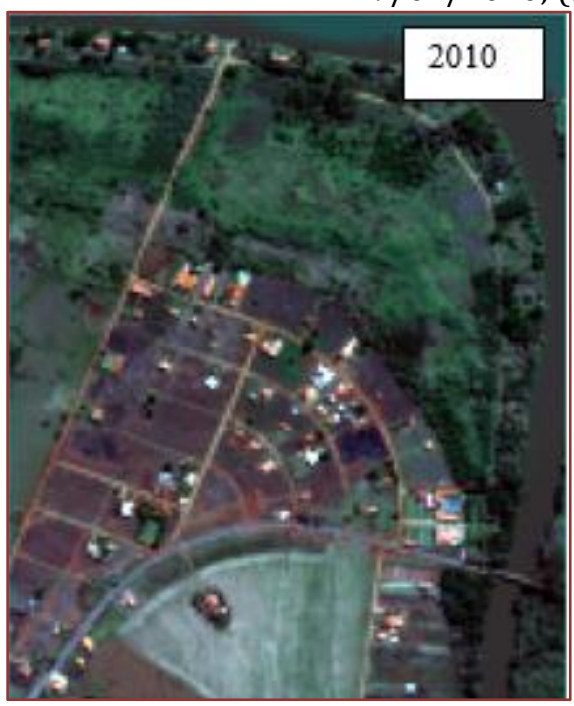

(a)

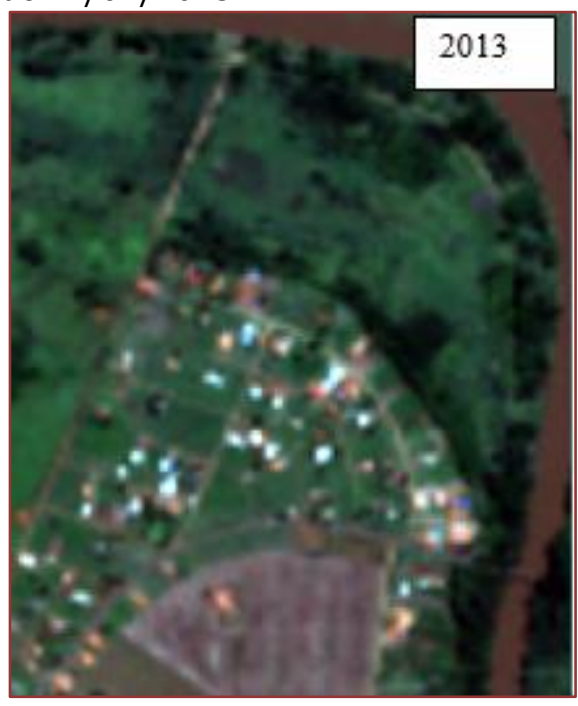

(b) 
Figura 4. Área teste extraída de composição colorida normal (RGB) das imagens: (a) WordView-2 de 02/09/2011; (b) Spot-6 de 22/10/2012.

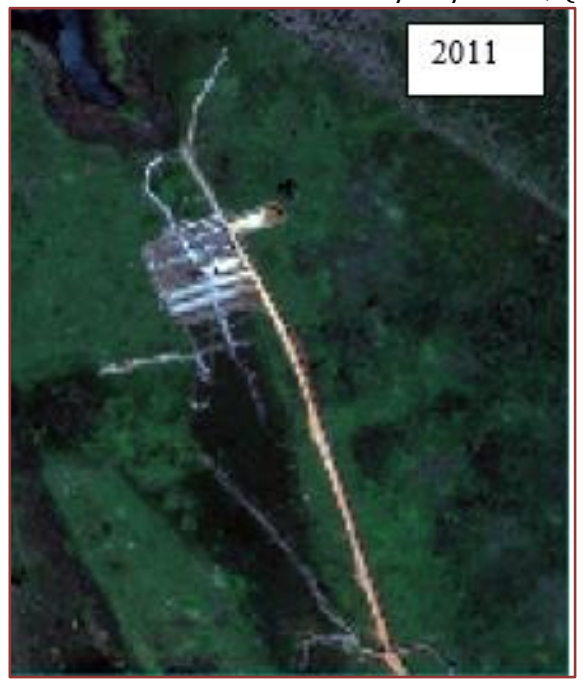

(a)

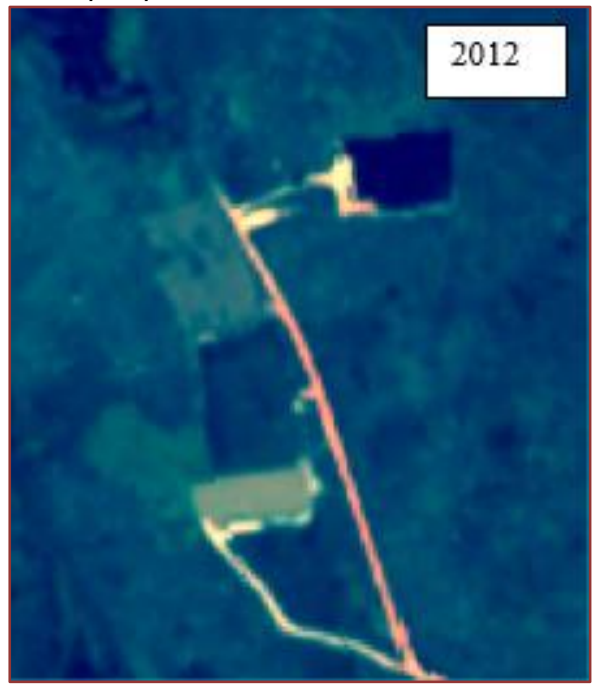

(b)

Nota-se que nas Figuras (3) e (4) há a presença de alterações entre as duas datas, como: trapiches, casas e áreas de exploração irregular do solo, as quais devem ser detectadas pelo algoritmo de detecção de alterações.

Para a visualização das mudanças mais significativas, tanto as que correspondem a novos objetos/feições quanto a objetos/feições que deixaram de existir, serão aplicados limiares para realçar as alterações detectadas. Estes limiares são valores aleatórios resultantes das imagens de detecção quando o usuário sabe onde há uma alteração. Nestas situações, ele pode usar este valor do pixel como base. Inicialmente define-se um valor percentual Lperc que corresponde às maiores modificações. Assumindo-se que as imagens que permitem detectar alterações, seja pela Equação (2) ou Equação (4), estejam normalizadas no intervalo [0-255], a partir do valor Lperc pode-se determinar os seguintes limiares superiores e inferiores (expressos em valores de ND), com a Equação (5):

$$
\begin{gathered}
L_{S U P}=255 *\left(\frac{100-L_{p e r c}}{100}\right) \\
L_{I N F}=255-L_{S U P}
\end{gathered}
$$

sendo: $L_{S U P}$ e $L_{I N F}$ Os limiares superior e inferior. Para efeito de visualização, aos valores de ND maiores que $L_{S U P}$ serão realçados na cor azul e os valores de ND menores que $L_{I N F}$ foram associados à cor vermelha.

Para o cálculo das imagens e aplicação das equações, pode-se utilizar qualquer linguagem de programação, como Pyhton, Matlab, C, C++, Java, entre outras. A metodologia é simples, o usuário terá que fazer com que o programa leia as imagens já corrigidas previamente e após isso executar, pixel a pixel, as equações mostradas anteriormente.

A Figura (5) exemplifica um código em Matlab para a aplicação da Equação (1), onde as variáveis i e j representam as posições dos pixels em linha e coluna, respectivamente e l e c, o total de linhas e colunas das imagens, respectivamente. 
Figura 5. Exemplo de parte de um código em Matlab, para o cálculo do NDVI.

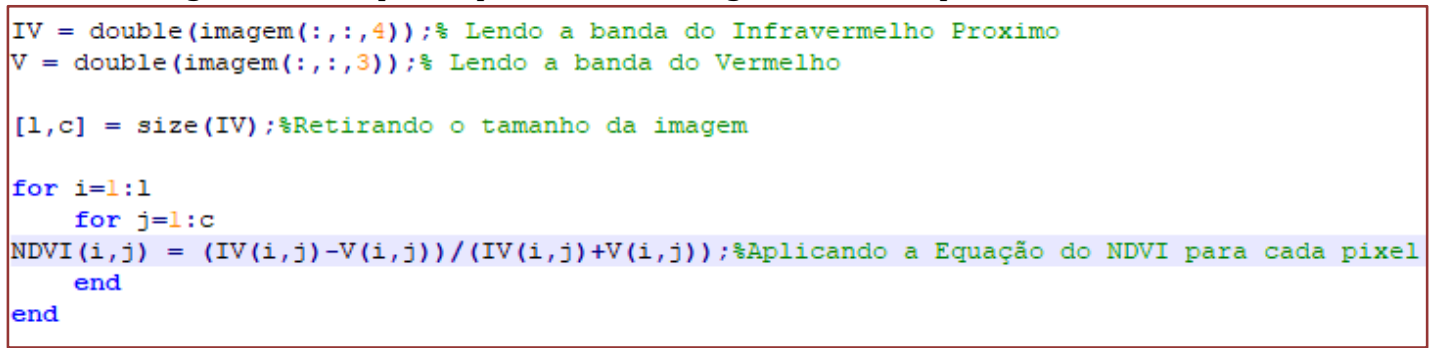

Fonte: Autores (2020)

As Figuras (6) e (7) apresentam as imagens NDVI (Equação 1) geradas para cada área teste e para ambos os sensores utilizando o código da Figura (5).

Figura 6. Imagens NDVI da área teste resultantes da aplicação da Equação (1) às imagens multissensor: (a) Wordview-2, (b) Spot-6.

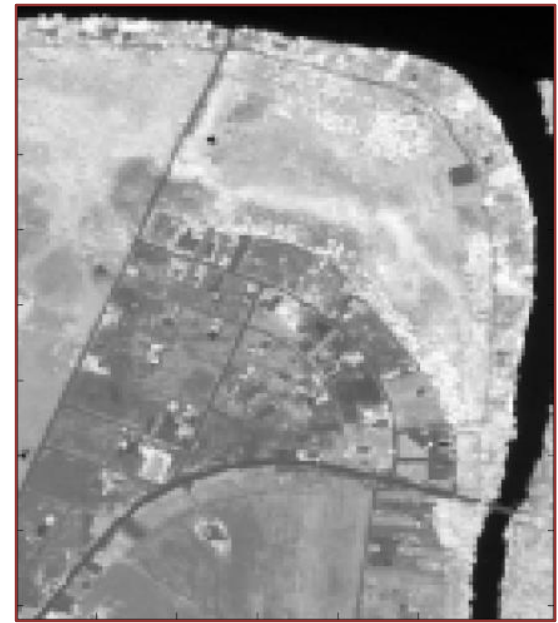

(a)

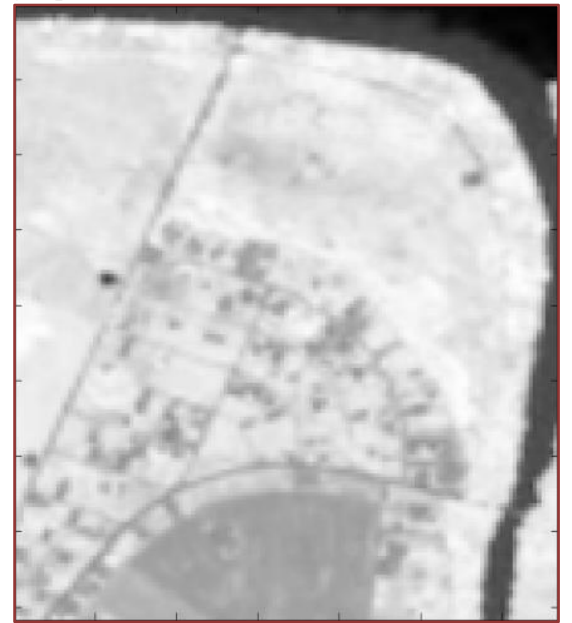

(b)

Fonte: Autores (2020)

Figura 7. Imagens NDVI da área teste resultantes da aplicação da Equação (1) às imagens multissensor: (a) Wordview-2, (b) Spot-6.

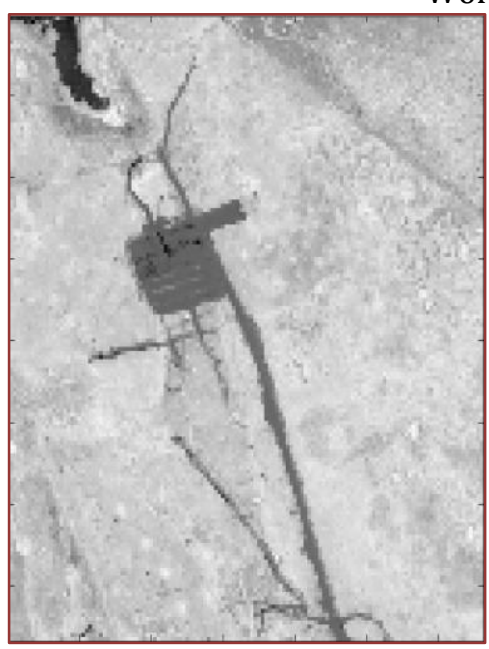

(a)

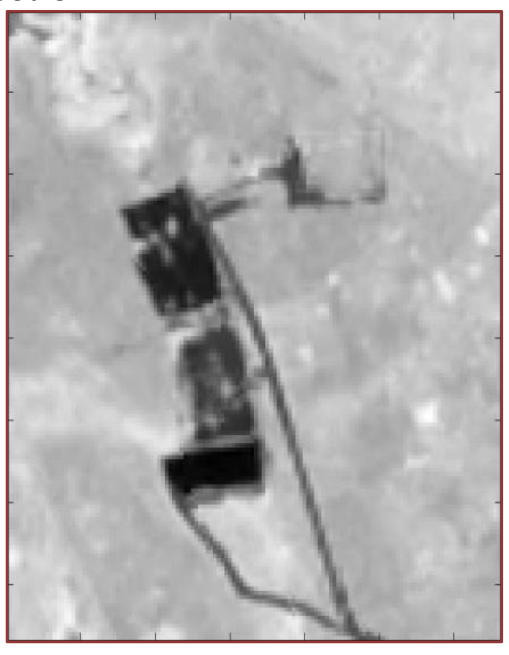

(b)

Fonte: Autores (2020). 


\subsubsection{COMPARAÇÃO DOS RESULTADOS A PARTIR DA APLICAÇÃO DE LIMIARES}

Para ter uma melhor interpretação dos dados e consequentemente uma melhor avaliação do algoritmo, o usuário deverá utilizar de um limiar para destacar as alterações que foram construídas de um ano para outro, ou seja, alterações com grandes diferenças positivas nos ND’s e alterações que foram removidas de um ano para o outro, ou seja, alterações com grandes diferenças negativas nos ND’s.

As Figuras (8) e (9) apresentam as detecções realçadas em ambos os métodos para as áreas testes, os quais foram sequenciados a partir de uma imagem representando a detecção principal a ser encontrada pelos métodos citados. Estes limiares não são válidos para representar a validação dos métodos. 0 procedimento de validação será realizado em uma próxima etapa, assim sendo, estes limiares serão apresentados somente para uma melhor visualização dos resultados, como dito anteriormente.

Figura 8. Imagem da área teste com detecções realçadas, sendo em vermelho as alterações que foram removidas ao longo do tempo e em azul as alterações construídas ao longo do tempo, onde em (a) imagem final do método RCEN modificado, com destaque dos alvos a serem detectados, em (b) imagem final do método de diferenciação de imagens NDVI, com destaque dos alvos a serem detectados e em (c.1 e c.2) imagens exemplo, para os alvos a serem detectados.

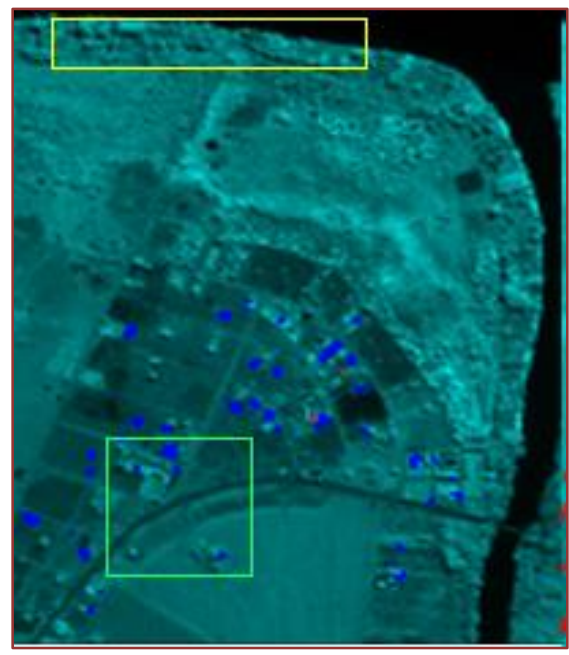

(a)

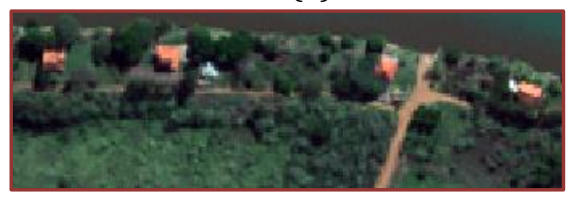

(c.1)

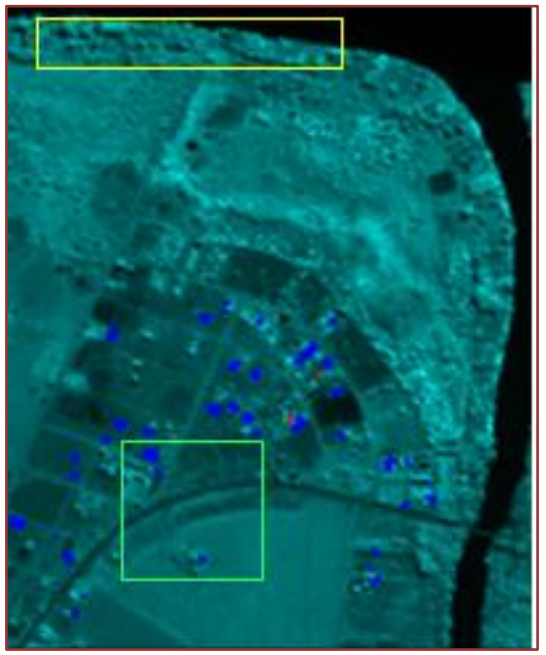

(b)

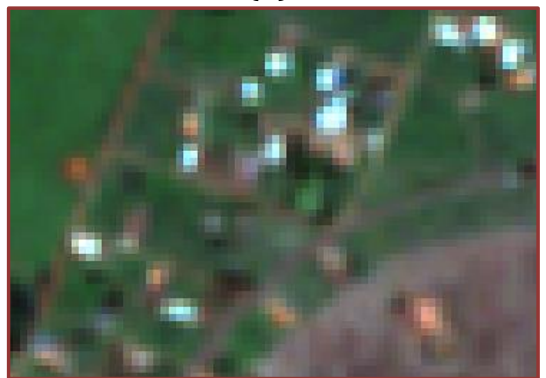

(c.2)

Fonte: Autores (2020)

A Figura (8) mostra uma área onde se destacam dois grupos de alterações. As alterações de áreas com construções e áreas com remoções, utilizando-se de um limiar de 30\%, ou seja, os 30\% maiores valores de ND foram destacados. Nesta área destacam-se as construções representadas na Figura (8.c.1) que foram removidas entre os anos de 2011 e 2014 e na Figura (8.c.2) que foram construídas. Respeitando a lógica anterior, as alterações teriam que aparecer em tons de vermelho e azul, respectivamente. Percebe-se que utilizando o método NDVI os alvos construídos não foram destacados pontualmente e nem corretamente, porém este método destacou alguns alvos que foram removidos. 0 fato de ter crescido vegetação no lugar dos alvos removidos, ajudou para detectar estes alvos. Comparando com o método RCEN modificado percebe-se que este destacou os alvos construídos corretamente, ou seja, da cor azul e bem definido na imagem, representando então que este alvo não estava presente em 2011 e agora está em 2014. 
Figura 9. Imagem da área teste com detecções realçadas, sendo em vermelho as alterações que foram removidas ao longo do tempo e em azul as alterações construídas ao longo do tempo, onde em (a) imagem final do método RCEN modificado, com destaque dos alvos a serem detectados, em (b) imagem final do método de diferenciação de imagens NDVI, com destaque dos alvos a serem detectados e em (c) imagem exemplo para os alvos a serem detectados.

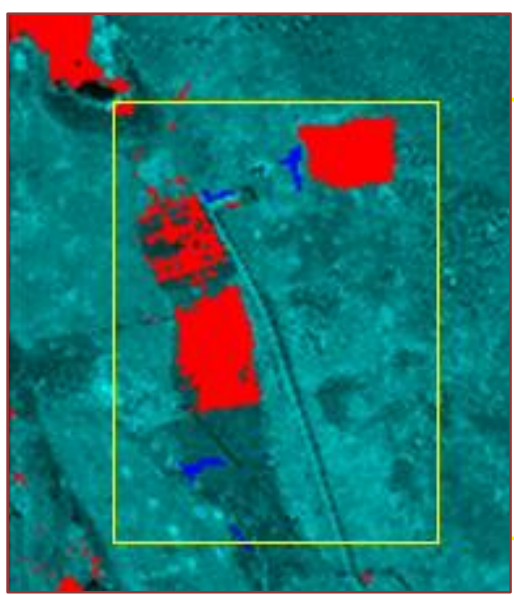

(a)

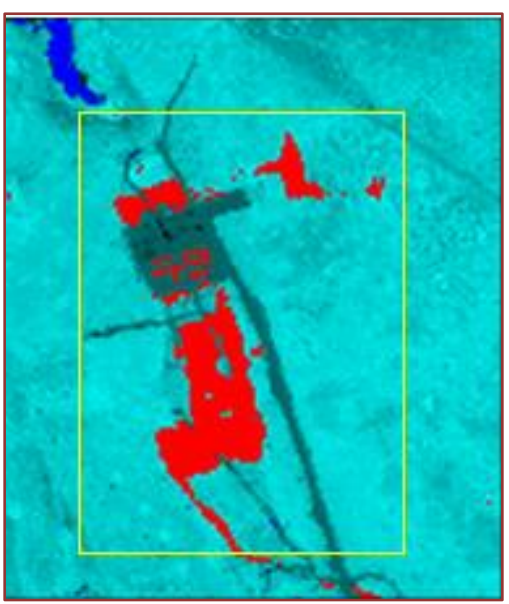

(b)

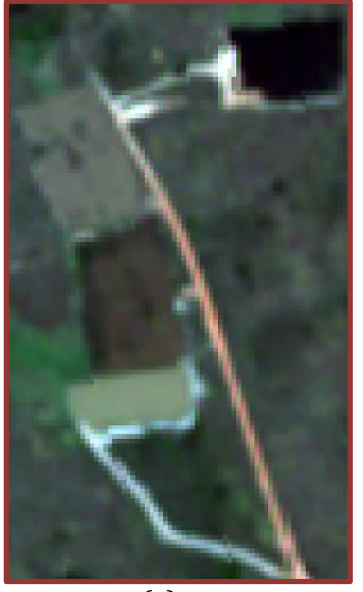

(c)

Fonte: Autores (2020)

A Figura (9) mostra uma área onde se destacam duas áreas de alterações, utilizando-se de um limiar de $30 \%$, ou seja, serão destacados os 30\% menores valores de ND, onde as alterações representam uma extração ilegal de argila. Percebe-se que ambos os métodos obtiveram bons resultados, pois detectaram boa parte da extração de argila. Porém nota-se que o método RCEN modificado ainda demonstra melhores resultados em relação ao método de NDVI.

Este método de destaque das detecções pode ser feito apenas modificando o valor original do pixel pelas cores vermelha ou azul, ou seja, basta apenas percorrer a imagem e quando o valor do pixel for maior ou igual ao limiar proposto, adota-se as cores azul ou vermelha, como visto em um exemplo de código na Figura (10).

Após a execução dos códigos, discute-se as vantagens e desvantagens de cada método, como no exemplo mostrado.

Figura 10. Exemplo de parte de um código em Matlab para destaque em vermelho e azul para os pixeis que apresentaram alteração

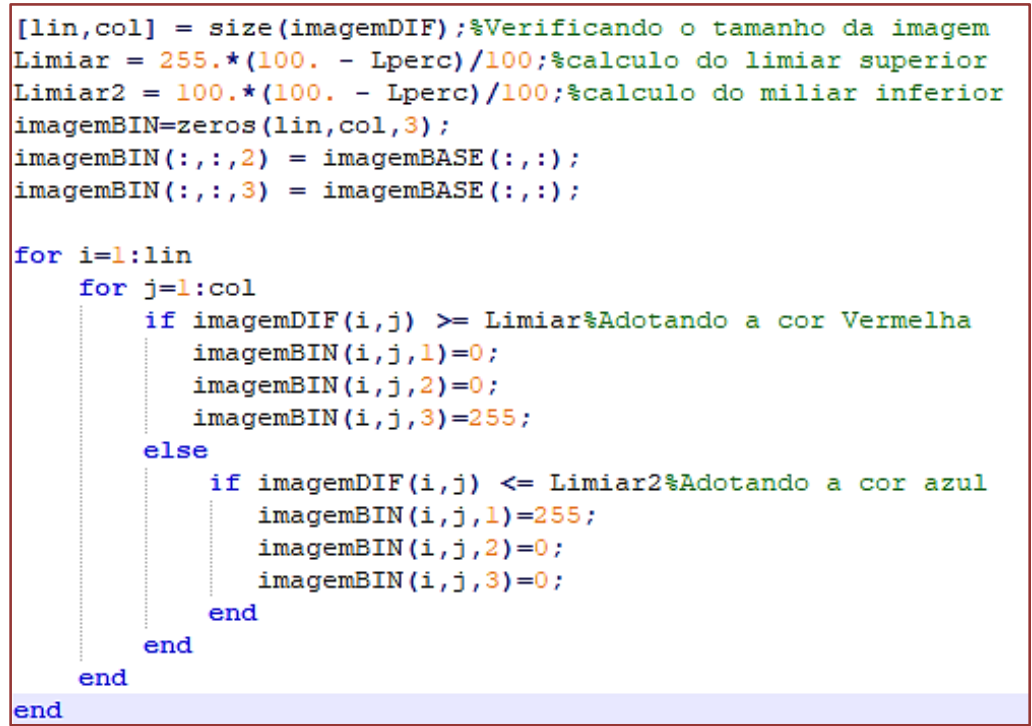

Fonte: Autores (2020). 


\section{BIBLIOGRAFIA}

[1] ASOKAN, A.; ANITHA, J. Change detection techniques for remote sensing applications: a survey. Earth Science Informatics, [S. l.], n. 12, p. 143-160, 2019. DOI: 10.1007/s12145-019-00380-5.

[2] CALDEIRA, C. R. T. Detecção de mudanças no entorno de reservatórios a partir de série temporal de imagens orbitais. 2016. Dissertação (Mestradoem Ciências Cartográficas) - - FCT/Universidade Estadual Paulista, Presidente Prudente, 2016.

[3] CALDEIRA, C. R. T.; GALO, M.; IMAI, N. N.; GALO, M. de L. T. B.; HASEGAWA, J. K.; AMORIM, A.; SHIMABUKURO, M. H.; PINTO, M. Detecção de mudanças de forma automática no entorno de reservatórios: estudo de caso - Canoas I. Revista Brasileira de Cartografia, [S. l.], v. 70, n. 4, p. 1348-1377, 2018. DOI: 10.14393/rbcv70n4-46508.

[4] COPPIN, P.; JONCKHEERE, I.; NACKAERTS, K.; MUYS, B.; LAMBIN, E. Digital change detection methods in ecosystem monitoring: A review. International Journal of Remote Sensing, [S. l.], v. 25, n. 9, p. 1565-1596, 2004. DOI: 10.1080/0143116031000101675.

[5] COPPIN, P. R.; BAUER, M. E. Digital Change Detection in Forest Ecosystems with Remote Sensing Imagery. Remote Sensing Reviews, [S. l.], v. 13, n. 3-4, p. 207-234, 1996. DOI: 10.1080/02757259609532305.

[6] DEER, P. J. Digital Change Detection Techniques: Civilian and Military Applications. In: (., Org.)INTERNATIONAL SYMPOSIUM ON SPECTRAL SENSING RESEARCH 1995, Report (Greenbelt, MD: Goddard Space Flight Center). Anais [...]. Report (Greenbelt, MD: Goddard Space Flight Center) p. 1-13.

[7] GREEN, K.; KEMPKA, D.; LACKEY, L. Using remote sensing to detect and monitor land-cover and land-use change. Photogrammetric Engineering and Remote Sensing, [S. l.], v. 60, n. 3, p. 331-337, 1994.

[8] HUSSAIN, M.; CHEN, D.; CHENG, A.; WEI, H.; STANLEY, D. Change detection from remotly sensed imagens: From pixel-based to object-based approaches. ISPRS Journal of Photogrammetry and Remote Sensing, [S. l.], v. 80, p. 91-106, 2013.

[9] JENSEN, J. R.; COWEN, D.; NARUMALANI, S.; HALLS, J. Principles of change detection using digital remote sensor data. In: (., Org.)INTEGRATION OF GEOGRAPHIC INFORMATION SYSTEMS AND REMOTE SENSING 1997, Cambridge. Anais [...]. Cambridge: Cambridge University Press, 1997. p. 37-54.

[10] LEE, K.; KIM, K.; LEE, S. G.; KIM, Y. Determination of the normalized difference vegetation index (NDVI) with top-of-canopy (TOC) reflectance from a KOMPSAT-3A image using orfeo tool box (OTB) extension. ISPRS International Journal of Geo-Information, [S. l.], v. 9, n. 4, p. 1-16, 2020. DOI: 10.3390/ijgi9040257.

[11] LIU, W. T. H. Aplicações de sensoriamento remoto. UNIDERP ed. Campo Grande: UNIDERP, 2007. v. 53 DOI: 10.1017/CB09781107415324.004.

[12] LU, D.; MAUSEL, P.; BRONDIZIO, E.; MORAN, E. F. Change Detection Techniques. International Journal of Remote Sensing, [S. l.], v. 25, n. 12, p. 2365-2407, 2004.

[13] MALDONADO, F. D.; SANTOS, J. R.; GRAÇA, P. M. L. Change detection technique based on the radiometric rotation controlled by no-change axis, applied on a semi-arid landscape. International Journal of Remote Sensing, [S. l.], v. 28, n. 8, p. 1789-1804, 2007. DOI: 10.1080/01431160600905821.

[14] MISHRA, S.; SHRIVASTAVA, P.; DHURVEY, P. Change Detection Techniques in Remote Sensing: A Review. International Journal of Wireless and Mobile Communication for Industrial Systems, [S. l.], v. 4, n. 1, p. 1-8, 2017. DOI: 10.21742/ijwmcis.2017.4.1.01.

[15] MOUAT, D. A.; MAHIN, G. G.; LANCASTER, J. Remote sensing techniques in the analysis of change detection. Geocarto International, [S. l.], v. 8, n. 2, p. 39-50, 1993. DOI: 10.1080/10106049309354407.

[16] RADKE, R. J.; ANDRA, S.; AL-KOFAHI, O.; ROYSAM, B. Image change detection algorithms: A systematic survey. IEEE Transactions on Image Processing, [S. l.], v. 14, n. 3, p. 294-307, 2005. DOI: 10.1109/TIP.2004.838698.

[17] SERPICO, S. B.; BRUZZONE, L. Change detection. In: (., Org.)INFORMATION PROCESSING FOR REMOTE SENSING 1999, Singapore: World Scientific Publishing. Anais [...]. Singapore: World Scientific Publishing p. 319-336.

[18] SINGH, A. Digital change detection techniques using remotely-sensed data. International Journal of Remote Sensing, [S. l.], v. 10, n. 6, p. 989-1003, 1989.

[19] TEWKESBURY, A. P.; COMBER, A. J.; TATE, N. J.; LAMB, A.; FISHER, P. F. A critical synthesis of remotely sensed optical image change detection techniques. Remote Sensing of Environment, [S. l.], v. 160, p. 1-14, 2015. DOI: 10.1016/j.rse.2015.01.006.

[20] THONFELD, F.; HECHELTJEN, A.; BRAUN, M.; MENZ, G. From algorithms to processing chains: A review of land cover and land use change detection methodologies. Technology, [S. l.], n. 1, p. 99775-99775, 2005.

[21] WARNER, T. A.; ALMUTAIRI, A.; LEE, J. Y. Remote Sensing of Land Cover Change. In: (., Org.)THE SAGE HANDBOOK OF REMOTE SENSING 2008, Anais [...]. [s.l: s.n.] p. 459-474. DOI: 10.4135/9780857021052.n33. 


\section{Capítulo 6}

\section{Aula prática: Nivelamento geométrico, determinação de desníveis e altitudes}

Mayara Cobacho Ortega Caldeira

Carlos Rodrigo Tanajura Caldeira

Lucas Daniel Noronha Ferreira 


\subsection{OBJETIVOS INSTRUCIONAIS}

Ao final deste capítulo teórico e prático referente ao Nivelamento Geométrico, determinação de desníveis e de altitudes, os alunos serão capazes de:

4) Enunciar este método aplicável à observação de altitudes do terreno;

5) Identificar o uso de equipamentos necessários para a execução;

6) Conceituar Nivelamento Geométrico, desnível e altitude, e;

7) Operacionalizar as leituras em campo e cálculos a partir do emprego deste método.

\subsection{NIVELAMENTO GEOMÉTRICO}

A determinação de um ponto da superfície terrestre só está completa, no ponto de vista da Geomática, se além das coordenadas planimétricas $(\mathrm{X}, \mathrm{Y})$, estiver também associada a elas uma componente altimétrica (h ou H) (CORDINI, 2014). Conforme afirma Silva e Segantine (2015), é por meio da altimetria que se representa o relevo de um terreno para projetos de engenharia e mapeamento, como por exemplo projetos de vias de transporte, saneamento, distribuição de água e esgoto, construção de barragens, entre outros.

A determinação de desníveis entre dois pontos e o transporte de altitudes em qualquer parte da superfície terrestre representa uma das operações fundamentais sob atuação da Topografia e Geodésia, conforme afirma Ghilani e Wolf (2012). Atualmente, com o surgimento de novas tecnologias, houve um aumento na diversidade de se obter esse desnível acompanhada de um aumento na quantidade e variedade de equipamentos, os quais cada um possui sua precisão que possibilitaram o desenvolvimento e aprimoramento da técnica (NICACIO et al., 2018).

De acordo com Norma Brasileira NBR13.133, o conjunto de operações e técnicas realizadas para determinar a altitude, cotas, ou desníveis dos pontos de interesse, é denominada de Levantamento Altimétrico ou Nivelamento (ABNT, 1994).

Conforme visto em outras aulas e destacado Silva e Segantine (2015) e em outras literaturas, existem vários métodos de nivelamento disponíveis, como por exemplo: Nivelamento Trigonométrico, Nivelamento Taqueométrico, Nivelamento Geométrico, Nivelamento por Satélite GNSS e Nivelamento a Laser e Digital, e também o método antigo de nivelamento Barométrico o qual se baseava na medição de pressão atmosférica associada à altitude. No entanto, o enfoque deste capítulo é o Nivelamento Geométrico.

O Nivelamento Geométrico é definido como o método de determinação das componentes altimétricas com base nos dados obtidos através de visadas horizontais a partir da diferença de nível entre pontos do terreno (GHILANI; WOLF, 2012). Conforme apresentado Figura 1, este processo é realizado por intermédio de leituras em miras graduadas colocadas verticalmente nos referidos pontos de interesse, obtidas com equipamento topográfico denominado Nível (ABNT, 1994; VEIGA; ZANETTI; FAGGION, 2012).

Figura 1. Princípio Básico do nivelamento Geométrico.

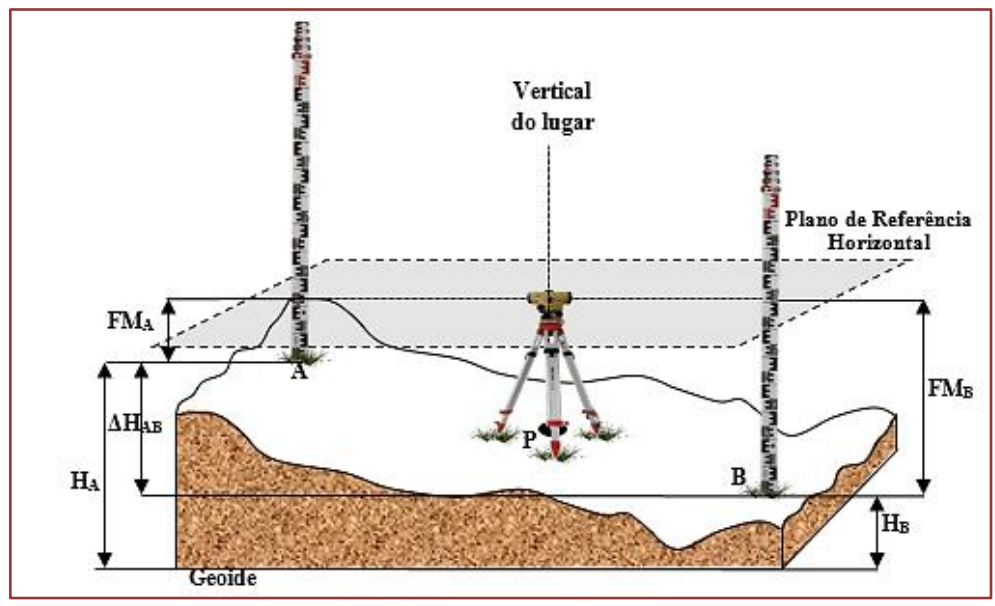

Fonte: Adaptado de Silva e Segantine (2015) 
O Nível deve ser instalado e nivelado para que seu eixo vertical coincida com a vertical do lugar, deste modo, a luneta estabelece um plano horizontal de referência (KAVANAGH; MASTIN, 2014). Vale ressaltar que diferentemente dos outros métodos de nivelamento, o desnível é determinado com base em ângulos verticais ou zenitais. Além disso, neste método as distâncias verticais (desnível) são obtidas a partir da interseção do plano horizontal com a mira vertical (SILVA; SEGANTINE, 2015).

Deste modo, o nivelamento geométrico estabelece operações de obtenções dos desníveis em pontos de interesse no terreno com suas alturas referidas a uma superfície arbitrária (cotas) ou ao nível médio do mar (altitude) (ABNT, 1994).

Diante disso, a relação que é atribuída ao uso deste equipamento durante o levantamento possibilita a determinação do desnível entre dois pontos, podendo ser aplicada em duas vertentes diferentes, sendo elas: 1) geodésicas ou 2) topográficas (VEIGA; ZANETTI; FAGGION, 2012). Porém, convém ressaltar que dentro da área de levantamentos geodésicos este método de levantamento é utilizado para fins monitoramentos de grandes estruturas, o que embasa o necessário entendimento acerca desta forma de nivelamento (SIGUEL et al., 2013).

\subsection{EQUIPAMENTOS: NÍVEL TOPOGRÁFICO E MIRA ESTADIMÉTRICA}

Conforme visto da Figura 2, o Nível é um equipamento que possui uma luneta telescópica e pode girar em torno do seu eixo vertical. Além disso, possui uma base nivelante com um ou dois níveis de bolha para ser fixado a um tripé (NADOLINETS, LEVIN; AKHMEDOV, 2017; SILVA; SEGANTINE, 2015). Neiga, Zanetti e Faggion (2012), definem o Nível como:

"Equipamentos que permite definir com precisão um plano horizontal ortogonal à vertical definida pelo eixo principal do equipamento. As principais partes de um nível são: 1) Luneta; 2) Nível de bolha; 3) Sistemas de compensação (para equipamentos automáticos); 4) Dispositivos de calagem" (VEIGA; ZANETTI; FAGGION, 2012, p. 196).

Figura 2. Representação do Nível Topográfico
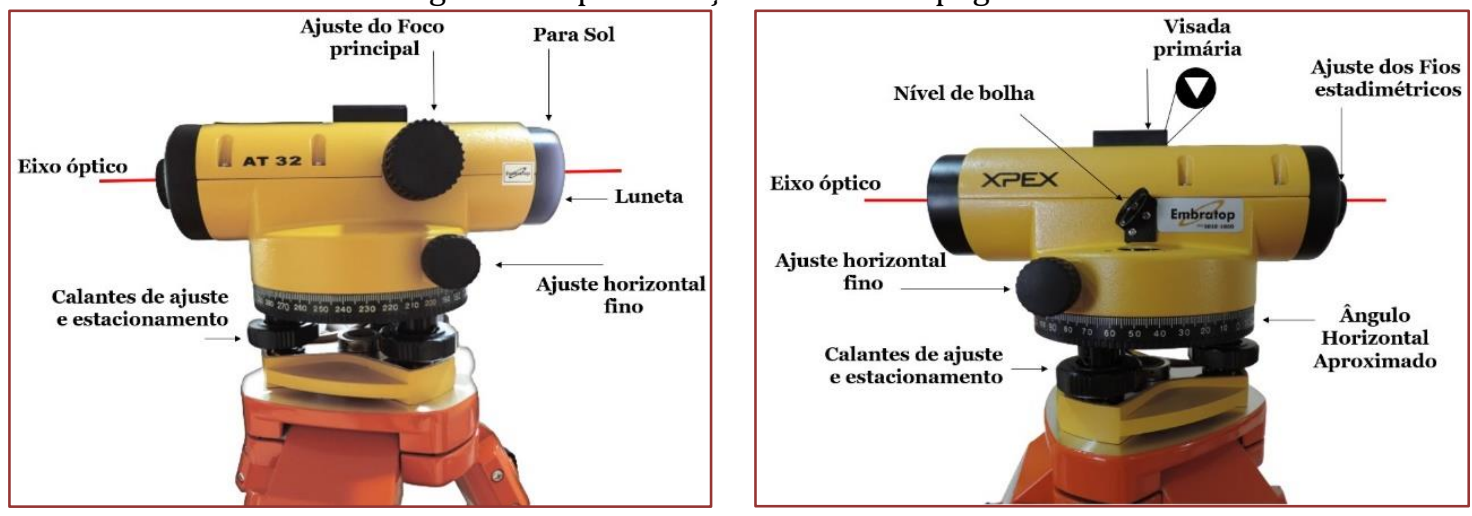

Fonte: Autores (2020)

No entanto, atualmente - além destes níveis ópticos, com o advento da tecnologia pode-se empregar equipamentos mais robustos e precisos, como Níveis Digitais e Níveis Laser (NADOLINETS; LEVIN; AKHMEDOV, 2017). Todavia, a NBR 13.133 (ABNT, 1994) classifica os níveis quanto a precisão, considerando $1 \mathrm{~km}$ de duplo nivelamento, conforme apresentado na Tabela 1.

Tabela 1. Classificação dos níveis segundo a NBR13.133

\begin{tabular}{|c|c|}
\hline Classes de Níveis & Desvio-Padrão \\
\hline 1- Precisão Baixa & $> \pm 10 \mathrm{~mm} / \mathrm{km}$ \\
\hline 2- Precisão Média & $\leq \pm 10 \mathrm{~mm} / \mathrm{km}$ \\
\hline 3- Precisão Alta & $\leq \pm 03 \mathrm{~mm} / \mathrm{km}$ \\
\hline 4- Precisão Muito Alta & $\leq \pm 01 \mathrm{~mm} / \mathrm{km}$ \\
\hline
\end{tabular}


Outro equipamento que integra o nivelamento geométrico é a Mira estadimétrica, ou também denominada de Falante ou Régua estadimétrica. Porém, existem miras para operações normais (Figura 3b) e miras de precisão mais elevada (de ínvar, empregadas na rede altimétrica do Instituto Brasileiro de Geografia e Estatística- IBGE), ou ainda, miras com códigos de barra quando se utiliza níveis Digitais (Figura 3a) (CORDINI, 2014; KAVANAGH; MASTIN, 2014).

Figura 3. Mira estadimétrica

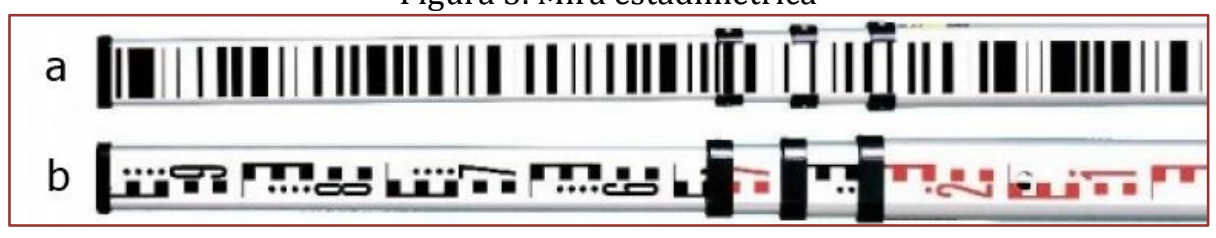

Fonte: Furtado, Schmidt (2020)

As miras têm a grande vantagem de possibilitar que sejam determinadas as leituras diretamente do aparelho com auxílio dos fios estadimétricos (Superior - FS, Médio - FM e Inferior - FI) do retículo da luneta, as alturas de visadas aos pontos topográficos (GARCIA; PIEDADE, 1984; VEIGA, ZANETTI; FAGGION, 2012), como apresentado na Figura 4a.

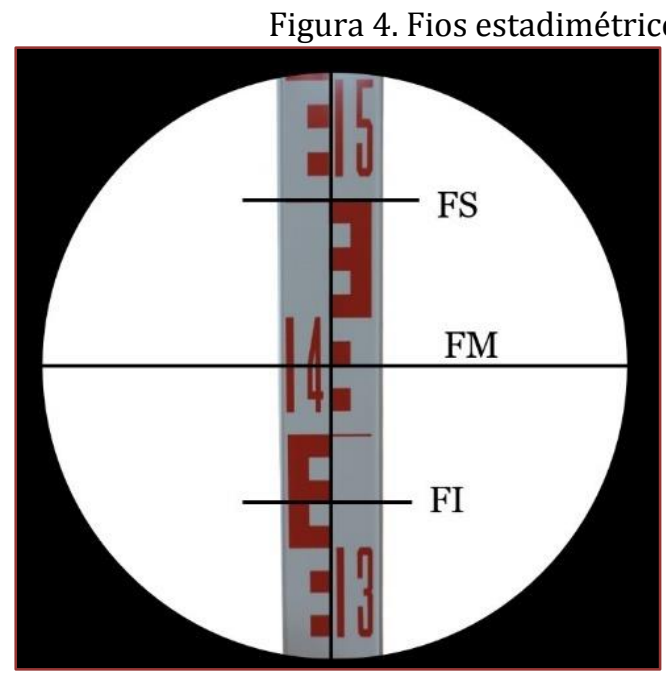

(a)

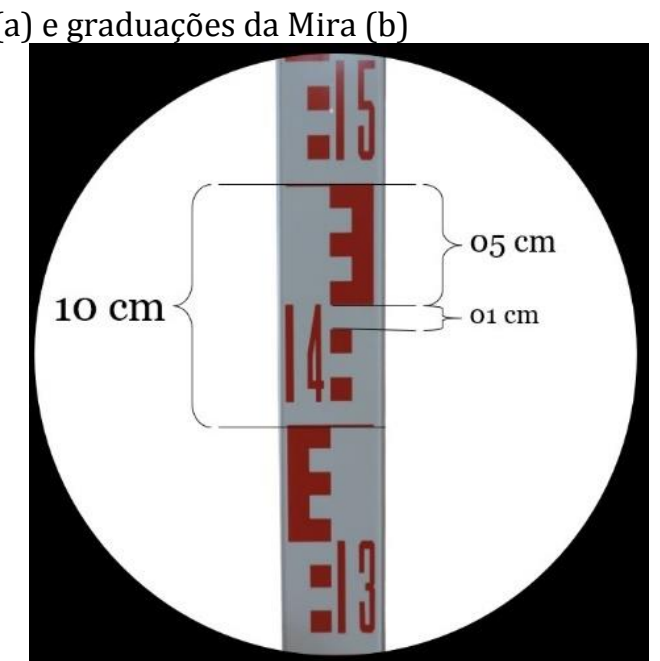

(b)

Fonte: Autores (2020)

As miras devem ser colocadas verticalmente nos pontos a nivelar, podendo ser de encaixe ou dobráveis. Vale ressaltar que para manter a verticalidade, um nível de cantoneira ou um nível de bolha junto à mesma, faz-se necessário (KAVANAGH; MASTIN, 2014). Sua menor célula gráfica de graduação é o centímetro e são numeradas de decímetro em decímetro (Figura 4b) (CORDINI, 2014).

A leitura na mira é constituída de um número de quatro casas decimais (metro, decímetro, centímetro e milímetro estimado pelo operador), como o exemplo a Leitura do Fio Médio da Figura 4a é 1,431m, sendo que o milímetro é interpretativo e varia para cada operador (CORDINI, 2014). Para evitar erro, deve-se observar o sentido do crescimento da graduação. Além disso, frisa-se que um erro de $1 \mathrm{~mm}$ na leitura da mira ocasiona um erro de $10 \mathrm{~cm}$ no terreno (IBGE, 2017).

\subsection{CÁLCULOS MATEMÁTICOS PARA DETERMINAÇÃO DA ALTITUDE}

O procedimento de campo é realizado a cada lance, que é o conjunto básico formado pelas visadas a ré e a vante, ou seja, as etapas envolvendo mira a mira (IBGE, 2017). Tais processos consistem em nivelar e instalar o Nível entre os pontos de interesse, visar a mira posicionada verticalmente no ponto inicial, o qual possui altitude conhecida que será a referência altimétrica para os demais pontos, e realizar a leitura 
dos fios estadimétricos, denominada de leitura da ré ou visada à ré (SILVA; SEGANTINE, 2015). Em seguida, repete-se o procedimento de leitura para a vante.

Considerando a Figura 5, é fácil notar que a diferença entre a Leitura da ré e a vante resulta no desnível $(\Delta h)$, conforme expresso na Equação 1.

$$
\Delta h_{A, B}=\mathrm{FM}_{\mathrm{A}}^{\mathrm{Ré}}-\mathrm{FM}_{\mathrm{B}} \mathrm{Vt}
$$

Sendo:

$\mathrm{FM}_{\mathrm{A}} \mathrm{Ré}^{\mathrm{e}}$ fio médio da visada à ré;

$\mathrm{FM}_{\mathrm{B}} \mathrm{Vt}$ : fio médio da visada à vante.

Figura 5. Lance do Nivelamento Geométrico

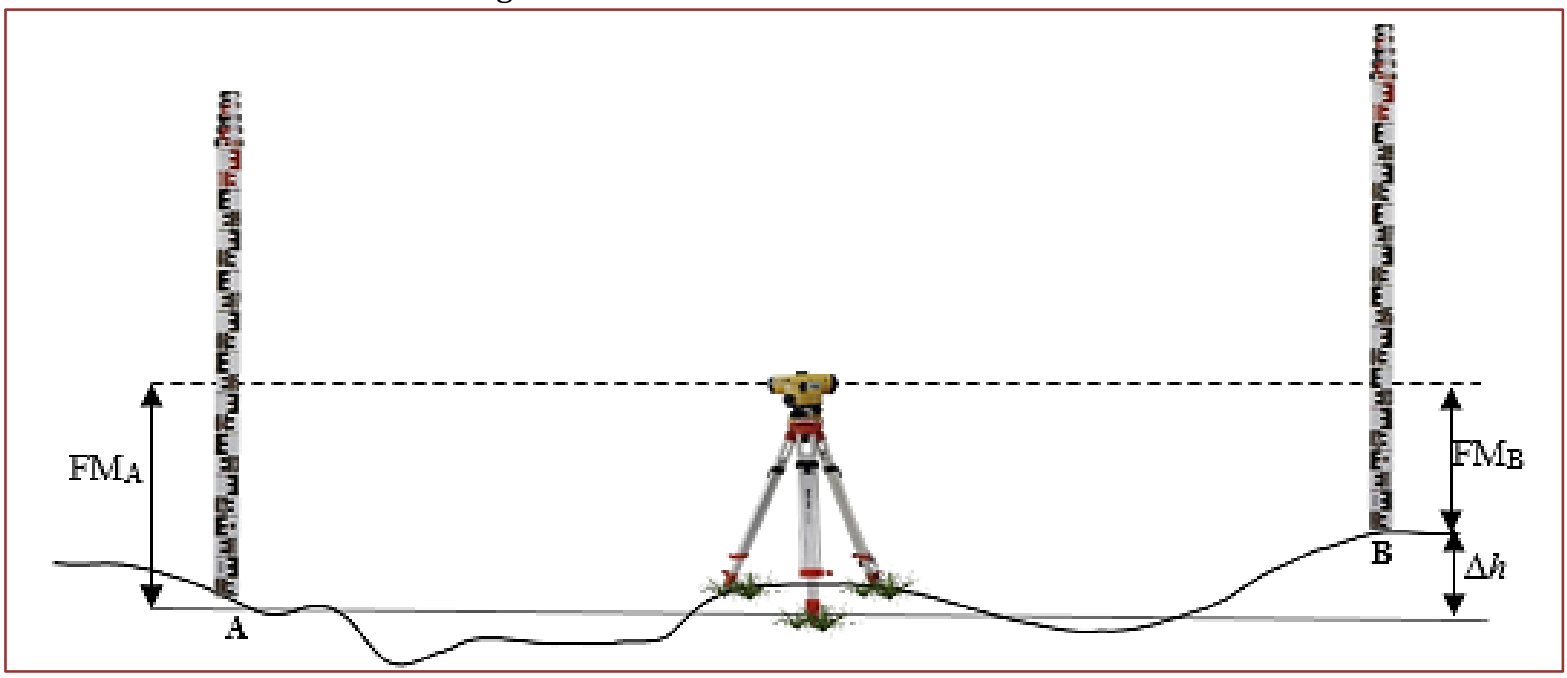

Fonte: Adaptado de Silva e Segantine (2015)

Conhecendo a altitude do ponto $A\left(\mathrm{H}_{\mathrm{A}}\right)$ e considerando o desnível obtido na Equação 1, pode-se determinar o valor da altitude do ponto $\mathrm{B}\left(\mathrm{H}_{\mathrm{B}}\right)$ a partir do transporte de altitudes conforme o cálculo das altitudes prévias apresentadas na Equação (2).

$$
\mathrm{H}_{\mathrm{B}}=\mathrm{H}_{\mathrm{A}}+\Delta h_{A, B}
$$

No entanto, há dois tipos de nivelamento geométrico: simples e composto. No nivelamento geométrico simples (Figura 6), a medição dos desníveis e altitudes dos pontos são determinadas a partir de uma única instalação do Nível, tomando como referência a leitura à ré para os demais pontos (GHILANI; WOLF, 2012; VEIGA, ZANETTI; FAGGION, 2012). Um limitante para este método é a distância entre os pontos (não podendo ser muito grande) e a variação do terreno, uma vez que os pontos devem ser visados de uma única estação, ou seja, aplicações se restringem a pequenas áreas e relativamente planas (SILVA; SEGANTINE, 2015). 
Figura 6 - Nivelamento Geométrico Simples

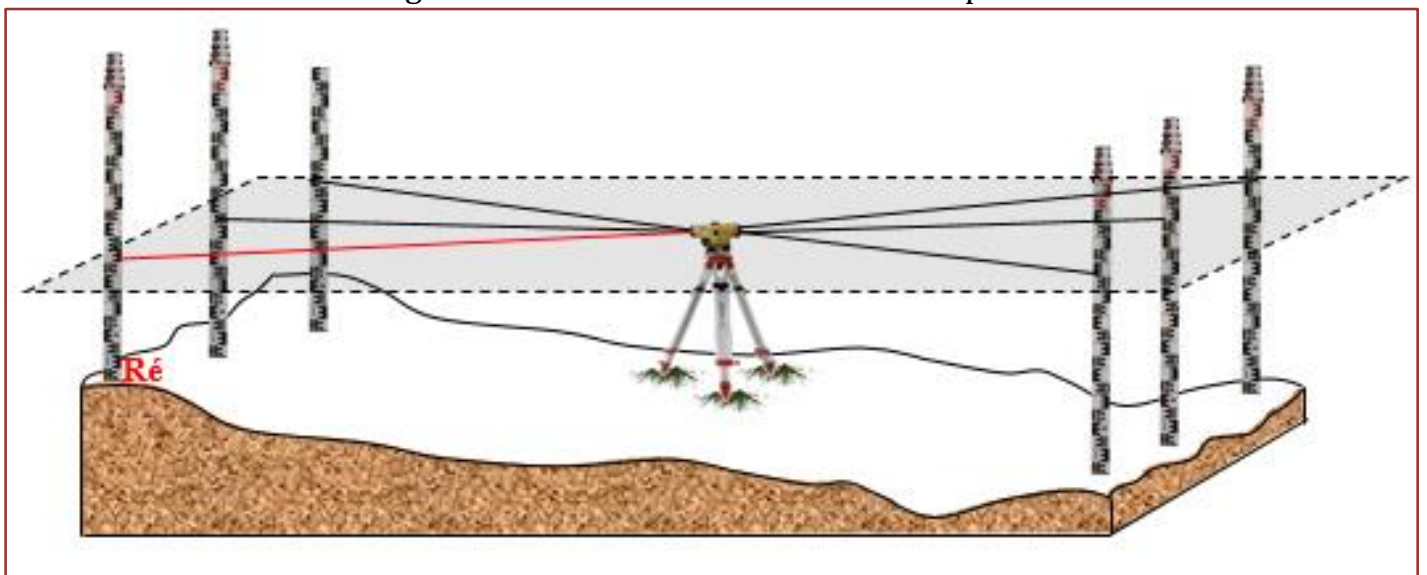

Fonte: Autores (2020)

Já no que concerne ao nivelamento geométrico composto (Figura 7), estaciona-se o aparelho em mais de uma estação para se nivelar o local de estudo (CORDINI, 2014). Ou seja, é quando ocorre uma sucessão de nivelamentos por um caminhamento, os quais são realizadas leituras a ré de pontos intermediários, denominados de pontos de mudança (SILVA; SEGANTINE, 2015).

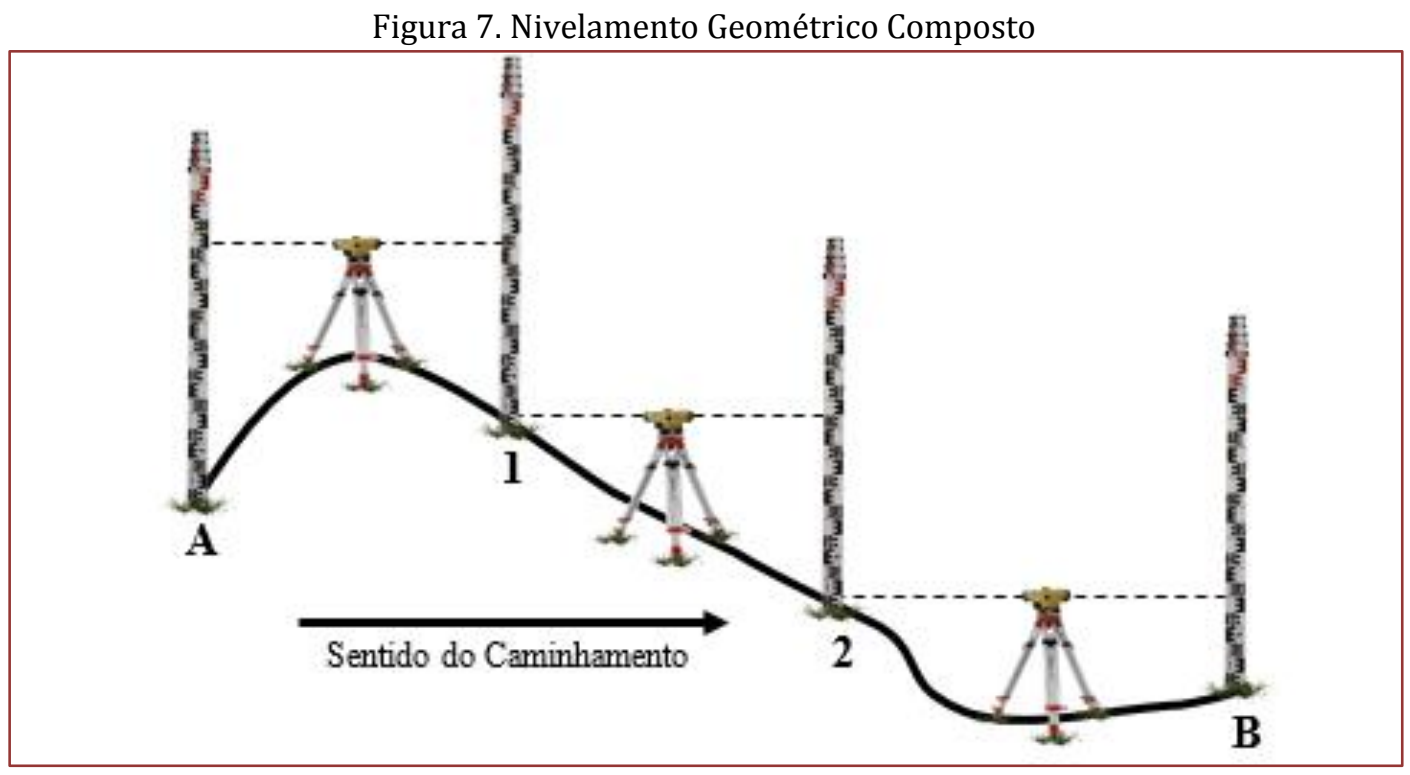

Fonte: Autores (2020)

Conforme indicado na Figura 7, tem-se a seguinte sequência de cálculos para determinar o desnível entre o A e B (Equação 3). Nota-se que os pontos 1 e 2 são pontos de mudança, que serão referência a ré para determinação dos pontos 2 e B, respectivamente.

$$
\begin{gathered}
\Delta h_{A, 1}=\mathrm{FM}_{\mathrm{A}}-\mathrm{FM}_{1} \rightarrow \mathrm{H}_{1}=\mathrm{H}_{\mathrm{A}}+\Delta h_{A, 1} \\
\Delta h_{1,2}=\mathrm{FM}_{1}-\mathrm{FM}_{2} \rightarrow \mathrm{H}_{2}=\mathrm{H}_{1}+\Delta h_{1,2} \\
\Delta h_{2, B}=\mathrm{FM}_{2}-\mathrm{FM}_{\mathrm{B}} \rightarrow \rightarrow \mathrm{H}_{\mathrm{B}}=\mathrm{H}_{2}+\Delta h_{2, B} \\
\Delta h_{A, B}=\sum F M^{R e ́}-\sum F M^{\text {Vante }} \\
\Delta h_{A, B}=\sum \Delta h
\end{gathered}
$$


Além disso, vale frisar que esta metodologia pode ser empregada para vários pontos de mudança, de modo a abranger toda área de estudo. Assim como, possibilita que sejam efetuadas irradiações em cada ponto estacionado, similar ao procedimento do nivelamento simples, afim de um detalhamento altimétrico da superfície a ser representada, conforme explicitado na Figura 8. Na literatura, este método é denominado de Caminhamento Misto ou Nivelamento com irradiações.

Figura 8. Nivelamento Geométrico com Caminhamento Misto

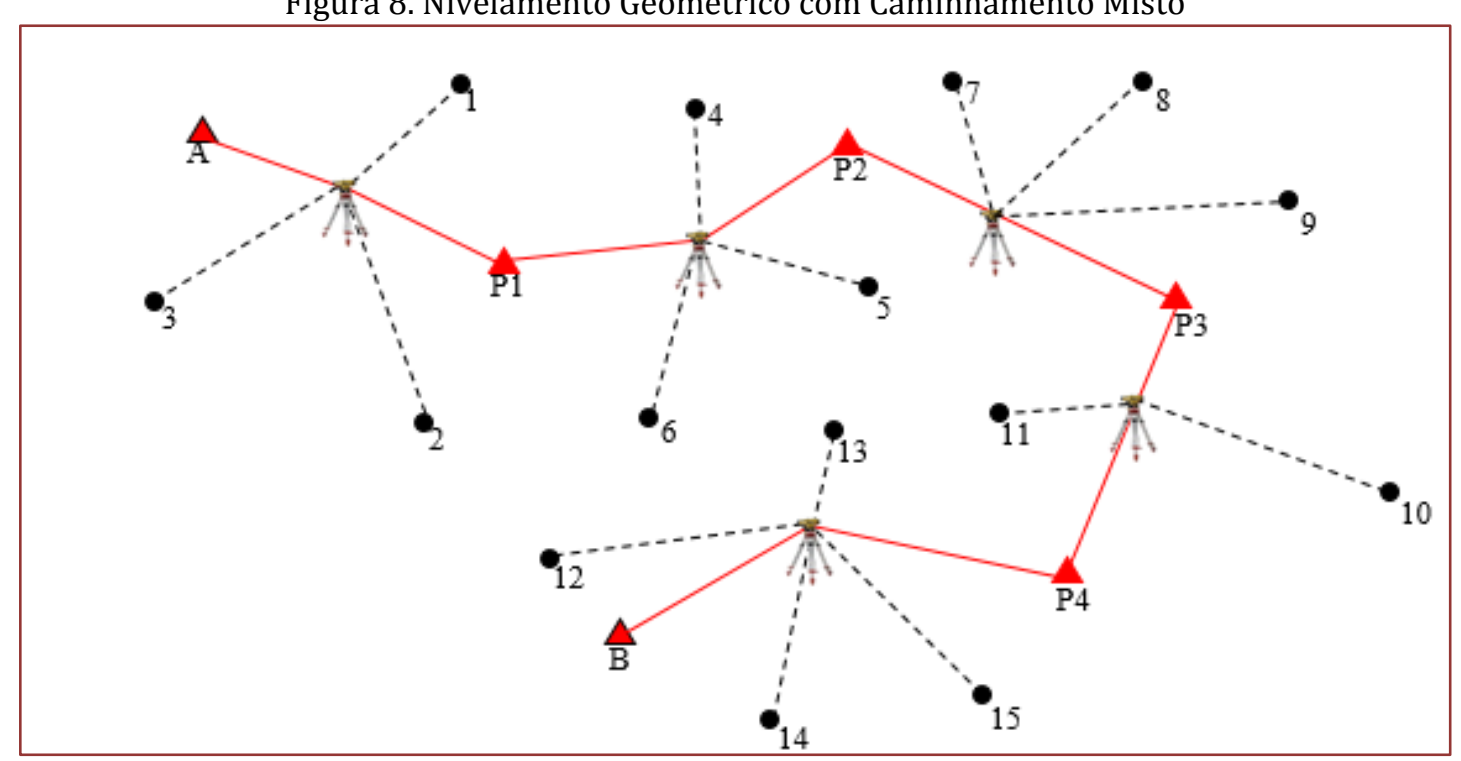

Fonte: Autores (2020)

Na Figura 8, os pontos A, P1, P2, P3, P4, B pertencem ao caminhamento sendo que o ponto A e B devem ter altitude conhecida para possibilitar o erro de fechamento e transporte de altitude. Já os pontos 1 ao 15 são pontos irradiados, ou seja, os pontos que foram lidos a partir da instalação do equipamento e das visadas. Destaca-se que as altitudes dos pontos irradiados são determinadas com base na leitura de ré da estação correspondente.

Convém ressaltar que este método é recomendado para grandes extensões de áreas e quando se observa que o terreno possui uma inclinação muito expressiva não sendo viável ter a visualização de todos os pontos apenas em uma única instalação do Nível (SILVA; SEGANTINE, 2015).

No entanto, devido a vários fatores inerentes ao processo de medição, existe uma série de erros que podem afetar o resultado do nivelamento. Por esta razão deve-se fechar o caminhamento em um ponto com altitude conhecida, podendo ser a mesma ou diferente do ponto de partida. Desta forma, pode-se obter um parâmetro de qualidade do nivelamento (GHILANI; WOLF, 2012; KAVANAGH; MASTIN, 2014).

Para a realização dos procedimentos matemáticos para determinar o erro de fechamento altimétrico, deve-se obter a diferença entre a altitude do ponto conhecida e a calculada (Equação 4) ou comparar os desníveis determinados com a diferença das altitudes conhecidas com os desníveis obtidos em campo (Equação 5) (VEIGA, ZANETTI; FAGGION, 2012).

$$
\begin{aligned}
& e_{a}=H_{B_{(\text {calculada })}}-H_{B_{(\text {conhecida })}} \\
& e_{a}=\sum \Delta h_{\text {Calculados }}-\left(H_{B_{(\text {conhecida })}}-H_{A_{(\text {conhecida })}}\right)
\end{aligned}
$$

Para que o erro de fechamento possa ser distribuído é necessário que ele seja menor que a tolerância do projeto. Normalmente os erros do nivelamento são acidentais em função do comprimento da linha de visada (SILVA; SEGANTINE, 2015). Por essa razão, a tolerância do erro de fechamento do nivelamento geométrico (T) é expressa pela Equação 6 (ABNT, 1994). 
Onde:

$k$ : constante adotada em função da precisão considerada no nivelamento;

$d$ : comprimento total do trecho nivelado, em quilômetros.

Segundo Garcia \& Piedade (1984), classifica-se em:

- Alta ordem: o erro médio admitido é de $\pm 1,5 \mathrm{~mm} / \mathrm{km}$ percorrido;

- Primeira ordem: o erro médio admitido é de $\pm 2,5 \mathrm{~mm} / \mathrm{km}$ percorrido;

- Segunda ordem: o erro médio admitido é de $1,0 \mathrm{~cm} / \mathrm{km}$ percorrido;

- Terceira ordem: o erro médio admitido é de $3,0 \mathrm{~cm} / \mathrm{km}$ percorrido;

- Quarta ordem: o erro médio admitido é de $10,0 \mathrm{~cm} / \mathrm{km}$ percorrido.

Nota-se um rigor maior em relação à tolerância ao longo dos anos, especialmente seguindo critérios de precisão estabelecidos pela NBR13133 para a execução de atividades desse tipo, especialmente quando se trata de obras que envolvem engenharia de estradas, engenharia civil e outras modalidades de engenharia que necessitam de resultados muito precisos para a boa execução das mesmas.

Dentre o que foi exposto, é tido como nivelamento com qualidade aquele que o erro de fechamento $\left(e_{a}\right)$ é menor que a tolerância (T), caso isso não ocorra deve-se realizar novas observações em campo, atendendo-se aos seguintes pontos, que segundo Ghilani e Wolf (2012), são fontes de erro mais comuns no nivelamento;

- $\quad$ Execução sem a devida verificação do nivelamento do nível de bolha do aparelho;

- Leitura incorretas da mira;

- $\quad$ Erro de anotação da mira;

- $\quad$ Erro de verticalidade da mira;

- $\quad$ Erro da graduação da mira;

- $\quad$ Erro de horizontalidade do eixo de visada (eixo óptico não está perpendicular com o eixo vertical).

- Erro devido a influência da curvatura e refração terrestre;

- Erro na na determinação a altitude dos Pontos de Mudança;

- Focagem incorreta dos retículos estadimétricos; e

- Calor ou reverberação e ventos.

Por outro lado, caso esteja dentro das tolerâncias pré-estabelecidas, é importante realizar as compensações para que os erros se dilua nas observações. A compensação $\left(\mathrm{C}_{\mathrm{h}}\right)$ é oposta ao erro $\left(e_{a}\right)$, ou seja, $\mathrm{C}_{\mathrm{h}}=-e_{a}$. Na verdade, $\mathrm{C}_{\mathrm{h}}$ é distribuído repartindo o valor a cada ponto, podendo ser empregado proporcionalmente ao número de pontos de mudança (Equação 7) ou inversamente proporcional a distância do lance (Equação 8) (SILVA; SEGANTINE, 2015). Vala-se ressaltar, que a Equação 8, considerase que quanto maior a distância do lance, maior é o erro.

$$
\begin{gathered}
C_{h}=-\frac{e_{a}}{n} \\
C_{h}=-e_{a} \frac{D_{i}}{\sum d}
\end{gathered}
$$

Onde: 
n: número de pontos de mudança do caminhamento ou números de desníveis.

$\sum d$ : é a comprimento total do trecho nivelado, ou seja, é o somatório das distâncias de cada visada $D_{i}$.

De modo que, as distâncias de cada visada (Nível à Mira) são determinadas a partir a equação 9, ou seja, é a subtração do fio superior e fio inferior, multiplicada pela constante estadimétrica da mira (L), sendo normalmente igual a 100 .

$$
D i_{(\text {Nível à Mira A) }}=\left(\mathrm{FS}_{\mathrm{A}}-\mathrm{FI}_{\mathrm{A}}\right) \times \mathrm{L}
$$

Por fim, chega-se a etapa de se realizar a correção das altitudes a partir da compensação. Atém-se que nesse método não são definidas coordenadas planimétricas (X, Y) (KAVANAGH; MASTIN, 2014). Logo, a partir da Equação (10) determina-se as altitudes corrigidas dos pontos.

$$
H_{i}=H_{i-1}+\Delta h_{i-1, i}+C_{h}
$$

\subsection{PRÁTICA}

Em síntese, os materiais recomendados para esta aula prática serão:

- 1 Nível Topográfico;

- 1 Tripé;

- 2 Mira estadimétrica;

- 2 Nível de cantoneira;

- 1 Trena de $30 \mathrm{~m}$;

- 9 Piquetes; e

- Prancheta e recursos necessários para anotação de dados.

\subsubsection{PROCEDIMENTOS EM CAMPO}

Recomenda-se adotar grupos de quatro alunos, de modo que dois destes verticalizam as miras estadimétricas na Ré e na Vante; outro aluno, portanto, instale, nivele e opere o Nível assim como realiza as leituras das miras; e o último auxilia o operador, anotando e verificando as leituras a partir dos cálculos. No entanto, vale frisar que essa quantidade é para fins didáticos, pois na prática somente dois profissionais são suficientes para esta operação.

Considerando essa quantidade de alunos por grupo, sugere-se uma poligonal com no mínimo oito pontos para um caminhamento fechado (começa e termina no mesmo ponto de referência) ou nove pontos para encaminhamento apoiado (começa e termina em pontos de referência diferente), totalizando oito estacionadas. Este procedimento é para que os alunos tenham a oportunidade de operar pelo menos duas vezes o equipamento, desde que seja feito o devido rodízio de funções entre os operadores.

O objetivo deste procedimento prático é para que os alunos consigam executar todas as etapas do nivelamento geométrico, iniciando com o planejamento dos pontos, partindo com as coletadas de dados, realização dos cálculos apresentados no tópico anterior (3.4), bem como analisar o erro e distribuição do mesmo.

Primeiramente, deve-se checar se o ponto de partida e chegada tem altitude conhecida para realizar o transporte das altitudes e realizar a materialização dos pontos de interesse com piquetes, chapas ou pinos, encravados no solo. Caso julguem necessário, pode-se empregar estacas a fim de auxiliar a localização destes pontos. 
Posteriormente, dois alunos devem colocar as miras sobre os pontos de interesse do primeiro lance. As miras deverão estar verticalizadas com o auxílio do nível de cantoneira e serão apoiadas sobre chapas, pinos ou piquetes materializados, e no caminhamento, deverá colocar sobre sapatas, evitando apoiar diretamente sobre o solo. Vale frisar que neste método, diferentemente dos demais métodos planialtimétricos, o Nível não é estacionado nos pontos de interesse, assim, não há necessidade de centralizar o Nível em nenhum ponto materializado.

O Nível deve ser instalado sobre o tripé a meia equidistância das miras, de modo a minimizar o efeito da curvatura terrestre e da refração atmosférica, bem como compensar a horizontalidade do eixo de colimação da luneta (IBGE, 2017). Para tal fim, recomenda-se empregar uma trena de 30m ou realizar uma contagem a passo, já que se aceita uma discrepância entre a distância para a Ré e a distância para a Vante de $3 \mathrm{~m}$. Além disso, para uma leitura mais precisa recomenda-se que esta distância seja inferior a 60m (IBGE, 2017). Após a instalação, nivela-o com o auxílio dos calantes e tripé, conforme já visto em sala de aula.

Em seguida, orienta-se um aluno operar o Nível e ler na mira à Ré os fios estadimétricos (FS, FM, FI) e outro aluno anotar na planilha (APENNDICE 1) e verificar a leitura do FM lido está condizente com a equação 11, de modo que a diferença entre o FM lido e FM o calculado não deve exceder $2 \mathrm{~mm}$. Em seguida visar a mira à Vante repetir os procedimentos da ré. Vale ressaltar que as leituras nas miras deverão se situar acima de 20-50 cm do solo para evitar turbulências causadas pela reverberação (IBGE, 2017).

$$
F M_{\text {Calculado }}=\frac{F M+F I}{2}
$$

Ao realizar o cálculo do desnível do primeiro lance, deve-se seguir para o próximo lance tomando o cuidado de alternar as miras, ou seja, a mira que estava posicionada no ponto Ré seja posicionada neste lance no ponto Vante. Este processo possibilita minimizar um possível erro de índice da Mira (IBGE, 2017).

Este processo deve ser feito até o último lance da poligonal, com alternância das funções dos alunos de modo que todos os alunos do grupo passem por todas as etapas (instalar e nivela o Nível, aprumar a mira, realizar as leituras e os cálculos) afim de fixar os conhecimentos.

Após o procedimento de campo e coletar os dados, deve-se finalizar os cálculos dos desníveis (Equação 1), do transporte das altitudes (Equação 2), erro de fechamento altimétrico (Equação 4 ou 5), conforme descrito no tópico 3.4 .

Caso o erro de fechamento altimétrico seja maior que a tolerância estabelecida $(1,0 \mathrm{~cm} / \mathrm{km})$, o trabalho deverá ser refeito, tomando-se os devidos cuidados enfatizados no item anterior (seção 3.4). Caso contrário, deverão proceder com os cálculos de compensação do erro altimétrico (Equação 7 e 8 ) e determinação da altitude (Equação 10).

\section{BIBLIOGRAFIA}

[1] ABNT. Associação Brasileira de Normas Técnicas. NBR 13133: Execução de Levantamento topográfico. Rio de Janeiro, RJ: ABNT, 1994.

[2] IBGE. Instituto Brasileiro de Geografia e Estatística. Especificações e Normas para Levantamentos Geodésicos Associados ao Sistema Geodésico Brasileiro. Rio de Janeiro, 2017.

[3] CORDINI, J. Altimetria: teoria e métodos visando a representação do relevo. Florianópolis, 2014. Disponível em: <https://topografia.paginas.ufsc.br/files /2015/09/Altimetria-Apostila.pdf>. Acesso em: 28 ago 2020.

[4] FURTADO, SCHMIDT. Sistema de Equipamentos Topográficos. Mira código de barras GSS112. Disponível em <https://www.furtadonet.com.br/mira-codigo-de-barras-gss112-p75>. Acesso em 20 ago 2020.

[5] GARCIA, G. J.; PIEDADE, G.C.R. Topografia aplicada às ciências agrárias. 3. ed. São Paulo: Nobel, 1984. 
[6] GHILANI, C. D.; WOLF, P. R. Elementary Surveying an Introduction to Geomatics. 13 $^{\text {th }}$ Edition. Pearson, 2012, p.962.

[7] KAVANAGH, B. F.; MASTIN, T. B. Surveying: principles and applications. 19th Edition, Pearson, 2014, p.600.

[8] NADOLINETS, L.; LEVIN, E. AKHMEDOV, D. Surveying Instruments and Technology. Taylor \& Francis, CRC Press, 2017, p. 253.

[9] NICACIO, E. JARAMILO, A.G.S.; ZANETTI, G.Z.; FAGGION, P.L. Avaliação de técnica de nivelamento e métodos de posicionamento GNSS para determinação de desnível de primeira ordem. Revista Brasileira de Geomática, v.6. n.6, p.274-293, 2018.

[10] SIGUEL, A. R.; FAGGION, P.L.; VEIGA, L. A. K.; NADAL, C.A. MATTOS, M. da S. Aplicação do Método de Irradiação Tridimensional no Monitoramento de Barragens. Boletim de Ciência Geodésicas, v. 19, n. 3, p.391-406, 2013.

[11] VEIGA, L. A. K.; ZANETTI, M. A. Z.; FAGGION, P. L. Fundamentos de Topografia. Curitiba, PR: UFPR, 2012. 


\section{APÊNDICE 1}

\section{NIVELAMENTO GEOMÉTRICO}

Saída $=$ ; $\mathrm{H}=$ ; Chegada $=$ $; \mathrm{H}=$

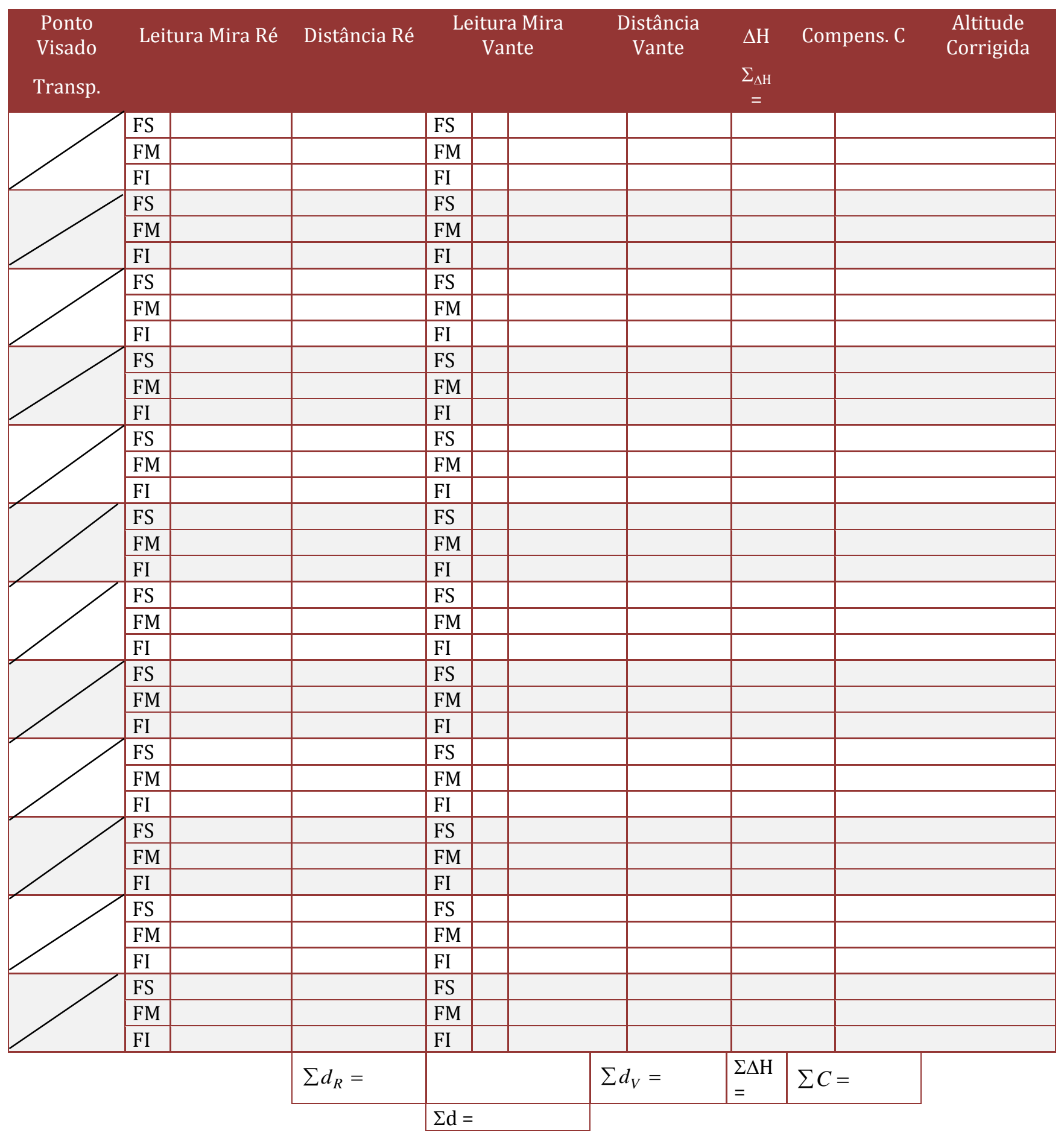




\section{Capítulo 7}

Aula prática: Sistema de recalque Levantamento da curva de uma bomba centrífuga

Hélio da Silva Almeida

José Almir Rodrigues Pereira

Jorge Fernando Hungria Ferreira 


\subsection{INTRODUÇÃO}

A necessidade de transportar água de um reservatório situado em uma cota inferior para outro situado em uma cota superior, impõe a existência de um equipamento eletromecânico que forneça uma certa quantidade de energia ao líquido. Esta energia é expressa em termos de coluna de líquido e é denominada altura manométrica total (Hman), dada por:

$$
\mathrm{Hman}=\mathrm{Hg}+\text { perdas }=\mathrm{Hr}+\mathrm{Hs}
$$

Onde:

Hg - é a altura geométrica, diferença de níveis entre os reservatórios. $(\mathrm{Hr}+\mathrm{Hs})$

$\mathrm{Hr}$ - é a altura manométrica de recalque, diferença entre a cota piezométrica na saída da bomba e a cota do eixo.

Hs - é a altura manométrica de sucção, diferença entre a cota piezométrica na entrada da bomba e a cota do eixo.

A altura manométrica de recalque é sempre positiva e a altura manométrica de sucção pode ser negativa ou positiva, dependendo se a linha piezométrica corta ou não a tubulação de sucção. No caso da instalação montada a bomba encontra-se não afogada, ou seja, o eixo da bomba está acima do nível do líquido.

As perdas de carga localizadas, ocasionadas pela mudança de seção do escoamento ou direção do fluido, diferenciam-se das perdas distribuídas, uma vez que estas dependem de parâmetros definidos e bem conhecidos, enquanto aquelas dependem de fatores de difícil determinação e bastante diversificados. As perdas de carga localizadas variam de acordo com as características do escoamento à montante e jusante da singularidade e, apesar de denominadas localizadas, na realidade se verificam em um pequeno trecho de um lado ou de outro do acessório. Em outras palavras, a queda da linha de energia, devido a presença do acessório, não ocorre verticalmente.

Para tubulações de PVC, de diâmetros menores que 4", transportando água fria, a perda de carga unitária pode ser calculada pela equação de Fair-Whipple-Hsiao:

$$
J=0,00086 \frac{Q^{1,75}}{D^{4,75}} \operatorname{com} J(m / m), Q\left(m^{3} / s\right) e D(m)
$$

\subsection{DESENVOLVIMENTO}

\subsubsection{OBJETIVO GERAL}

Levantar experimentalmente a curva de uma bomba centrifuga e comparar com a curva do fabricante.

\subsubsection{OBJETIVOS ESPECÍFICOS}

- Operacionalizar um experimento de medição de vazão;

- Observar o funcionamento de um medidor de vazão;

- Identificar as partes constituintes de um sistema de turbobombas;

- Confeccionar a curva da bomba com os dados obtidos;

\subsubsection{METODOLOGIA}

No laboratório de hidráulica do curso de engenharia sanitária da UFPA, está instalado um sistema de recalque com duas bombas em paralelo marca KSB, com manovacuômetro na entrada da bomba e manômetro (ambos marca Mecaltec) na saída da mesma. O sistema é composto com tubulações de PVC, sendo $75 \mathrm{~mm}$ na sucção e $50 \mathrm{~mm}$ no recalque. A bomba encontrava-se não afogada, e succiona do 
reservatório 1 de $500 \mathrm{~L}$, para o reservatório 2 de $310 \mathrm{~L}$, sendo que deste a água retorna para o reservatório 1 por gravidade, ver Figura 1.

Figura 1- Instalação de recalque com recirculação

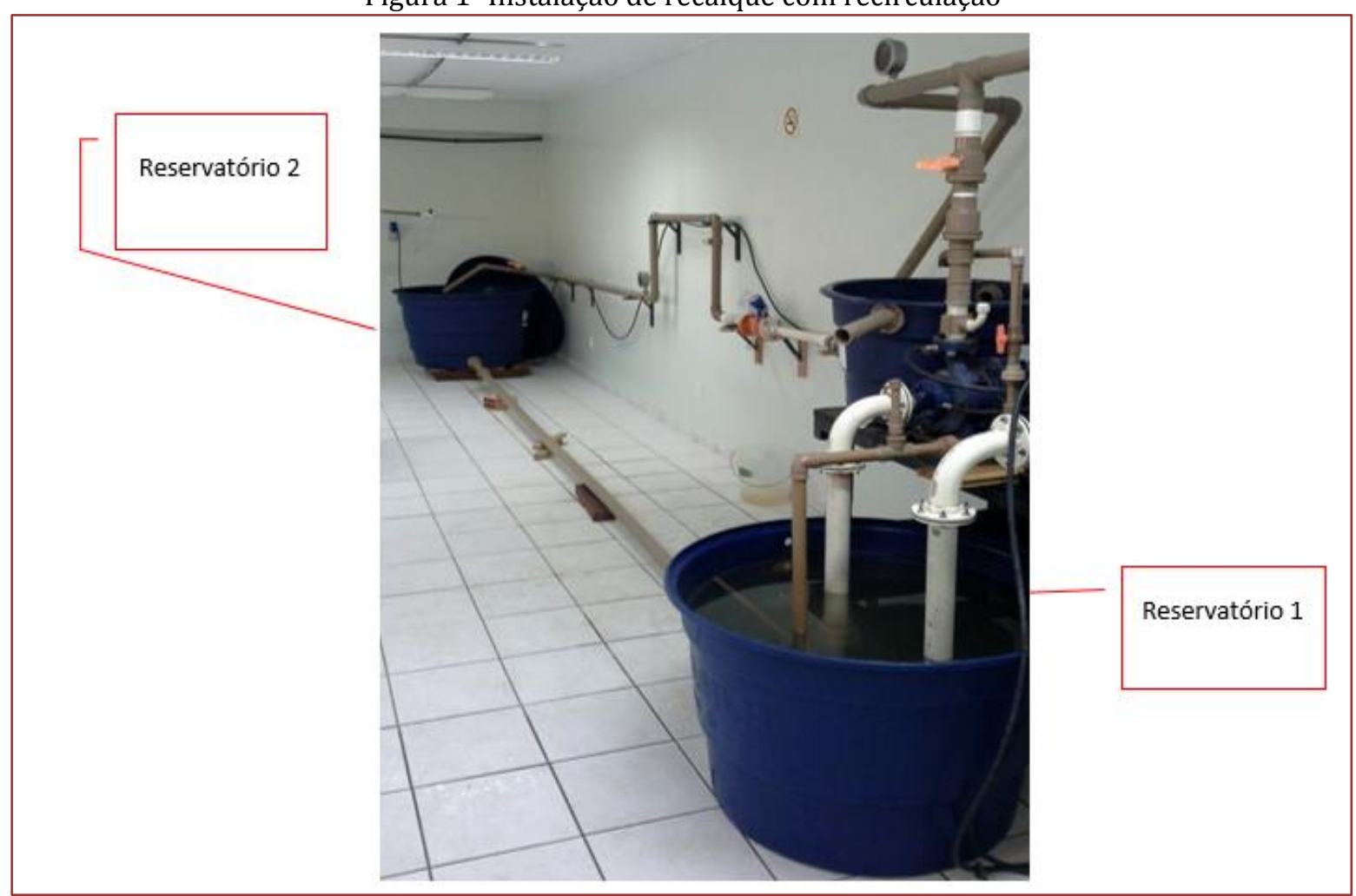

Na Figura 2 verifica-se detalhes da bomba e dos medidores de pressão.

Figura 2-Bomba centrífuga e manômetros de medição

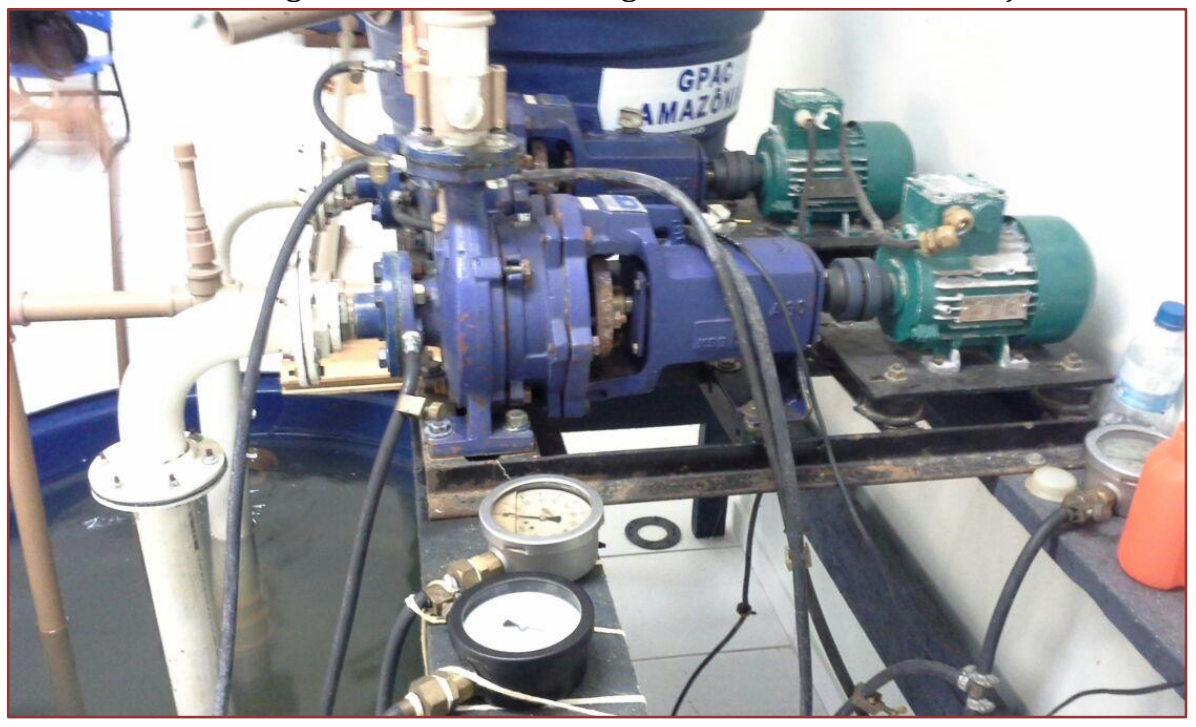

Na Figura 3 indica-se o medidor de vazão (de engrenagens) oval Tech-meter, que foi utilizado na pesquisa, e as adaptações feitas para o funcionamento do mesmo na tubulação de recalque do sistema de bombas. 
Figura 3- Medidor de engrenagens (vazão em L/min)

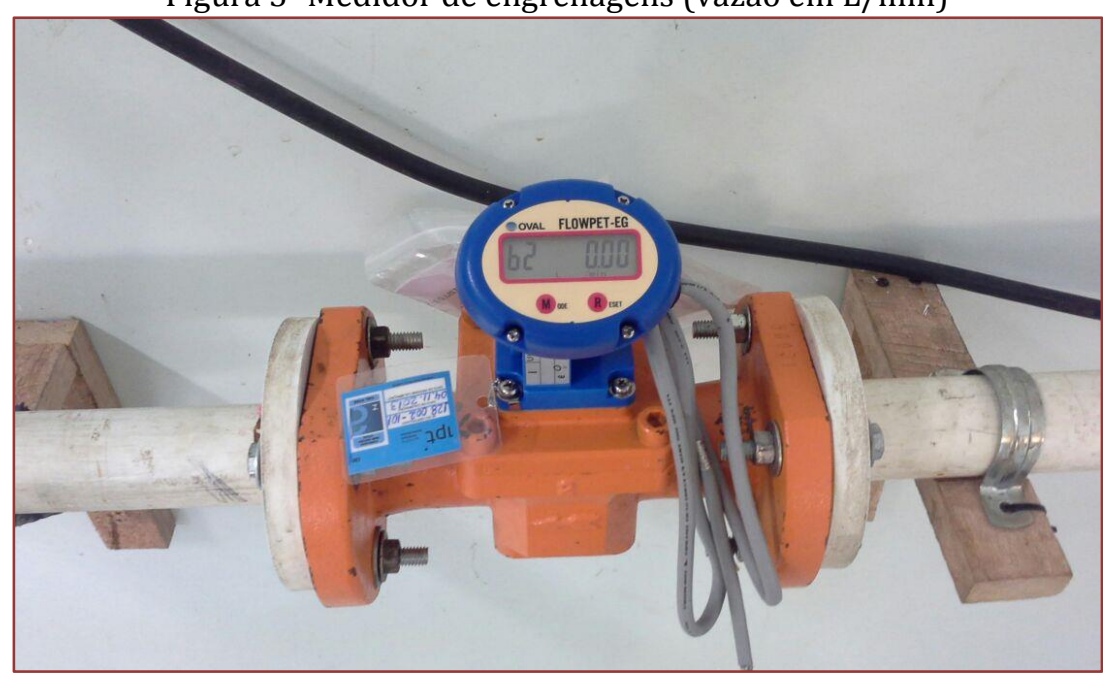

Figura 4- Detalhe do medidor na tabulação

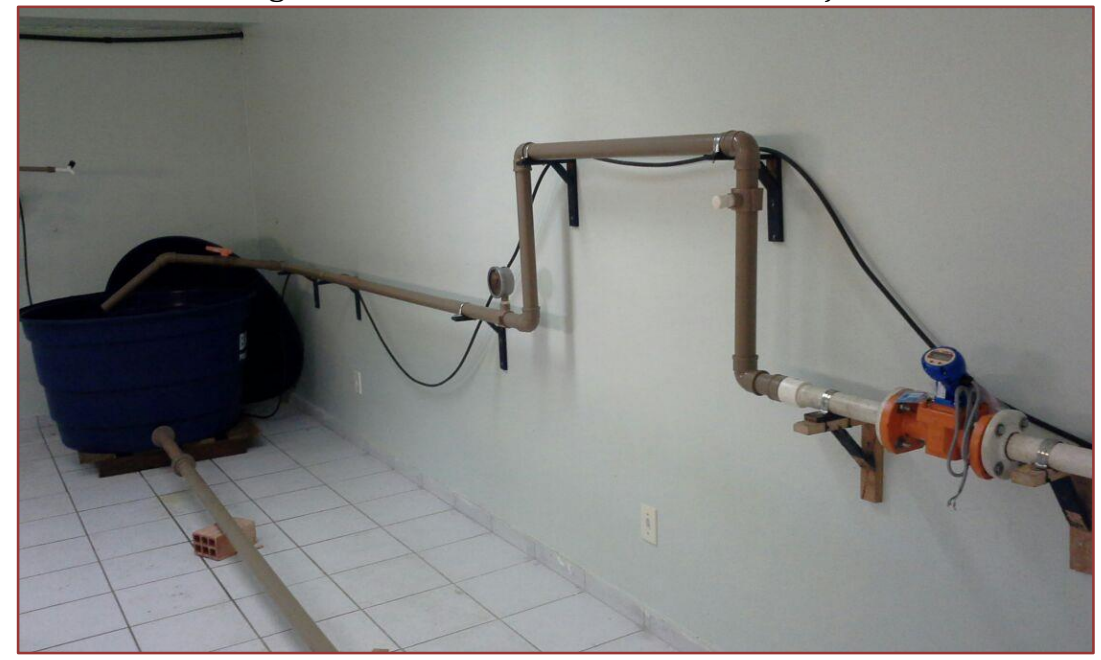

\section{Procedimentos práticos desenvolvidos:}

1. Realizar os levantamentos, a trena, das cotas lineares e conexões para a obtenção dos comprimentos reais e equivalentes para determinação da perda de carga;

2. Elaborar o desenho isométrico da instalação;

3. Escorvar e ligar a bomba;

4. Conferir as condições de bombeamento;

5. Após estabilização da vazão, para dez diferentes manobras de registro na caixa d'água de $310 \mathrm{~L}$, anotar os dados de vazão para 10 medições, no medidor de engrenagens (Flowpet - OVAL TechMeter);

6. Para cada medida de vazão anotar as pressões correspondentes na saída e entrada da bomba;

7. Construir o gráfico do ensaio (curva da bomba);

8. Comparar com dados do fabricante.

Pela tabela abaixo quantificou-se os comprimentos equivalentes das conexões e determinou-se as perdas de carga. 
Tabela1- Comprimentos equivalentes

\begin{tabular}{|c|c|c|c|c|c|c|c|c|c|c|c|c|c|c|c|c|c|}
\hline \multicolumn{18}{|c|}{ Perdas de carga localizadas - Sua equivalência em metros de tubulaçăo de PVC rigido } \\
\hline & & $\begin{array}{l}\text { Joelho } \\
90^{\circ}\end{array}$ & $\begin{array}{l}\text { Joelho } \\
45^{\circ}\end{array}$ & $\begin{array}{l}\text { Curva } \\
90^{\circ}\end{array}$ & $\begin{array}{c}\text { Curva } \\
45^{\circ}\end{array}$ & \begin{tabular}{|c|} 
Te $90^{\circ}$ \\
Passagem \\
Direita
\end{tabular} & $\begin{array}{l}\text { Té } 90^{\circ} \\
\text { Saida } \\
\text { de lado }\end{array}$ & \begin{tabular}{|c|} 
Té $90^{\circ}$ \\
Saida \\
Billateral
\end{tabular} & \begin{tabular}{|l|} 
Entrada \\
Normal
\end{tabular} & $\begin{array}{l}\text { Entrada } \\
\text { de Borda }\end{array}$ & $\begin{array}{c}\text { Saida de } \\
\text { Canalizaçăo }\end{array}$ & $\begin{array}{l}\text { Valvula de } \\
\text { Pé e Crivo }\end{array}$ & $\begin{array}{l}\text { Välvula de } \\
\text { Retençào } \\
\text { Tipo Leve }\end{array}$ & \begin{tabular}{|c|} 
Valvula de \\
Retençăo \\
Tipo Pesado
\end{tabular} & \begin{tabular}{|l|} 
Registro \\
de Globo \\
Aberto
\end{tabular} & $\begin{array}{c}\text { Registro } \\
\text { de Gaveta } \\
\text { Aberto }\end{array}$ & $\begin{array}{l}\text { Registro } \\
\text { de Ângulo } \\
\text { Aberto }\end{array}$ \\
\hline $\mathrm{DE}(\mathrm{mm})$ & $\begin{array}{l}\text { D. ret. } \\
\text { (poll) }\end{array}$ & $\ddot{\exists}$ & 을 & $i$ & $\Leftrightarrow$ & Г曰 & ᄃ行 & 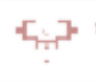 & "קי" & $\stackrel{7}{-}$ & 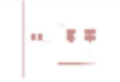 & $\underline{\text { 도. }}$ & & it & T & 可 & 5 \\
\hline 20 & is & 1,1 & 0,4 & 0,4 & 0,2 & 0,7 & 2,3 & 2,3 & 0,3 & 0,9 & 0,8 & 8,1 & 2,5 & 3,6 & 11,1 & 0,1 & 5,9 \\
\hline 25 & 3 & 1,2 & 0,5 & 0,5 & 0,3 & 0,8 & 2,4 & 2,4 & 0,4 & 1 & 0,9 & 9,5 & 2,7 & 4,1 & 11,4 & 0,2 & 6,1 \\
\hline 32 & 1 & 1,5 & 0,7 & 0,6 & 0,4 & 0,9 & 3,1 & 3,1 & 0,5 & 1,2 & 1,3 & 13,3 & 3,8 & 5,8 & 15 & 0,3 & 8,4 \\
\hline 40 & $1 \%$ & 2 & 1 & 0,7 & 0,5 & 1,5 & 4,6 & 4,6 & 0,6 & 1,8 & 1,4 & 15,5 & 4,9 & 7,4 & 22 & 0,4 & 10,5 \\
\hline 50 & $1 \%$ & 3,2 & 1,3 & 1,2 & 0,6 & 2,2 & 7,3 & 7,3 & 1 & 2,3 & 3,2 & 18,3 & 6,8 & 9,1 & 35,8 & 0,7 & 17 \\
\hline 60 & 2 & 3,4 & 1,5 & 1,3 & 0,7 & 2,3 & 7,6 & 7,6 & 1,5 & 2,8 & 3,3 & 23,7 & 7,1 & 10,8 & 37,9 & 0,8 & 18,5 \\
\hline 75 & $2 \%$ & 3,7 & 1,7 & 1,4 & 0,8 & 2,4 & 7,8 & 7,8 & 1,6 & 3,3 & 3,5 & 25 & 8,2 & 12,5 & 38 & 0,9 & 19 \\
\hline 85 & 3 & 3,9 & 1,8 & 1,5 & 0,9 & 2,5 & 8 & 8 & 2 & 3,7 & 3,7 & 26,8 & 9,3 & 14,2 & 40 & 0,9 & 20 \\
\hline 110 & 4 & 4,3 & 1,9 & 1,6 & 1 & 2,6 & 8,3 & 8,3 & 2,2 & 4 & 3,9 & 28,6 & 10,4 & 16 & 42,3 & 1 & 22,1 \\
\hline
\end{tabular}

Fonte: Tigre manual técnico

\subsubsection{RESULTADOS DE UM EXPERIMENTO:}

Os resultados das medições efetuadas e dimensionamentos realizados são apresentados nas tabelas abaixo.

Tabela 2- resultados dos 10 experimentos.

\begin{tabular}{|c|c|c|c|c|c|}
\hline Ensaio & $\begin{array}{c}\text { Vazão } \\
(\mathbf{L} / \mathbf{m i n})\end{array}$ & $\begin{array}{c}\text { Vazão } \\
\left(\mathbf{m}^{3} / \mathbf{s}\right)\end{array}$ & $\begin{array}{c}\text { Vacuômetro } \\
\text { (mca) }\end{array}$ & $\begin{array}{c}\text { Manômetro } \\
\text { (mca) }\end{array}$ & $\begin{array}{c}\text { Hman } \\
\text { (mca) }\end{array}$ \\
\hline 1 & 56,43 & 0,0009405 & 3,85 & 6 & 9,85 \\
\hline 2 & 53,1 & 0,000885 & 3,7 & 7 & 10,7 \\
\hline 3 & 50,5 & 0,000841667 & 3,5 & 8 & 11,5 \\
\hline 4 & 48,6 & 0,00081 & 3,4 & 9 & 12,4 \\
\hline 5 & 44,9 & 0,000748333 & 3,2 & 10 & 13,2 \\
\hline 6 & 42,7 & 0,000711667 & 3 & 11 & 14 \\
\hline 7 & 40,31 & 0,000671833 & 2,9 & 12 & 14,9 \\
\hline 8 & 35,87 & 0,000597833 & 2,6 & 13 & 15,6 \\
\hline 9 & 29,27 & 0,000487833 & 2,2 & 15 & 17,2 \\
\hline 10 & 20,54 & 0,000342333 & 1,9 & 16 & 17,9 \\
\hline
\end{tabular}

Para tubulações de PVC, de diâmetros menores que 4", transportando água fria, a perda de carga unitária pode ser calculada pela equação de Fair-Whipple-Hsiao:

$$
\begin{aligned}
& J=0,00086 \frac{Q^{1,75}}{D^{4,75}} \operatorname{com} J(\mathrm{~m} / \mathrm{m}), Q\left(\mathrm{~m}^{3} / \mathrm{s}\right) \text { e } D(\mathrm{~m}) \\
& \text { ? ? }=\text { ? ?.? } \\
& \text { ?=? ? ? +? ? ? ? ? }
\end{aligned}
$$

Deste modo calculou-se as perdas de carga para cada vazão verificada, na sucção e no recalque do sistema. Pelo levantamento in loco foi determinada comprimento real da sucção de 0,85 m. 0 comprimento equivalente foi referente a uma curva $90^{\circ}$ (1,4 m) e uma válvula de pé com crivo (25 m). (Tabela 3) 
Tabela 3- Perda de carga na sucção $D=75 \mathrm{~mm}$

\begin{tabular}{|c|c|c|c|c|c|}
\hline Ds (m) & $\mathbf{Q}\left(\mathrm{m}^{3} / \mathrm{s}\right)$ & J & Lreal & Leq & $\mathrm{Hfs}(\mathrm{m})$ \\
\hline 0,075 & 0,000957933 & 0,0010 & 0,85 & 26,4 & 0,0261 \\
\hline 0,075 & 0,000861208 & 0,0009 & 0,85 & 26,4 & 0,0235 \\
\hline 0,075 & 0,000788774 & 0,0008 & 0,85 & 26,4 & 0,0215 \\
\hline 0,075 & 0,000737575 & 0,0007 & 0,85 & 26,4 & 0,0201 \\
\hline 0,075 & 0,000642131 & 0,0006 & 0,85 & 26,4 & 0,0175 \\
\hline 0,075 & 0,000588087 & 0,0006 & 0,85 & 26,4 & 0,016 \\
\hline 0,075 & 0,000531698 & 0,0005 & 0,85 & 26,4 & 0,0145 \\
\hline 0,075 & 0,000433484 & 0,0004 & 0,85 & 26,4 & 0,0118 \\
\hline 0,075 & 0,000303691 & 0,0003 & 0,85 & 26,4 & 0,0083 \\
\hline 0,075 & 0,000163397 & 0,0002 & 0,85 & 26,4 & 0,0045 \\
\hline
\end{tabular}

No recalque mediu-se 11,31 m de comprimento linear e 39,1 m de comprimento equivalente, referentes a 2 válvulas de gaveta, 1 Tê saída lateral, 1 tê passagem direta, 7 joelhos $90^{\circ}$, 02 joelhos $45^{\circ}$.

Tabela 4-Perda de carga no recalque $\mathrm{D}=50 \mathrm{~mm}$

\begin{tabular}{|c|c|c|c|c|c|}
\hline Dr $(\mathbf{m})$ & $\mathbf{Q}\left(\mathbf{m}^{3} / \mathbf{s}\right)$ & $\mathbf{J}$ & Lreal & Leq & Hfs(m) \\
\hline 0,05 & 0,0009405 & 0,00657 & 11,31 & 39,1 & 0,331 \\
\hline 0,05 & 0,0009405 & 0,00591 & 11,31 & 39,1 & 0,298 \\
\hline 0,05 & 0,000885 & 0,00541 & 11,31 & 39,1 & 0,273 \\
\hline 0,05 & 0,000841667 & 0,00506 & 11,31 & 39,1 & 0,255 \\
\hline 0,05 & 0,00081 & 0,00441 & 11,31 & 39,1 & 0,222 \\
\hline 0,05 & 0,000748333 & 0,00404 & 11,31 & 39,1 & 0,203 \\
\hline 0,05 & 0,000711667 & 0,00365 & 11,31 & 39,1 & 0,184 \\
\hline 0,05 & 0,000671833 & 0,00297 & 11,31 & 39,1 & 0,150 \\
\hline 0,05 & 0,000597833 & 0,00208 & 11,31 & 39,1 & 0,105 \\
\hline 0,05 & 0,000487833 & 0,00112 & 11,31 & 39,1 & 0,057 \\
\hline
\end{tabular}

Na tabela 5 apresenta-se a perda total do sistema.

Tabela 5-Perda total no sistema.

\begin{tabular}{|c|c|c|c|c|c|c|}
\hline Ensaio & Vazão (L/min) & Vazão(m $\left.{ }^{3} / \mathbf{s}\right)$ & Hman(m) & Hfr(m) & Hfs(m) & $\begin{array}{c}\text { Perda } \\
\text { total (m) }\end{array}$ \\
\hline 1 & 56,43 & 0,0009405 & 9,85 & 0,331 & 0,0261 & 0,3575 \\
\hline 2 & 53,1 & 0,000885 & 10,7 & 0,298 & 0,0235 & 0,3214 \\
\hline 3 & 50,5 & 0,000841667 & 11,5 & 0,273 & 0,0215 & 0,2943 \\
\hline 4 & 48,6 & 0,00081 & 12,4 & 0,255 & 0,0201 & 0,2752 \\
\hline 5 & 44,9 & 0,000748333 & 13,2 & 0,222 & 0,0175 & 0,2396 \\
\hline 6 & 42,7 & 0,000711667 & 14 & 0,203 & 0,016 & 0,2194 \\
\hline 7 & 40,31 & 0,000671833 & 14,9 & 0,184 & 0,0145 & 0,1984 \\
\hline 8 & 35,87 & 0,000597833 & 15,6 & 0,15 & 0,0118 & 0,1618 \\
\hline 9 & 29,27 & 0,000487833 & 17,2 & 0,105 & 0,0083 & 0,1133 \\
\hline 10 & 20,54 & 0,000342333 & 17,9 & 0,057 & 0,0045 & 0,0610 \\
\hline
\end{tabular}

Nas Figuras 5 e 6 são representados, respectivamente, a vista frontal do sistema proposto e a curva característica da bomba levantada experimentalmente. 
Figura 5- Detalhes do sistema

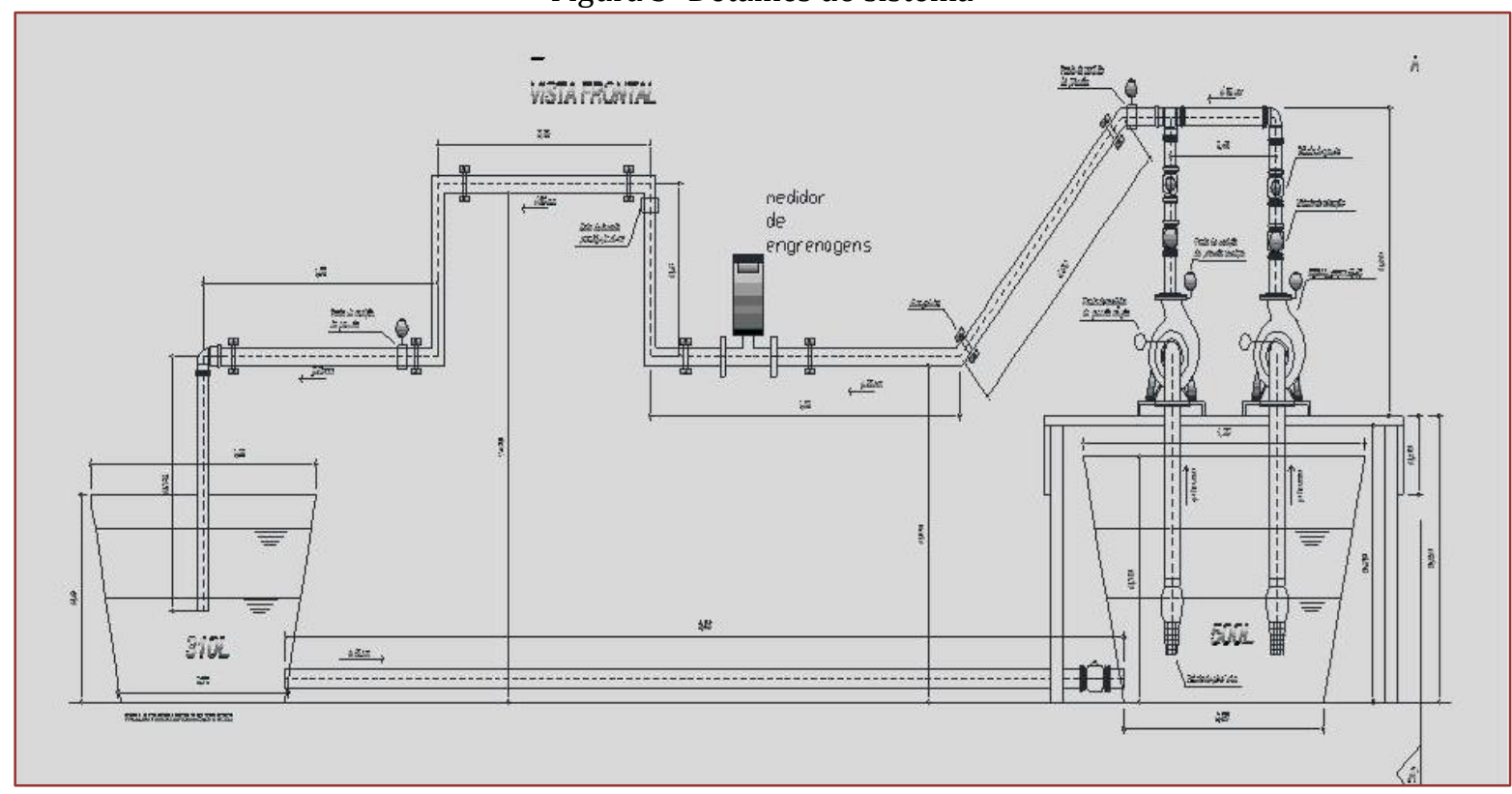

Figura 6- Curva característica experimental da bomba.

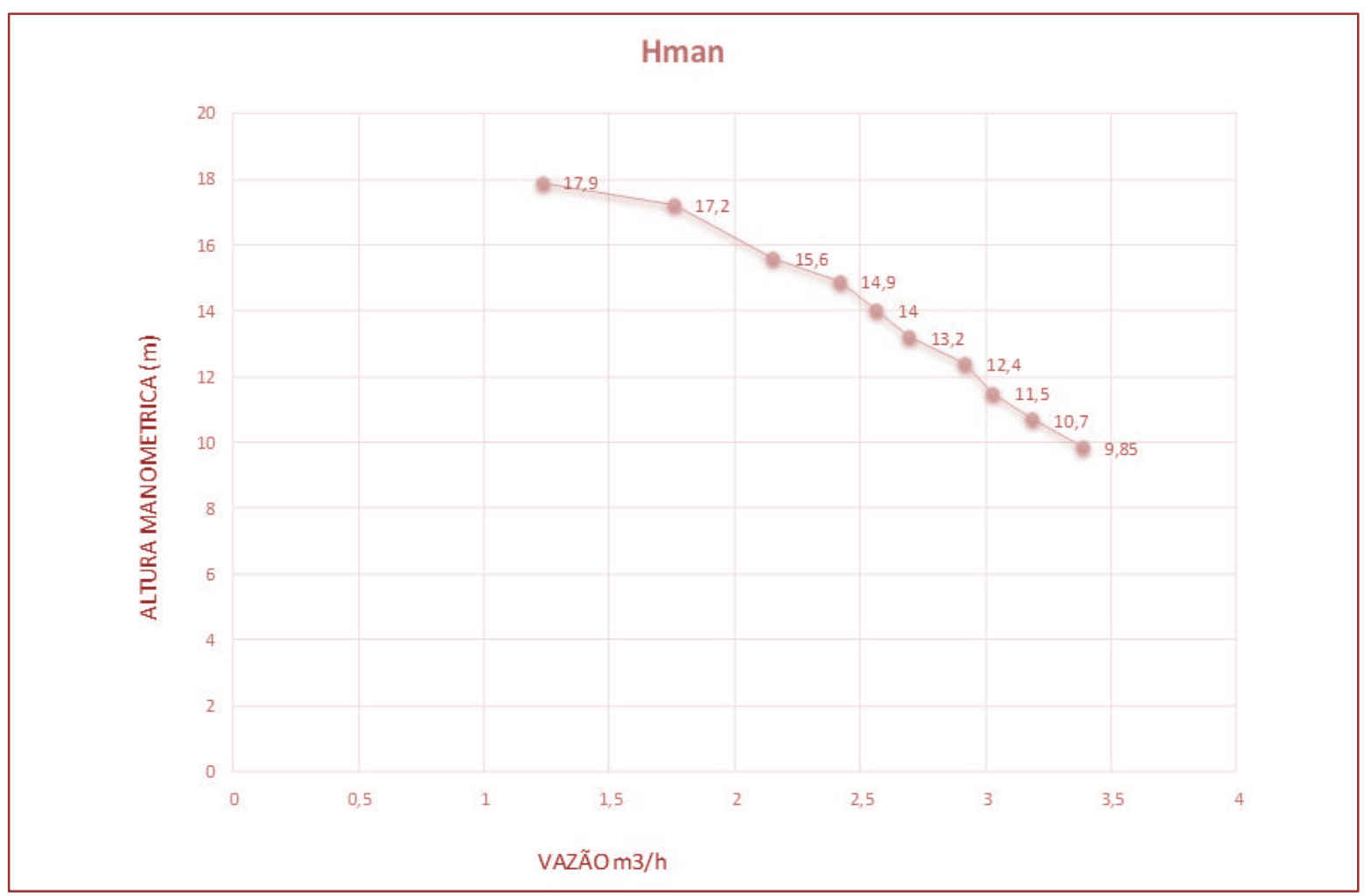

Comparando-se as Figuras 6 e 7, percebe-se que o rotor que mais se aproxima da curva da bomba levantada experimentalmente foi o de $195 \mathrm{~mm}$, para o modelo $25-200$ com $1750 \mathrm{rpm}$. 
Figura 7- curva do fabricante.

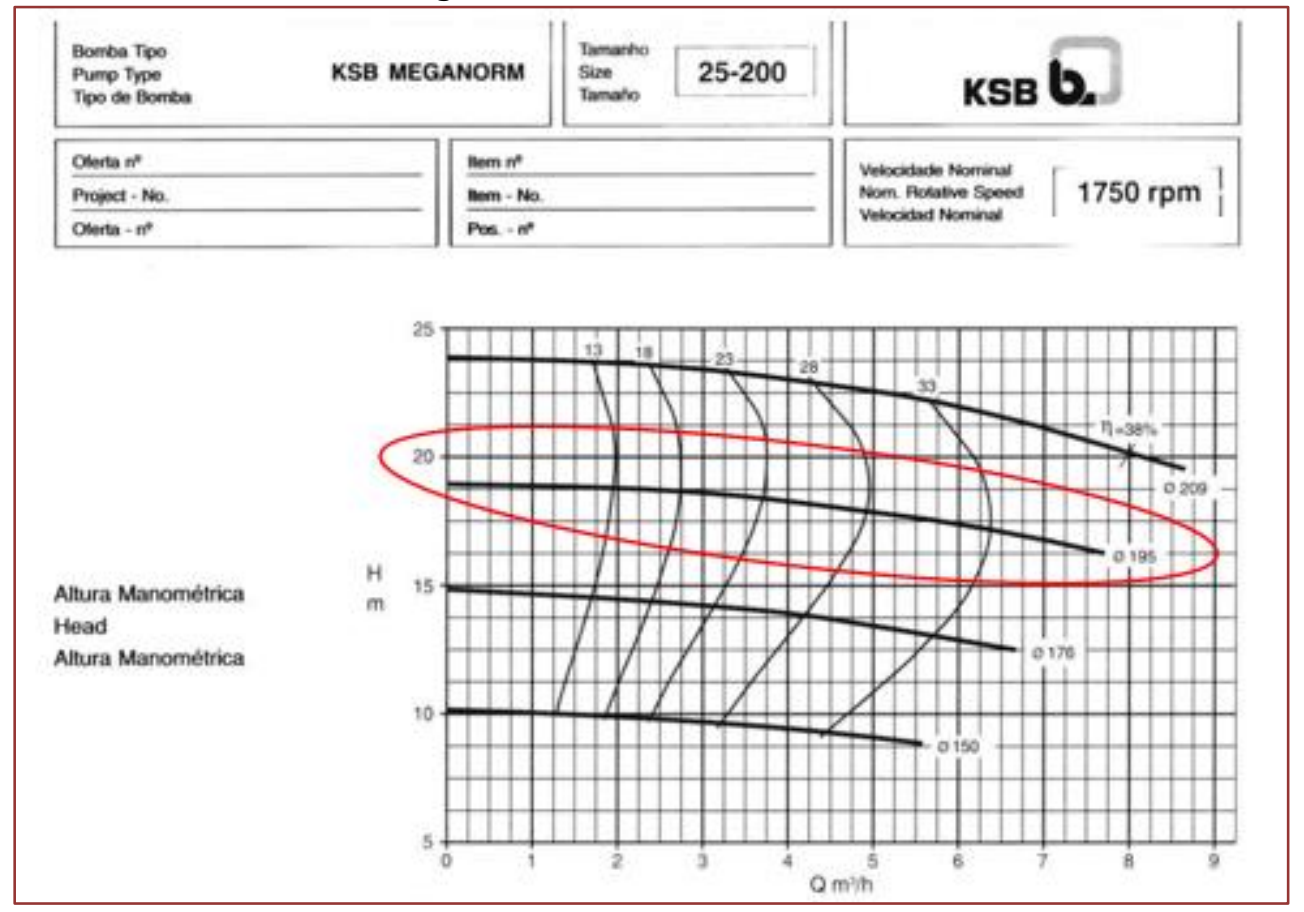

\section{BIBLIOGRAFIA}

[1] MANUAL DE CURVAS CARACTERISTAS KSB. http://www.ksb.com.br/ksb-br-pt/

[2] MACINTYRE, Archibald Joseph - Bombas e Instalações de Bombeamento. - Ed. Guanabara Dois, 1980 (Capítulos 3, 6 e 8).

[3] NETTO, J.M.A. Manual de hidráulica.8a Ed. São Paulo: Edgard Blucher,

[4] PORTO, R.M. Hidráulica Básica. São Carlos-SP, EESC-USP, 1999

[5] SILVESTRE, PASCHOAL - Hidráulica Geral - Livros Técnicos e Científicos Editora S.A., 1979 (Capítulos 9 e 12).

[6] http://www.ksb.com.br/frame.htm

[7] http://www.schneider.ind.br/

[8] http://www.thebe.com.br/ 


\section{Capítulo 8}

Aula prática: Carga fixa-poluição

Neyson Martins Mendonça 


\subsection{INTRODUÇÃO: QUALIDADE DA ÁGUA E OS TIPOS DE FONTES}

A água é usada para diversos fins, como consumo humano, lazer, irrigação, entre outros e nos dias atuais é considerada como uma "commodity" preciosa e cuja escassez tem sido tema de preocupação em diversos países em razão da disponibilidade dessa em termos de quantidade e de qualidade, frente as alterações climáticas e situações de desastres e emergências que possam acontecer.

A ANA menciona que no Brasil o conhecimento sobre a qualidade das águas está entre um dos mais relevantes e emblemáticos desafios a serem trabalhados com a devida atenção na área ambiental desse Pais, em decorrência de se ter informações esparsas ou inexistentes quanto ao monitoramento da qualidade dos corpos hídricos brasileiros, capazes de subsidiar um sistema de gestão hídrica fundamento numa economia ambientalmente sustentável e socialmente justa.

Um dos principais objetivos para implantação desse sistema de gestão hídrica permeia pela identificação das fontes pontuais que são locais fixos de descarga dos efluentes e das fontes não pontuais, também conhecidas como difusas que podem ocorrer devido ao escoamento superficial ou pela transferência da atmosfera para o sistema aquático.

Seja para fontes pontuais ou não pontuais, o que se deseja caracterizar é a variabilidade espaço-temporal da carga liberada para o corpo d'água receptor, a qual é normalmente expressa em unidades de massa por unidade de tempo para um dado conjunto de poluentes químicos, físicos e biológicos.

Assim no presente capítulo será tratado o procedimento técnico prático para se obter a carga de poluição oriunda de fonte pontual de descarga de efluente, tendo por base as notas de aulas da Disciplina TE06144 - Qualidade da Agua do Curso de Engenharia Sanitária e Ambiental da UFPA.

\subsection{OBJETIVOS INSTRUCIONAIS}

Ao final desta aula prática de caracterização de fonte fixa de poluição para descarga dos efluentes o discente deverá ser capaz de:

1). Identificar os locais para medição da descarga dos efluentes (bruto ou tratado);

2). Identificar os principais dispostos e/ou equipamentos para caracterização de fonte fixa de poluição;

3). Obtenção do volume representativo de amostra composta para caracterização de fonte fixa de poluição;

4). Organizar e tratar os dados mensurados em campo para se obter a descarga de poluição para fonte pontual fixa.

\subsection{MÉTODO DE MEDIÇÃO DA CARGA FIXA DE POLUIÇÃO}

O método de medição da carga fixa de poluição segue as diretrizes da NBR 13402 da ABNT (1995) que versa sobre caracterização de cargas poluidoras em efluentes líquidos industriais e domésticos, e que para aplicação desse necessita que se observe sobre os seguintes aspectos principais, a saber:

-Demarcação de ponto de coleta: 0 ponto de coleta deve estar situado necessariamente no efluente da fonte geradora da carga poluidora;

-Determinação de vazão: deve ser efetuada utilizando-se dispositivos adequados, como: calha Parshall, calha palmer bowlus, e medidor de vazão eletromagnético. 
Tabela 1. Principais equipamentos de medição de vazão de acordo com o tipo de escoamento em conduto forçado ou livre.

Equipamento de medição de vazão
Medidor de vazão eletromagnético (MQE): esse equipamento aplica o princípio de medição de vazão com base na lei de Faraday que indica a tensão do sinal (E) é dependente da velocidade média do líquido (v) da intensidade do campo magnético (B) e do comprimento do condutor (D) associada a equação da continuidade $Q=A$. v, para mensurar a vazão em $\mathrm{m}^{3} / \mathrm{h}$ tubulações;

Calha Palmer Bowlus: esse dispositivo de medição de vazão é utilizado para tubos parcialmente cheios, o qual pode ser acoplado diretamente na tubulação de líquidos fluindo por gravidade para em conjunto com medidor de nível ultrassônico registrar a distância entre o transdutor e a superfície monitorada (lâmina de água), cujo valor é posteriormente inserido em formulação para obtenção da vazão $\left(\mathrm{m}^{3} / \mathrm{h}\right)$;

Calha Parshall: esse dispositivo consiste numa seção convergente, numa seção estrangulada "garganta" e uma seção divergente, dispostas em planta. 0 escoamento do fluido submetido a essa unidade é tranquilizado em sua seção convergente evitando os efeitos da velocidade, a partir de então com auxílio de medidor de nível ultrassônico se registra a distância entre o transdutor e a superfície monitorada (lâmina de água), cujo valor é posteriormente inserido em formulação para obtenção da vazão $\left(\mathrm{m}^{3} / \mathrm{h}\right)$.

-Definição das variáveis de poluição de interesse a serem determinadas: considerando a fonte pontual quanto a origem doméstica ou industrial e a legislação ambiental brasileira em termos do conjunto de poluentes químicos, físicos e biológicos para se caracterizar a carga poluidora gerada, recomenda-se a princípio realizar a análise de todos os contaminantes prováveis de serem encontrados, mediante consulta a Tabela 8 do Guia nacional de coleta e preservação de amostras CETESB (2011) e/ou a Tabela 1 da NBR 13402 da ABNT (1995). A

Tabela 2 a seguir ilustra exemplo de agrupamento de variáveis físico-químicas e os exames microbiológicos para monitoramento de lixiviado em aterro sanitário

Tabela 2. Grupo de variáveis físico-químicas e os exames microbiológicos para monitoramento de lixiviado em aterro sanitário.

\begin{tabular}{|c|c|}
\hline Grupo de variáveis físico-químicas e os exames microbiológicos & Legislação e/ou Referência técnica \\
\hline $\begin{array}{l}\text { Grupo 0: pH, Temperatura, SD (sólidos sedimentáveis), } \\
\text { DBO5,20C, OG (minerais) e OG (vegetais) }\end{array}$ & $\begin{array}{l}\text { Resolução CONAMA № 430/2011 } \\
\text { (Art 16. Condições de Lançamento) }\end{array}$ \\
\hline $\begin{array}{l}\text { Grupo 1: Arsênio (As), Bário (Ba), Boro (B), Cádmio (Cd), } \\
\text { Chumbo (Pb) } \\
\text { Cobre (Cu) dissolvido, Estanho total (Sn), Fe (Fe) dissolvido, Mn } \\
\text { (Mn) dissolvido, Mercúrio (Hg), Prata (Ag), Selênio (Se), Níquel } \\
\text { (Ni), Nitrogênio amoniacal total, Prata total (Ag), Selênio total } \\
\text { (Se), Sulfeto (S) e Zinco (Zn) }\end{array}$ & $\begin{array}{l}\text { Resolução CONAMA No 430/2011 } \\
\text { (Tabela I- Condições de Lançamento -Parâmetro } \\
\text { inorgânico) }\end{array}$ \\
\hline $\begin{array}{l}\text { Grupo 2: Benzeno, Clorofórmio, Dicloroeteno, Estireno, } \\
\text { Etilbenzeno, Fenóis totais, Tetracloreto de carbono, } \\
\text { Tricloroeteno, Tolueno e Xileno }\end{array}$ & $\begin{array}{l}\text { Resolução CONAMA № } 430 / 2011 \\
\text { (Tabela I- Condições de Lançamento -Parâmetro } \\
\text { orgânico) }\end{array}$ \\
\hline $\begin{array}{l}\text { Grupo 3: ST (Fixo e volátil), SST (Fixo e volátil), Condutividade, } \\
\text { AT, Cor aparente, Turbidez, Dureza Total }\left(\mathrm{Ca}^{2+} ; \mathrm{Mg}^{2+}\right) \text {, NTK, P, } \\
\text { Sulfato, Cloreto (Cl-), DQOB, DQO }{ }_{\text {, }} \text { Cloro* } \mathrm{THM}^{*} \mathrm{TH}^{*} \\
\text { Nota:*Quando se faz cloração no efluente tratado }\end{array}$ & $\begin{array}{c}\text { Usuais para controle da ETE e tem valores de } \\
\text { referência estabelecidos para níveis de restrições } \\
\text { dos padrões de lançamento (DAE artigo edição } 215 \\
\text { № 1764) }\end{array}$ \\
\hline $\begin{array}{l}\text { Grupo 4: Coliformes totais e E.coli; } \\
\text { Nota: Em relação ao Grupo 4, critérios relativos a reuso } \\
\text { também irão ser observados. }\end{array}$ & $\begin{array}{l}\text { Resolução CONAMA № 357/2005 } \\
\text { Resolução CONAMA № 274/2001 }\end{array}$ \\
\hline
\end{tabular}

- Finalizado a definição das variáveis de poluição de interesse a determinação da carga fixa de poluição, deve ser realiza para cada variável, utilizando-se o equacionamento a seguir:

$$
P_{C F}=C . Q . f
$$




\section{Em que:}

$\mathrm{P}_{\mathrm{CF}}$ : carga poluidora fixa, em $\mathrm{kg} / \mathrm{dia}$;

C: concentração, em mg/L;

$\mathrm{Q}=$ vazão, $\mathrm{em} \mathrm{m}^{3} / \mathrm{s}$

$\mathrm{f}=$ fator de conversão de unidade $(86,4)$

De acordo com a NBR 13402 da ABNT (1995) quando se trabalhar com um número (n) reduzido de amostra (mínimo de seis para cada ponto), a determinação da carga poluidora $\mathrm{P}_{\mathrm{CF}}$ deve ser calculada considerando as seguintes equações:

$$
\begin{aligned}
& \mathrm{P}_{\mathrm{CF}-\text { máx }}=\left(\overline{\mathrm{Q}}+\frac{\mathrm{t} \cdot \mathrm{S}_{\mathrm{Q}}}{\mathrm{n}}\right) \cdot\left(\overline{\mathrm{C}}+\frac{\mathrm{t} \cdot \mathrm{S}_{\mathrm{C}}}{\mathrm{n}}\right) \\
& \mathrm{P}_{\mathrm{CF}-\text { mín }}=\left(\overline{\mathrm{Q}}-\frac{\mathrm{t} \cdot \mathrm{S}_{\mathrm{Q}}}{\mathrm{n}}\right) \cdot\left(\overline{\mathrm{C}}-\frac{\mathrm{t}_{\mathrm{S}}}{\mathrm{n}}\right) \\
& \mathrm{P}_{\mathrm{CF}}=\left(\frac{\mathrm{P}_{\mathrm{CF}-\text { máx }}+\mathrm{P}_{\mathrm{CF}-\mathrm{m} \text { n }}}{2}\right)
\end{aligned}
$$

Em que:

$\mathrm{P}_{\mathrm{CF}}$ : carga poluidora fixa;

Q: média aritmética de vazão;

$\mathrm{S}_{\mathrm{Q}}$ : desvio padrão para vazão;

C: média aritmética de concentração;

$S_{\mathrm{c}}$ : desvio padrão para concentração;

t: coeficiente de Student (ver Tabela 2 da NBR 13402 da ABNT (1995);

n: número de amostra.

- E para a obtenção do volume representativo de amostra para caracterização de fonte fixa de poluição, se utiliza o equacionamento previsto pela CETESB (2011), conforme se pode observar a seguir:

$$
\mathrm{V}_{\mathrm{AL}}=\left(\frac{\mathrm{Q}_{\mathrm{i}} \cdot \mathrm{V}_{\mathrm{AC}}}{\overline{\mathrm{Q}} \cdot \mathrm{n}}\right)
$$

Em que:

Qi: vazão do horário (L/s);

$\bar{Q}$ : vazão média (L/s);

$\mathrm{n}=$ numero de determinações;

$\mathrm{V}_{\mathrm{AL}}=$ volume de alíquota de amostra correspondente ao horário $(\mathrm{mL})$;

$\mathrm{V}_{\mathrm{AC}}=$ volume de amostra composta $(\mathrm{mL})$. 


\subsection{ANTES DA MEDIÇÃO DA CARGA FIXA DE POLUIÇÃO}

Deve-se separar os seguintes materiais antes de se deslocar para o local de medição:

21) Protetor solar;

22) Tenda ou guarda sol e cadeiras;

23) Planilha de campo (Apêndice 1), prancheta, caneta e lapiseira;

24) Identificação no local de medição do dispositivo de vazão que será utilizado para media da descarga: calha Parshall, calha palmer bowlus, e medidor de vazão eletromagnético;

25) 50 Frascos PP (plástico de polipropileno autoclávavel) com graduação com tampa rosqueável antivazamento para armazenamento de $250 \mathrm{~mL}$ devidamente rotulados e identificados;

26) Caixa isotérmica com dimensional de $39,5 \mathrm{~cm} \times 27,5 \mathrm{~cm} \times 34 \mathrm{~cm}$ e gelo;

27) Termômetro Infravermelho Digital de LCD Portátil para faixa de medição de $-2^{\circ} \mathrm{C}$ a $40^{\circ} \mathrm{C}$;

28) Par luva de nitrilo preta sem pó descartável (Tamanho: P, M ou G);

Não esqueça de estar vestido adequadamente de calça, botas, camisa confortável, óculos de proteção solar e chapéu/boné. Também fiquem atentos para fazer registros fotográficos em todas as etapas.

\subsection{ATIVIDADES EM CAMPO}

Nesta atividade de campo será mensurada a descarga do efluente bruto e o volume representativo de amostra composta para caracterização de fonte fixa de poluição, para isso inicialmente serão formados 04 grupos contendo cinco 5 alunos para numa dada estação de tratamento de esgoto (ETE), identificarem o local de chegada da descarga do efluente e o equipamento de medição de vazão utilizado nessa unidade, mediante a elaboração do fluxograma das etapas que ocorrem nessa unidade tanto para a fase líquida como sólida.

A seguir, os grupos de alunos serão divididos por turnos de medição, obedecendo a seguinte ordem: Grupo 1-7:00 h até 9:30 h; Grupo 2-10:00 h até 12:30 h; Grupo 3-13:00 h até 15:30 h e Grupo 4-16:00 h até 18:30 h.

Cada grupo de medição, deverá em seu turno, realizar seis (06) leituras de medição de vazão e a obtenção mediante coleta simples de seis (06) amostras do efluente bruto com auxílio de coletor manual, para transferência dessas para os frascos PP de $250 \mathrm{~mL}$, acondicionados com gelo na caixa isotérmica, para posterior envio das amostras para laboratório de análises e determinação da demanda química de oxigênio (DQO).

Em cada grupo de medição, um (01) aluno deverá ser responsável pelo registro de fotográfico e preenchimento da ficha de campo, dois (02) alunos deveram ficar dedicados a medição de vazão e os dois (02) alunos restantes ficam envolvidos com a coleta de amostras do efluente bruto para obtenção da DQO.

\subsection{TRATAMENTO DOS DADOS OBTIDOS EM CAMPO}

Todos os dados obtidos nas atividades em campo devem ser organizados em planilha eletrônica Excel ou equivalente e trabalhados para a determinação da carga fixa de poluição e do volume representativo de amostra composta para caracterização de fonte fixa de poluição, mediante o uso do equacionamento descrito no item 8.3 do capitulo em questão.

E utilizando o Microsoft Excel ou Microsoft Minitab o tratamento de dados deverá conter os seguintes itens principais:

a) Estatística descritiva para vazão e DQO: número de determinações (n), máximo (máx), médio (x), mínimo (mín), desvio padrão (DP) e coeficiente de variação (x/DP);

b) Construir gráficos do comportamento temporal da vazão e da DQO;

c) Determinação da carga poluidora fixa (média e mediana), máxima e mínima; 
d) Obtenção do volume representativo de amostra composta, considerado as seguintes condições: Grupo 1-1.500 mL; Grupo 2-2.730 mL, Grupo 3-3.850 mL.e Grupo 4-835 mL.

e) Construir gráfico do comportamento temporal do volume de alíquota de amostra correspondente ao horário;

\section{BIBLIOGRAFIA}

[1] ABNT (1995). NBR 13.402- Caracterização de cargas poluidoras em efluentes líquidos industriais e domésticos. $7 \mathrm{p}$.

[2] ABNT (1995). NBR 13.403- Medição de vazão em efluentes líquidos e corpos receptores -Escoamento livre.

$7 \mathrm{p}$.

[3] APHA, AWWA and WPCF (1998) Standard Methods for the Examination of Water and Wastewater, 20a ed., Washington, D.C., Estados Unidos;

[4] Brasil (2005) Resolução CONAMA no 274, Define os critérios de balneabilidade em águas brasileiras, do Conselho Nacional do Meio Ambiente-CONAMA, 3p;

[5] Brasil (2005) Resolução CONAMA no 357, Dispõe sobre a classificação dos corpos de água e diretrizes para o seu enquadramento, bem como estabelece as condições e padrões de lançamento de efluentes, e dá outras providências, do Conselho Nacional do Meio Ambiente-CONAMA, 23p;

[6] Brasil (2011) Resolução CONAMA N. 430. Dispõe sobre as condições e padrões de lançamento de efluentes, complementa e altera a Resolução no 357, de 17 de março de 2005, do Conselho Nacional do Meio AmbienteCONAMA, 7p;

[7] CETESB (2011) Guia Nacional de Coleta e Preservação de Amostras: Água, Sedimento, Comunidades Aquáticas e Efluentes Líquidos. Companhia Ambiental do Estado de São Paulo, Organizadores: Carlos Jesus Brandão et al. São Paulo: CETESB, Brasília (DF) ANA, 326 pg.;

[8] Metcalf and Eddy (2003). Wastewater Engineering: Treatment, Disposal and Reuse 4.ed., New York, McGrawHill,Inc, 1819p.

[9] Mihelcic, J.R. \& Zimmerman, J.B. (2010). Engenharia Ambiental: Fundamentos, Sustentabilidade e Projeto. LTC, Rio de Janeiro, 617p.

[10] Triola, M.F. (2008) Introdução a estatística. 10 Edição, Rio de Janeiro, LTC, 696 pg. 


\section{APÊNDICE}

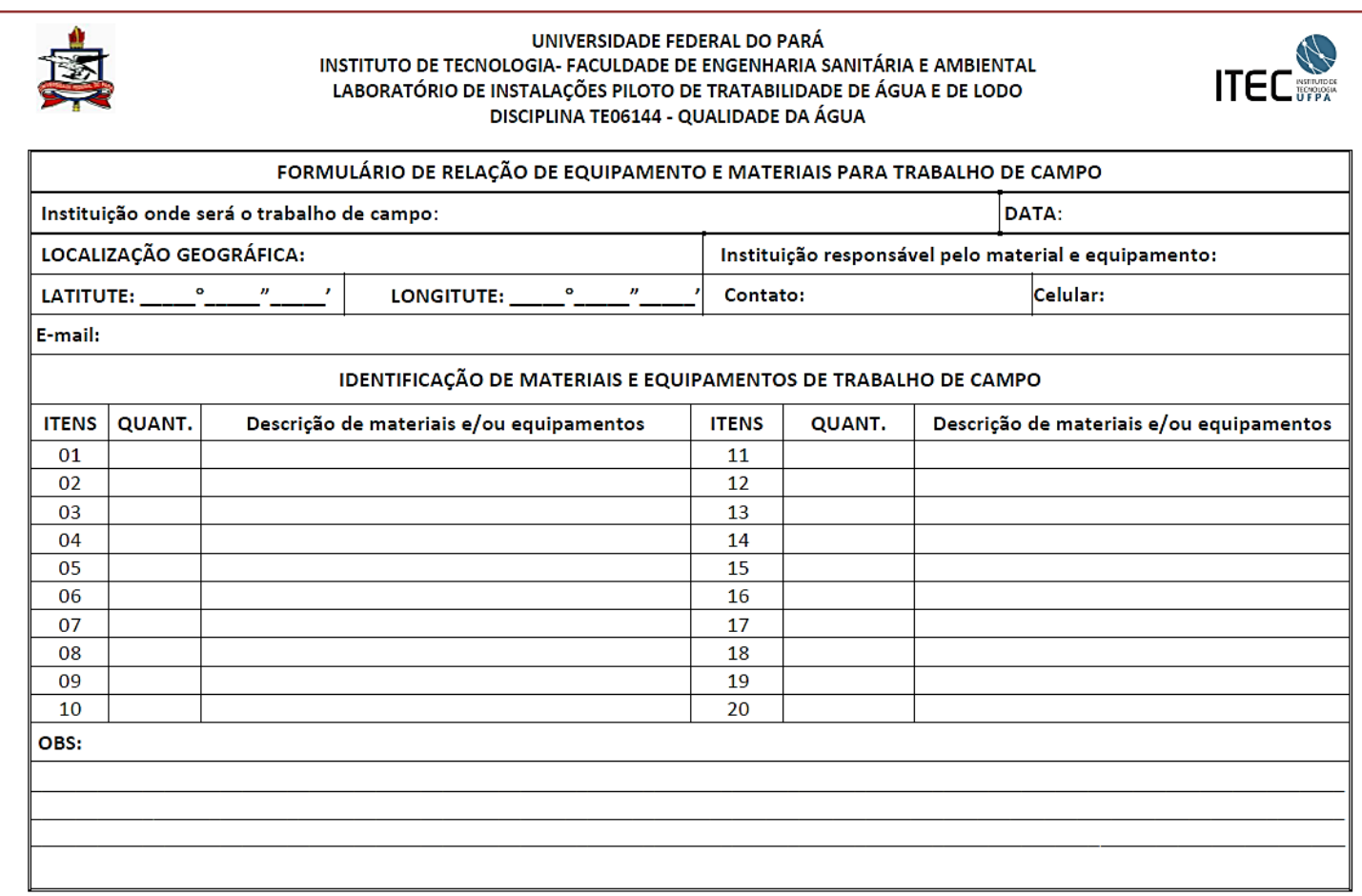

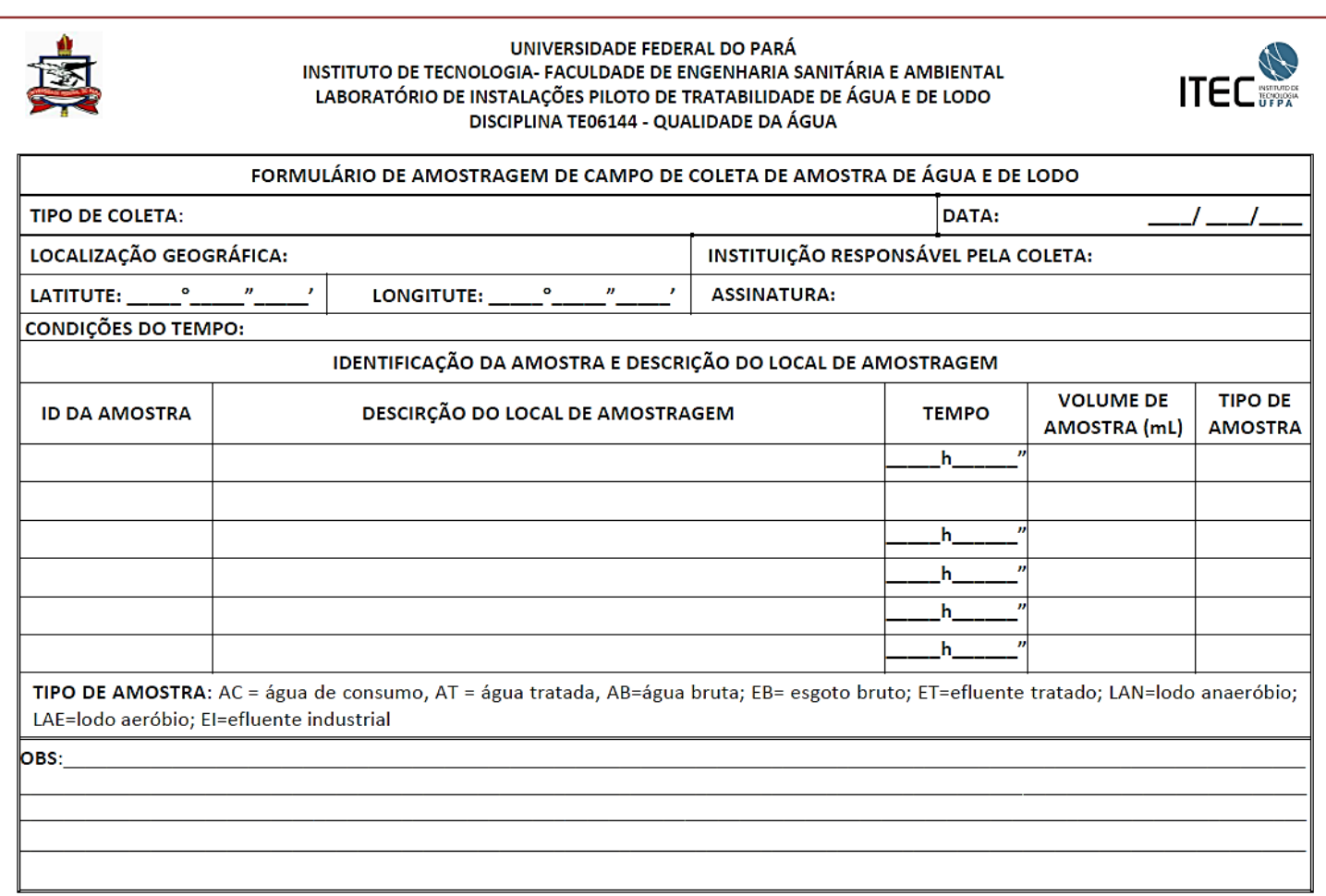




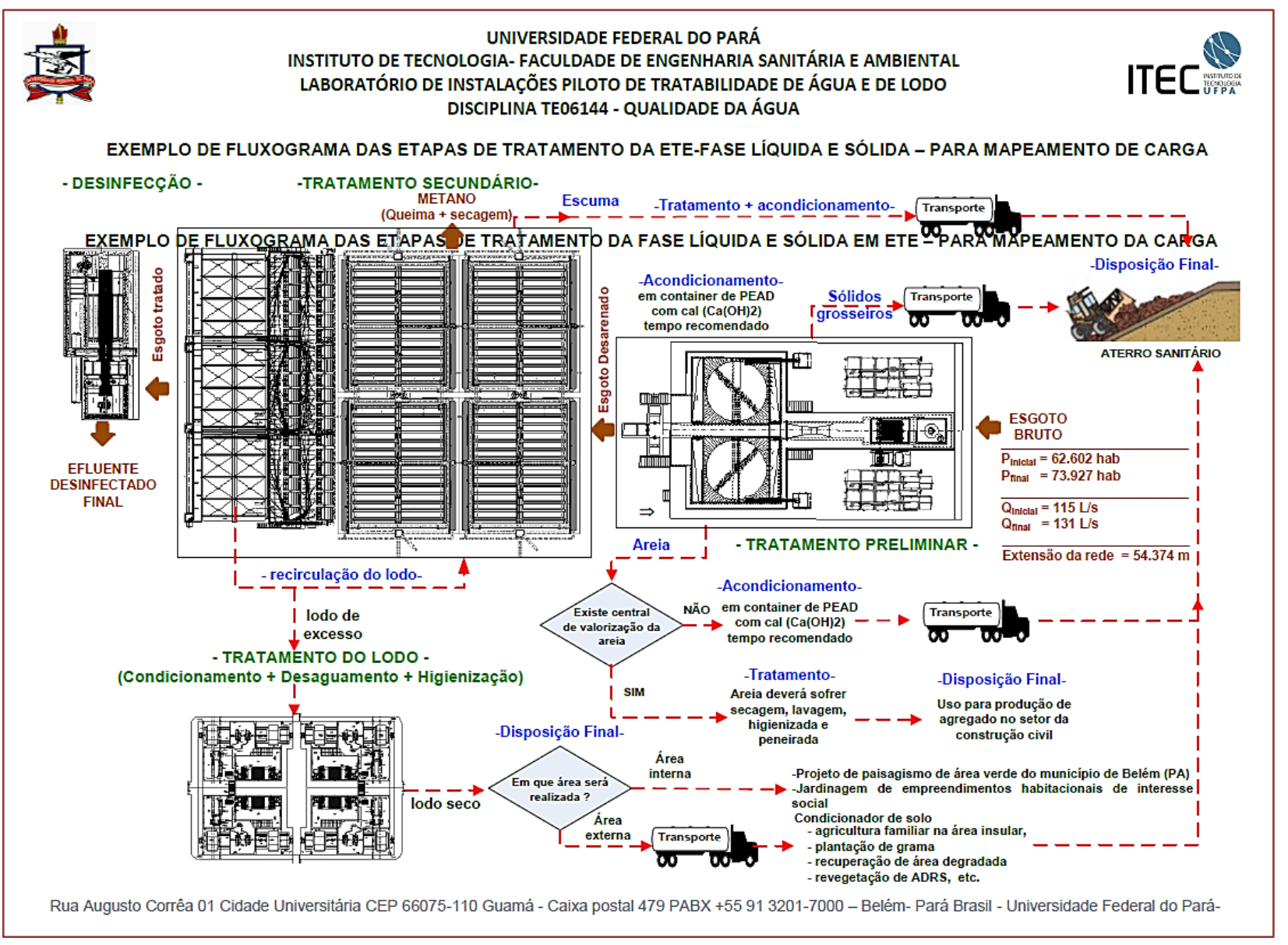




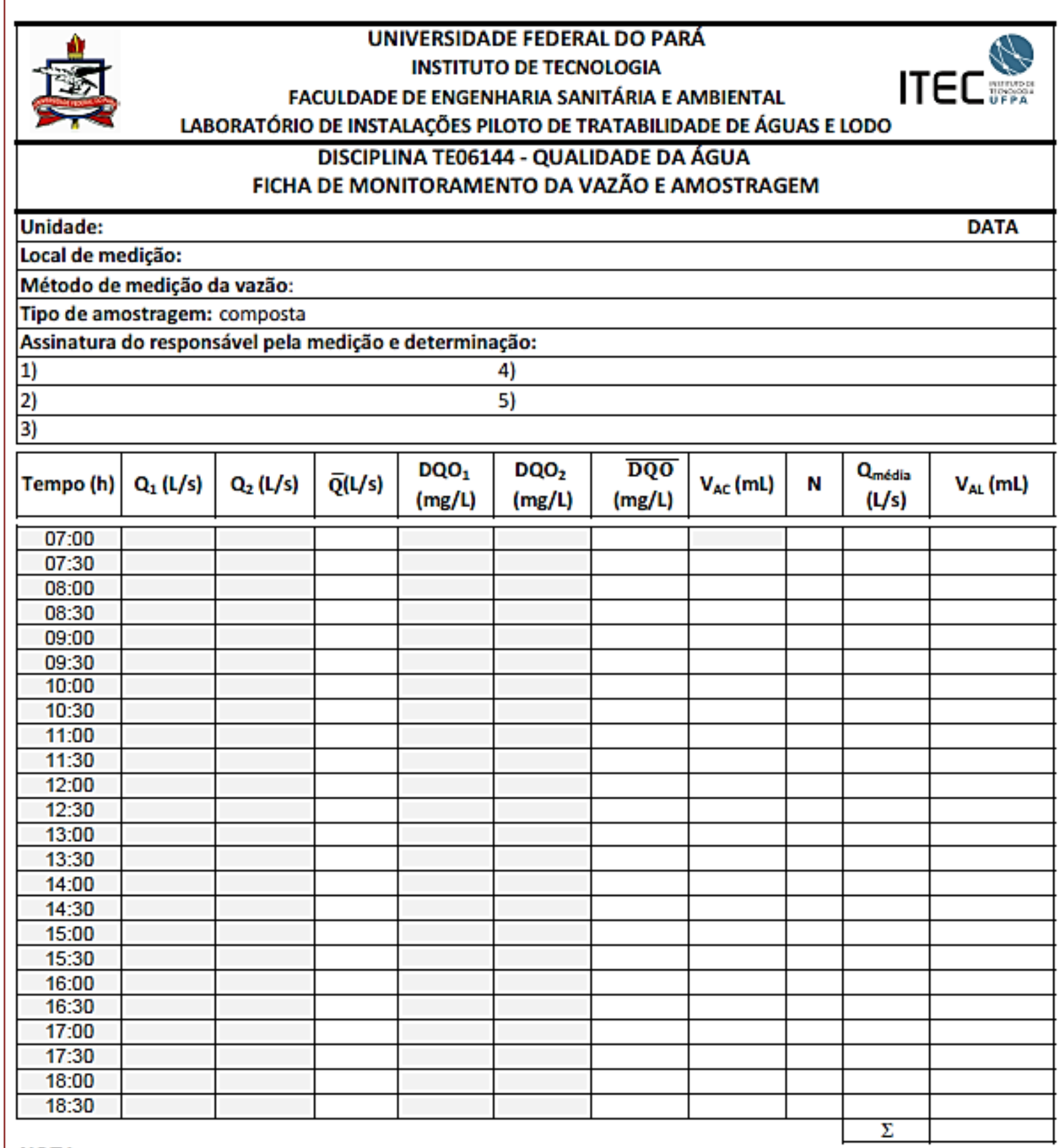

NOTA:

Preencher os campos em cinza para se obter as informações desejadas 


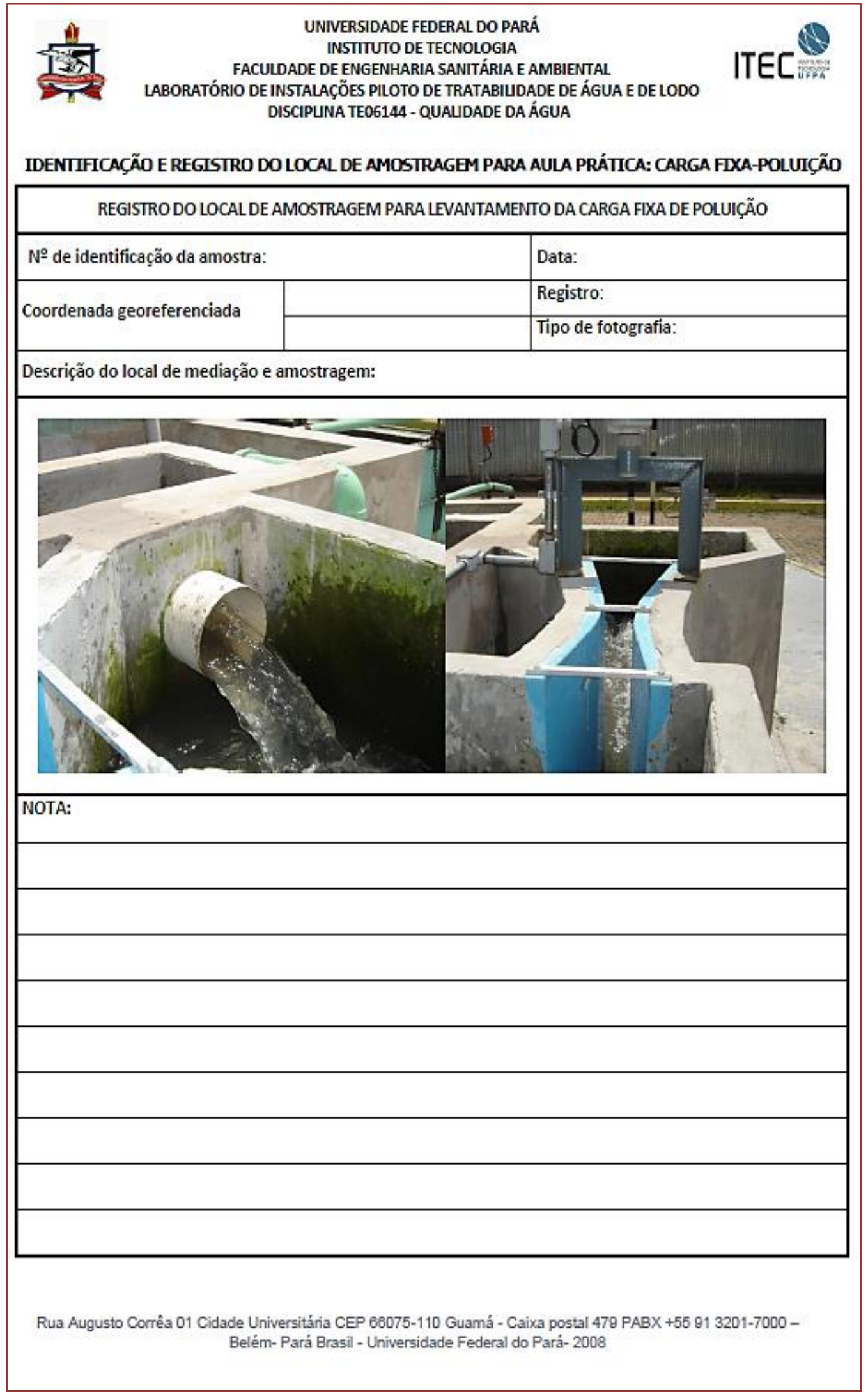




\section{Capítulo 9}

Aula prática: Ensaio de adensamento por gravidade em batelada de lodo de eta

Luiza Girard Teixeira Marcia Uchôa Matos 


\subsection{OBJETIVOS INSTRUCIONAIS}

Ao final desta aula prática de ensaio de adensamento por gravidade em batelada de lodo de Estação de Tratamento de Água - ETA você deverá ser capaz de:

1) Compreender o conceito de adensamento por gravidade de lodo de ETA e as variáveis envolvidas no processo;

2) Realizar o ensaio de adensamento por gravidade em batelada de lodo de ETA;

3) Avaliar os resultados obtidos.

\subsection{ADENSAMENTO POR GRAVIDADE DE LODO DE ETA}

Segundo a NBR 10004 (ABNT, 1987) os lodos gerados nas ETAs são classificados como resíduos sólidos e, portanto, devem ser disposto sem ocasionar danos ao meio ambiente.

As características dos lodos de ETAs podem variar com o processo de tratamento e depende de fatores como: qualidade da água bruta, tecnologia de tratamento, características da coagulação, floculação e filtração, uso de oxidante, método de limpeza de decantadores e filtros, entre outros (DI BERNARDO et al., 2011).

O tratamento desse lodo visa justamente obter um estado sólido ou semi-sólido, removendo a água para concentrar os sólidos, diminuindo seu volume e assim gerar condições adequadas para a sua disposição final (RICHTER, 2001). A primeira etapa para o tratamento deste resíduo é denominada de adensamento, que consiste na concentração de sólidos presentes no lodo, ou seja, visa remover o máximo de água possível do lodo, preparando-o para a etapa posterior de desidratação.

0 adensamento de lodos de ETAs pode ser executado por gravidade, por flotação com ar dissolvido ou por meio de adensadores mecânicos do tipo centrífugas ou esteira. Cada um apresenta vantagens e desvantagens e devem ser levados em consideração seus aspectos econômicos e técnicos para a determinação de parâmetros de projeto de cada processo unitário. Assim, a concepção e o dimensionamento corretos do sistema de adensamento são de suma importância no sucesso operacional do sistema de tratamento do lodo.

O adensamento por gravidade é o mais utilizado devido a simplicidade de operação e ao baixo consumo de energia. Além disso, pode servir como uma unidade de equalização.

Os adensadores podem ser operados de forma contínua ou por batelada. São normalmente unidades circulares com um mecanismo de raspagem de lodo no fundo. Em adensadores contínuos, o lodo entra pela parte central e se distribui radialmente. 0 sobrenadante é retirado pela parte superior através de vertedores. 0 fundo deve possuir uma inclinação de modo a facilitar a coleta de lodo adensado. Os adensadores por batelada são frequentemente equipados com tubulações de descarga e normalmente dois tanques operam em paralelo. 0 lodo é colocado em uma unidade até atingir o nível de operação. Após um determinado período, o sobrenadante é retirado, e o lodo é bombeado para posterior tratamento e disposição final. 0 sobrenadante do processo de adensamento pode ser retornado ao início da ETA.

Os lodos gerados nas ETA's são, em sua maioria, de difícil desidratação, tornando-se necessário o seu condicionamento para a melhoria de suas características de adensamento e posterior desidratação. 0 condicionamento químico é o mais utilizado, tanto para o processo de adensamento quanto para o de desidratação. 0 processo pode ocorrer pela adição de cloreto férrico, cal ou polímeros. 0 tipo e a dosagem de condicionante variam com a qualidade da água bruta, com o tipo de tratamento e com o processo de desidratação a ser utilizado (AWWA, 1996).

Os polímeros são os produtos mais utilizados no condicionamento de lodos provenientes de ETA's. A popularidade dos polímeros se deve à sua facilidade de manuseio, necessidade de pequeno espaço para armazenamento e sua eficiência. Podem ser catiônicos, não iônicos ou aniônicos, de acordo com a carga de seus grupos funcionais, e de baixo, médio ou alto peso molecular. Os mais utilizados para o condicionamento são os de alto peso molecular, e atuam pelo processo de formação de pontes interparticulares (AWWA,1989). YUZHU (1996) afirma que a carga tem a mesma importância do peso molecular, e que a seleção do polímero depende de testes com o lodo específico. Na Tabela 1 podem-se observar valores típicos de dosagem de polímeros. 
Tabela 1 - Dosagens típicas de polímeros usadas no condicionamento

\begin{tabular}{|c|c|c|}
\hline Tipo de lodo & Dosagem (g/kg ST) & Referência \\
\hline Lodos de $\mathrm{Al} \mathrm{e} \mathrm{Fe}$ & $1-10$ & Montgomery (1985) \\
\hline Lodos de $\mathrm{Al}$ & $1-10$ & Yuzhu (1996), Matos et al. (2013) \\
\hline Lodos de Fe & $2-8$ & Teixeira (1999), AWWA (1996) \\
\hline
\end{tabular}

Para dimensionamento dos adensadores por gravidade necessita-se definir a Velocidade de Sedimentação e Zona (VSZ), ou seja, a velocidade da interface na primeira fase da sedimentação e das condições do adensamento até o teor de sólidos totais desejados (DIBERNARDO et al., 2002). As relações mais usadas para se prever o comportamento da VSZ em relação à concentração de sólidos são:

$$
\begin{array}{ll}
V=A \cdot e^{-B x} & \text { Eq.(1) } \\
V=A \cdot x^{-B} & \text { Eq.(2) }
\end{array}
$$

onde: $\mathrm{A}$ e $\mathrm{B}=$ constantes;

$\mathrm{X}=$ Concentração de sólidos $\left(\mathrm{M} \cdot \mathrm{L}^{-3}\right)$;

$\mathrm{V}=$ velocidade de sedimentação em zona (L.T-1 ${ }^{-1}$;

$\mathrm{e}=$ base neperiana.

A equação (1) foi citada por GREGORY (1979) apud AWWA (1990) e a equação (2) por MONTGOMERY (1985). De acordo com a AWWA (1990), a equação (1) é a mais usada e a que tem apresentado melhores resultados.

A obtenção dos coeficientes A e B é feita através de ensaios de sedimentação por batelada, objeto desta aula prática. A coluna de sedimentação deve ter pelo menos $1 \mathrm{~m}$ de altura e $10 \mathrm{~cm}$ de diâmetro, de modo a reduzir a discrepância entre os valores encontrados em laboratório e os em escala real.

A coluna após preenchida com lodo é deixada em repouso, e são registrados os valores da altura da interface ao longo do tempo. 0 procedimento é repetido para os teores de sólidos. A velocidade de sedimentação deve ser calculada como a tangente do trecho inicial retilíneo, que terá valor negativo, já que o movimento da interface é descendente.

De posse desses valores obtêm-se um gráfico da velocidade de sedimentação em função da concentração de sólidos.

A equação da velocidade de sedimentação é calculada através da linearização da equação (1) resultando na equação (3):

$$
\ln V=\ln A-B . x \quad \text { Eq.(3) }
$$

Os coeficientes A e B são determinados através da curva de regressão linear dos pontos obtidos nos ensaios de sedimentação em batelada.

\subsection{ENSAIO DE ADENSAMENTO POR GRAVIDADE EM BATELADA DE LODO DE ETA}

Nossa aula prática acontecerá no laboratório Multiusuário de Tratabilidade de Águas -LAMAG e no Laboratório de Instalações Piloto- LAPIL, coordenado pelo Grupo de Estudos em Gerenciamento de Águas e Reúso de Efluentes - GESA, localizados no Laboratório de Engenharia Sanitária e Ambiental - LAESA da Universidade Federal do Pará - UFPA.

\subsubsection{CARACTERIZAÇAO DO LODO DE ETA COLETADO}

Uma bombona de lodo de ETA com 5 Litros estará previamente à disposição para a realização da caracterização. Para tal, deverá ser realizado o seguinte procedimento: 
Homogeneizar o conteúdo das bombonas e retirar 3 amostras de lodo;

- Determinar o teor de sólidos totais de cada amostra de acordo com o método descrito em APHA, AWWA, WEF (2005).

- Calcular a média aritmética dos três valores obtidos que será designado TST (teor de sólidos totais do lodo)

Nesta etapa você vai precisar:

3 cápsulas de porcelana de $100 \mathrm{~mL}, 1$ dessecador completo, 1 estufa, 1 proveta de vidro de $100 \mathrm{~mL}, 1$ pisceta com água destilada e 1 balança de precisão com 4 casas decimais.

\subsubsection{CONDICIONAMENTO DO LODO}

A seleção do polímero será feita seguindo sugestões do fabricante (de acordo com a disponibilidade do produto) para uso em lodo de ETA. Assim sendo, será testado um polímero em duas dosagens distintas pré-determiandas: 1 e $4 \mathrm{~g} / \mathrm{kg}$, que são, segundo a literatura, as dosagens comumente utilizadas no précondicionamento de lodos de ETAs (TEIXEIRA et al, 1997). O preparo da solução de polímero estará descrito no item 1.3.3.

\subsubsection{ENSAIO DE ADENSAMENTO EM BATELADA}

Os ensaios serão conduzidos em coluna de adensamento com 1,00 m de altura e $20 \mathrm{~cm}$ de lado (Figura 1). A coluna é graduada com a utilização de uma fita métrica fixada à superfície externa da mesma. 0 volume útil da coluna é de 20 litros, fazendo com que a altura do nível d'água seja de $51 \mathrm{~cm}$. Para este trabalho, adotou-se um valor médio de G.T (Gradiente de velocidade e tempo de mistura) de 3000, baseado em Teixeira (1999), o que resulta na rotação de $115 \mathrm{rpm}$, de modo a se evitar a quebra dos flocos previamente formados durante o pré-condicionamento. Na Figura 2 são mostradas as dimensões da palheta do agitador utilizado no ensaio. Serão realizados 3 ensaios de sedimentação de acordo com o estabelecido na Tabela 2.

Figura 1 - Coluna para ensaio de sedimentação.

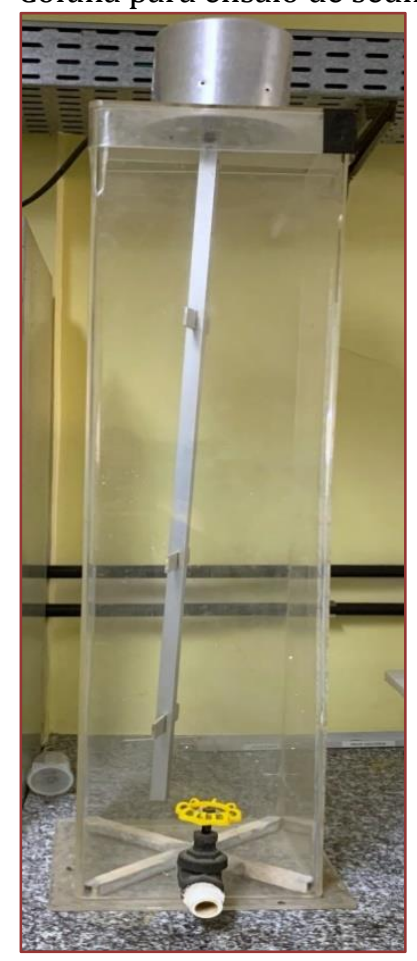


Figura 2 - Dimensões das palhetas do agitador utilizados durante os ensaios de adensamento

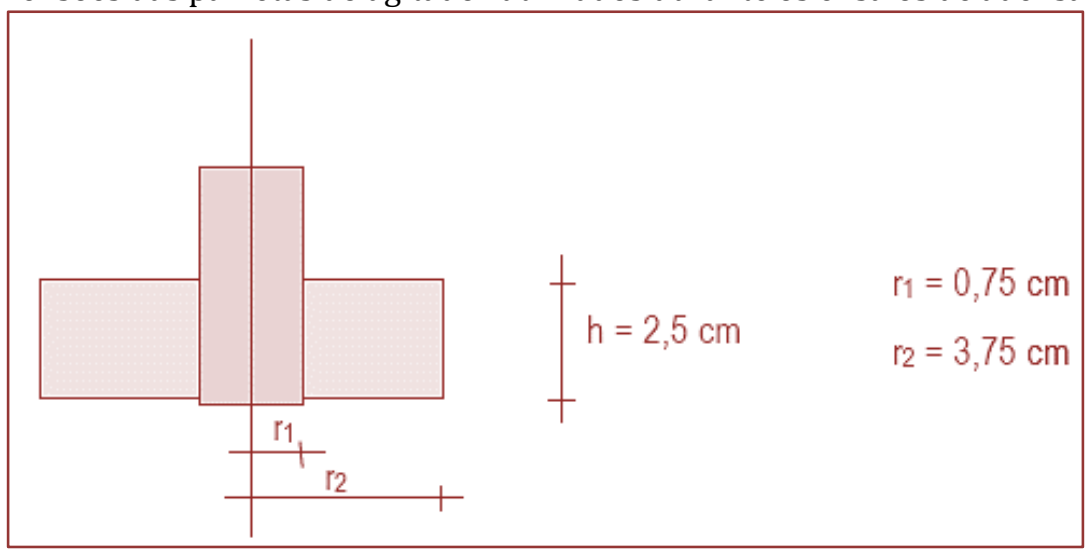

Tabela 2 - Resumo dos ensaios de sedimentação em coluna.

\begin{tabular}{|c|c|c|c|}
\hline & Teor de sólidos na coluna & \multicolumn{2}{c|}{ Dosagem de polímero $(\mathrm{g} / \mathrm{kg})$} \\
\hline Sem polímero & $(0,3 \%)$ & - & - \\
\hline Com polímero & $(0,3 \%)$ & 1 & 4 \\
\hline
\end{tabular}

Segundo a metodologia proposta por Teixeira (1999) o ensaio de adensamento em coluna ocorre em 3 passos, sendo a primeira o preparo da solução de polímero, seguida do preparo do lodo na coluna e por ultimo o ensaio de adensamento propriamente dito, conforme apresentado a seguir.

- Preparo da solução de polímero a 0,5\%.

- Em um béquer com capacidade de $1000 \mathrm{ml}$ adicionar $500 \mathrm{ml}$ de água, medida em balão volumétrico.

- Com o auxílio de uma seringa, tomar o volume equivalente a 2,5 g de polímero (estado líquido), calculado através da equação 1 . No caso do polímero em estado sólido pesar diretamente o conteúdo em balança de precisão.

$$
V=\frac{m}{\rho} \quad \text { Eq. (1) }
$$

onde $: \mathrm{V}=$ volume de polímero $\left(\mathrm{L}^{3}\right)$

$\mathrm{m}=$ massa de polímero $(\mathrm{M})$

$\rho=$ massa específica do polímero $\left(\mathrm{M} / \mathrm{L}^{3}\right)$

- Misturar o conteúdo do béquer com um agitador manual e inserir o volume de polímero previamente calculado próximo à região central, de tal forma a não permitir que o polímero fique aderido às paredes do béquer ou as hastes do agitador.

- Homogeneizar durante 60 segundos.

- Após 15 minutos agitar novamente por mais 60 segundos.

- Reservar em um balão de 1000 mL. 


\section{Nesta etapa você vai precisar:}

1 béquer de vidro de $100 \mathrm{~mL}, 1$ balão volumétrico de vidro de $500 \mathrm{~mL}, 1$ balão volumétrico de vidro de $1000 \mathrm{~mL}, 1$ bastão de vidro, 1 pisceta com água destilada, seringas plásticas de $10 \mathrm{~mL}$, agitador manual (tipo mix de cozinha), 1 cronômetro e 1 balança de precisão com 4 casas decimais.

\section{- Preparo do lodo na coluna}

- Com os valores já determinados de teor de sólidos do lodo coletado, calcular o volume necessário para a preparação do lodo, de acordo com o teor de sólidos desejado na coluna, através da equação:

$$
C_{b} \cdot V_{b}=C_{c} \cdot V_{c}
$$

onde: $\mathrm{Cb}=$ teor de sólidos na bombona (\%)

$\mathrm{Vb}=$ volume de lodo a ser disposto na coluna (lt)

$\mathrm{Cc}=$ teor de sólidos desejado na coluna (\%)

$\mathrm{Vc}=$ volume útil da coluna (lt)

- Despejar o volume de lodo calculado na coluna e preencher o restante do volume com água;

- Fixar o agitador na parte superior da coluna e homogeneizar o lodo;

- Retirar uma amostra do lodo da coluna para determinar o teor de sólidos totais de cada amostra de acordo com o método descrito em APHA, AWWA, WEF (2005).

\section{Nesta etapa você vai precisar:}

1 coluna de adensamento (já descrita neste item), 1 cápsula de porcelana de $100 \mathrm{~mL}, 1$ dessecador completo, 1 estufa, 1 balde de plástico graduado com capacidade pra $5 \mathrm{~L}, 1$ proveta de vidro de $100 \mathrm{~mL}, 1$ pisceta com água destilada e 1 balança de precisão com 4 casas decimais.

\section{- $\quad$ Ensaio de adensamento}

- Ajustar a rotação do agitador (115 rpm), aferindo com um rotâmetro.

- Inserir, com o auxílio de uma seringa, o volume de polímero calculado de acordo com a dosagem desejada. A massa de polímero (mp) deverá ser calculada multiplicando-se a massa de sólidos ( $\mathrm{kg}$ ) presente na coluna pela dosagem de polímero $(\mathrm{g} / \mathrm{kg})$.

- Imediatamente após a adição do polímero, deixar em mistura rápida por um tempo de um minuto.

-Parar a agitação, ligar o cronômetro e anotar a posição da interface na coluna a medida que esta desce, em intervalos de tempos regulares de 30 segundos, até que tenham decorrido dez minutos.

- Retirar uma amostra de lodo do fundo da coluna para determinar o teor de sólidos totais de cada amostra de acordo com o método descrito em APHA, AWWA, WEF (2005).

-Retirar uma amostra do sobrenadante e determinar cor aparente, turbidez e pH.

-Esvaziar a coluna de adensamento e lavar com água o conjunto agitador e coluna.

\section{Nesta etapa você vai precisar:}

1 coluna de adensamento (já descrita neste item), 1 cápsula de porcelana de $100 \mathrm{~mL}, 1$ dessecador completo, 1 estufa, 1 balde de plástico graduado com capacidade pra $5 \mathrm{~L}, 1$ proveta de vidro de $100 \mathrm{~mL}, 1$ pisceta com água destilada, 3 béquers de $50 \mathrm{~mL}, 1$ turbidímetro, 1 colorímetro, 1 medidor de $\mathrm{pH}$ e 1 balança de precisão com 4 casas decimais.

Não se esqueça de estar adequadamente vestido com calças compridas, sapatos fechados, jaleco, luvas e máscara. Também fiquem atentos para fazer registros fotográficos em todas as etapas. 


\subsection{TRATAMENTO DOS DADOS OBTIDOS LABORATÓRIO}

Todos os dados devem ser organizados em planilha eletrônica Excel ou equivalente e trabalhados para a determinação da velocidade de sedimentação e a melhor condição testada.

- Preencher a Tabela 2 com os valores de TST obtidos no fundo da coluna de adensamento em cada condição testada.

Tabela 2- Teor de Sólidos Totais (TST) no fundo da coluna de adensamento para cada condição testada.

\begin{tabular}{|c|c|c|c|c|}
\hline Sem polímero & \multicolumn{3}{|c|}{ Com polímero } \\
\hline T.S.T (\%) & $\begin{array}{c}\text { Dosagem de polímero } \\
(\mathrm{g} / \mathrm{kg})\end{array}$ & T.S.T (\%) & Dosagem de polímero (g/kg) & T.S.T (\%) \\
\hline & 1 & & 4 & \\
\hline
\end{tabular}

- Preencher a Tabela 3 com os valores de cor aparente, Turbidez e pH obtidos em cada condição testada.

Tabela 3 - Cor aparente, turbidez e pH para cada condição testada.

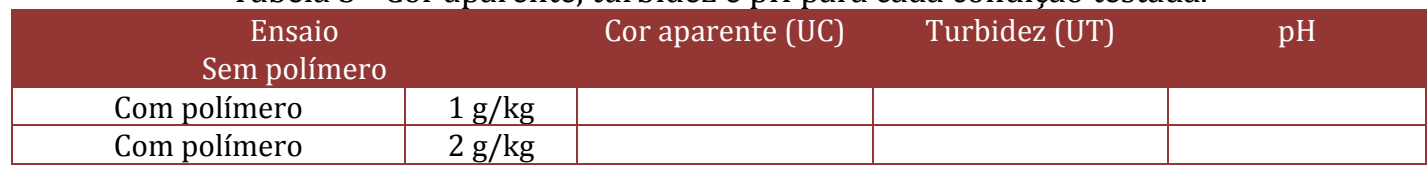

- Gerar gráfico de altura de interface com linha de tendência ao longo do tempo para cada condição testada.

- Calcular, para cada curva gerada, a velocidade de sedimentação em zona (vsz) pela tangente do trecho inicial retilíneo. Preencher a Tabela 4.

Tabela 4 - Velocidade de sedimentação em zona (vsz) para cada condição testada

\begin{tabular}{|c|c|c|c|c|}
\hline Sem polímero & \multicolumn{3}{|c|}{ Com polímero } \\
\hline Vsz $(\mathrm{cm} / \mathrm{s})$ & $\begin{array}{c}\text { Dosagem de polímero } \\
(\mathrm{g} / \mathrm{kg})\end{array}$ & Vsz $(\mathrm{cm} / \mathrm{s})$ & $\begin{array}{c}\text { Dosagem de polímero } \\
(\mathrm{g} / \mathrm{kg})\end{array}$ & Vsz $(\mathrm{cm} / \mathrm{s})$ \\
\hline & 1 & & 4 & \\
\hline
\end{tabular}

- Calcular os coeficientes A e B e estabelecer a equação da VSZ para cada condição testada.

- Comparar os resultados obtidos visando explicar e definir a melhor condição testada.

\section{BIBLIOGRAFIA}

[1] ABNT. NBR 10004.- Resíduos Sólidos - Classificação. Associação Brasileira de Normas Técnicas. Rio de Janeiro-RJ, 1987.

[2] AMERICAN PUBLIC HEALTH ASSOCIATION. Standard Methods for the Examination of Water and Wastewater. 21 ed. Washington, 2005.

[3] AWWA. AMERICAN WATER WORKS ASSOCIATION. Management of water treatment plant residuals. New York . American Society of Civil Engineers, 1996. 294 p.

[4] DI BERNARDO, L.; DI BERNARDO, A.; CENTURIONE FILHO, P. L. Ensaios de Tratabilidade de Água e dos Resíduos Gerados em Estações de Tratamento de Água. Universidade de São Carlos, 2002. 237p.

[5] DI BERNARDO, L.; DANTAS, A. D.; VOLTAN, P.E.N. Tratabilidade de água e resíduos gerados em estações de tratamento de água. São Carlos - SP. Editora LDiBe, 2011.

[6] GUIMARÃES, G. C; Estudo de adensamento e desidratação dos resíduos gerados na ETA- Brasília. Dissertação (Mestrado) - Universidade de Brasília. Faculdade de Tecnologia. Brasília, 2007.

[7] MATOS, M.R.U, GIRARD, L. Caracterização físico-química e ensaios de adensamento em coluna do lodo produzido em uma Estação de Tratamento de Água de grande porte. Revista Brasileira de Ciências Ambientais, n 28, 2013. 
[8] MONTGOMERY, J. M. Water treatment principles and design. 696 p. New York. John Wiley \& Sons 1985.

[9] RICHTER, C. A. Tratamento de Lodos de Estações de Tratamento de Água. E. Blucher, São Paulo, 2001.

[10] TEIXEIRA, L.C.G.M. Adensamento por gravidade de lodos produzidos em estações de tratamento de água. Dissertação (Mestrado) - Escola Politécnica da Universidade de São Paulo. São Paulo, 1999, 195p.

[11] YUZHU, W. Condicionamento de lodo de estação de tratamento de água: estudo de caso. São Paulo, 1996. 419p. Dissertação (Mestrado) -Escola Politécnica da Universidade de São Paulo. 


\section{Capítulo 10}

Aula prática: Determinação de oxigênio dissolvido em águas método químico

Silvana Carvalho Veloso 


\title{
10.1. OBJETIVOS INSTRUCIONAIS
}

Ao final da aula prática de análise de oxigênio dissolvido em amostras de água o aluno estará apto a:

1. Compreender a importância do oxigênio dissolvido como indicador de qualidade de ambientes aquáticos;

2. Entender as etapas no desenvolvimento da análise;

3. Realizar a análise de forma adequada;

4. Calcular os resultados da quantidade de oxigênio dissolvido presente na amostra;

5. Interpretar os resultados obtidos, comparando com as legislações ambientais vigentes, dentro das especificidades e objetivos de cada trabalho.

\subsection{A IMPORTÂNCIA DO OXIGÊNIO DISSOLVIDO (OD) COMO INDICADOR DE QUALIDADE}

O oxigênio dissolvido, dentre outros parâmetros ambientais, é fundamental na manutenção do equilíbrio dos ecossistemas aquáticos e na qualidade da água de mananciais. Muito utilizado em estudos ambientais é indicador de impactos relacionados aos lançamentos de efluentes, sendo um dos principais parâmetros de caracterização dos efeitos da poluição.

É fundamental nos estudos de autodepuração natural de corpos d'água e no monitoramento e controle operacional em estações de tratamento de esgoto. Pelo fato de fornecer uma boa indicação da condição de ambientes aquáticos é utilizado com frequência no planejamento e gestão de recursos hídricos.

O oxigênio pode ser inserido de ambientes aquáticos de várias formas, processos naturais e artificiais podem atuar para essa inserção de oxigênio no ambiente aquático. As plantas aquáticas e algas, durante os processos de fotossíntese, liberam e contribuem com oxigênio para os corpos d'água. A Atmosfera também contribui para aeração em corpos d'água, por difusão. Em mananciais superficiais com quedas d'águas e/ou corredeiras e intensa movimentação da água, a aeração é potencializada. Existem ainda, processos artificiais que são utilizados, principalmente, em processos de tratamento de efluentes. A depleção de oxigênio pode ocorrer a partir da oxidação de íons metálicos, da degradação de matéria orgânica, e pela elevação da temperatura de corpos hídricos. Esse rebaixamento da concentração do oxigênio em ambientes aquáticos é prejudicial à manutenção dos ecossistemas aquáticos.

A resolução 357/05 da legislação do Conselho Nacional do Meio Ambiente - CONAMA estabelece o valor mínimo de $5 \mathrm{mg} / \mathrm{L}$ (águas classe 2, quando não se te sem o enquadramento do corpo hídrico) como valor seguro para equilíbrio e manutenção de ambientes aquáticos.

\subsection{ETAPAS DO DESENVOLVIMENTO DA ANÁLISE DE OXIGÊNIO DISSOLVIDO (OD);}

A análise de oxigênio dissolvido pelo método químico, também conhecido como método de Winkler modificado ou iodométrico, é realizada em algumas etapas até sua finalização completa. As etapas seguidas no método são:

\author{
1. Coleta da amostra \\ 2. Fixação da amostra; \\ 3. Liberação da amostra; \\ 4. Titulação da amostra;
}

A coleta de amostras para análise de oxigênio dissolvido pode ser realizada utilizando-se um batiscafo ou uma garrafa hidrológica. 0 batiscafo (Figura 1) é indicado para realizar coletas superficiais ou subsuperficiais até $30 \mathrm{~cm}$ da coluna d'água. 
Figura 1 - Batiscafo para coleta de amostras superficiais

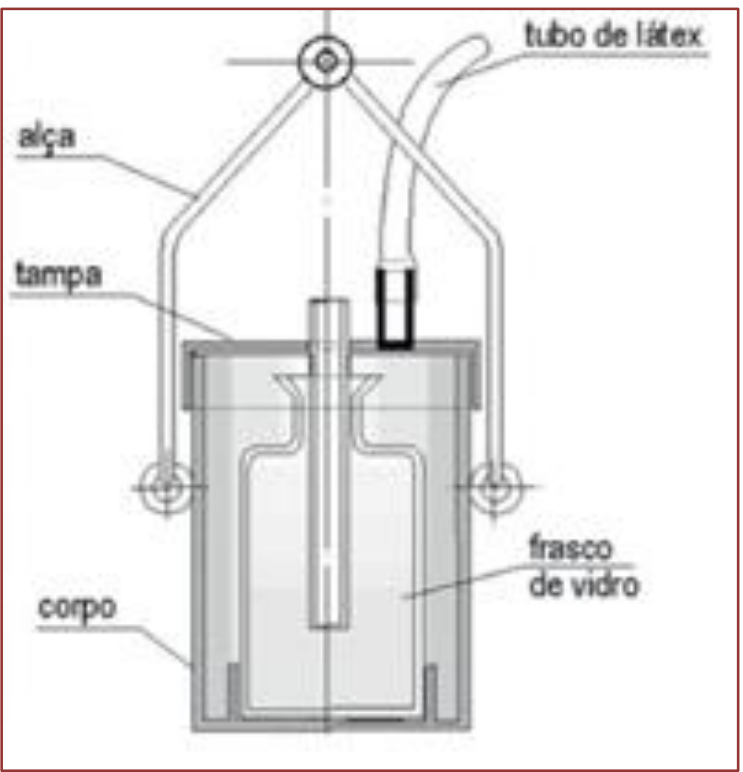

Fonte: CETESB 2011

A água entra através de um tubo localizado na parte superior da tampa do equipamento e atinge o interior do frasco, fazendo com que o ar contido saia por um orifício lateral à medida que ele vai sendo preenchido com água (CETESB, 2011). Para coleta de amostras superficiais e em diferentes profundidades utiliza-se a garrafa hidrológica. Existem modelos diferentes e capacidades variadas de garrafas hidrológicas. Os tipos mais utilizados são van Dorn e Niskin (Figura 2).

Figura 2 - Garrafas hidrológicas de coleta de amostra de água em superfície e em profundidade; A- garrafa de Niskin; B- garrafa de van Dorn

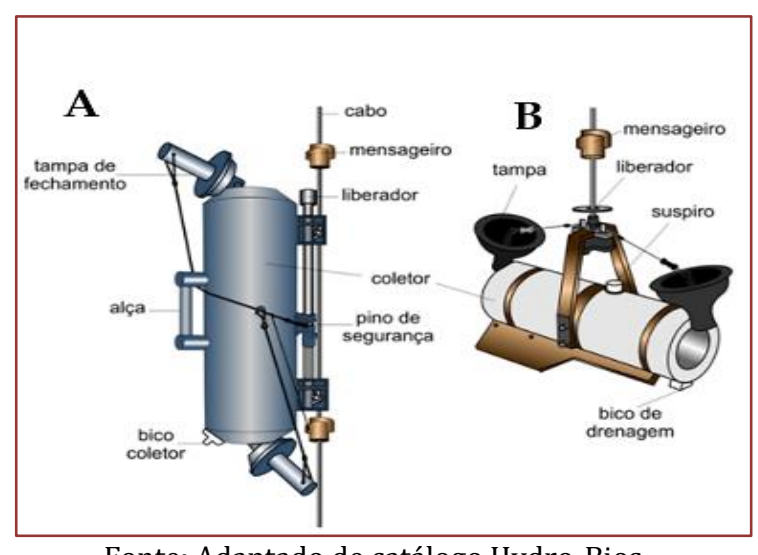

Fonte: Adaptado de catálogo Hydro-Bios

Para realizar a coleta de amostras a garrafa é mergulhada com ambas as extremidades abertas, ao atingir a profundidade desejada, o mensageiro (Figura 3) é solto e fecha o amostrador hermeticamente. 
Figura 3 - Modelos de mensageiros de garrafas hidrológicas

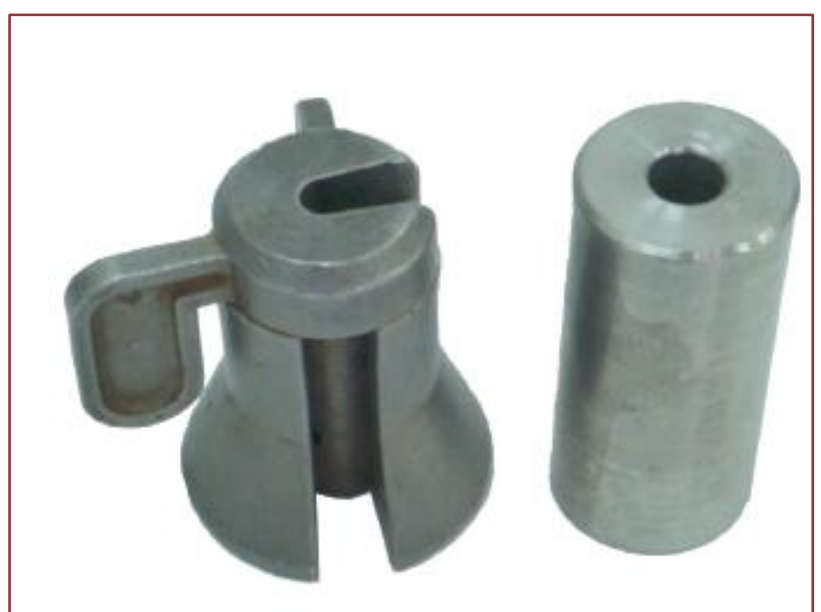

Fotos: Carlos Jesus Brandão/CETESB).

$\mathrm{Na}$ amostragem utilizando a garrafa hidrológica, a amostra coletada deve ser distribuída para o frasco de DBO (frasco de vidro borossilicato com tampa esmerilhada e selo d'água) de capacidade de $300 \mathrm{ml}$ (Figura 4), de forma cuidadosa, a fim de evitar a aeração da amostra no momento da transferência. É importante que a amostra coletada não contenha bolhas de ar no seu interior, o que pode causar inferência e levar a um falso resultado.

Figura 4 - Frasco de DBO com capacidade de $300 \mathrm{ml}$
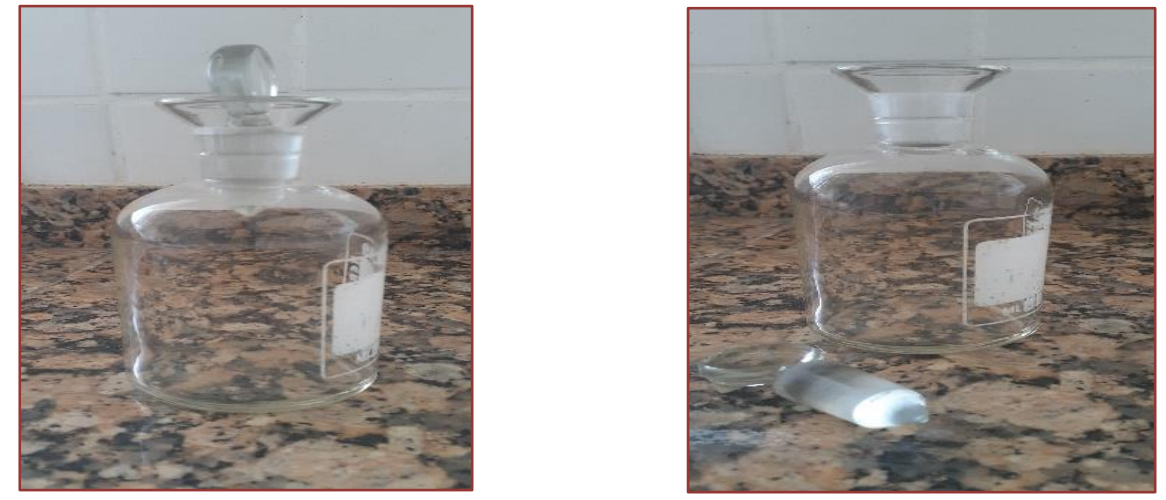

Nesse tipo de procedimento, é necessário introduzir a mangueira de saída de água da garrafa hidrológica até o fundo do frasco DBO e abrir o bico de drenagem devagar, enchendo o frasco cuidadosamente até extravasar a uma quantidade de água e só então tampar o frasco observando a ausência de bolhas de ar no interior do frasco. A incidência de luz também pode alterar as características iniciais da amostra e por isso é importante que após a coleta da amostra, o frasco seja mantido protegido da luz.

A fixação do oxigênio dissolvido na amostra é realizada com a adição de 2 (dois) reagentes, o sulfato manganoso $\left(\mathrm{MnSO}_{4}\right)\left(\mathrm{R}_{1}\right)$ e a solução álcali-iodeto-azida $\left(\mathrm{R}_{2}\right)$, que é uma solução de hidróxido de sódio $(\mathrm{NaOH})$, iodeto de sódio (NaI), e azida sódica $\left(\mathrm{NaN}_{3}\right)$. Os reagentes $\mathrm{R}_{1}$ e $\mathrm{R}_{2}$ são adicionados imediatamente após a coleta, a fim de evitar que ocorram alterações na concentração do oxigênio presente na amostra. Nessa etapa ocorre a formação de óxido manganês (Equação 1). Com intensa floculação da amostra (Figura 5).

$$
\mathrm{Mn}\left(\mathrm{OH}_{2}\right)+1 / 2 \mathrm{O}_{2} \rightarrow \mathrm{MnO}_{2}+\mathrm{H}_{2} \mathrm{O}
$$


Figura 5 - Floculação na amostra causada pela adição dos reagentes $\mathrm{R}_{1}$ e $\mathrm{R}_{2}$.

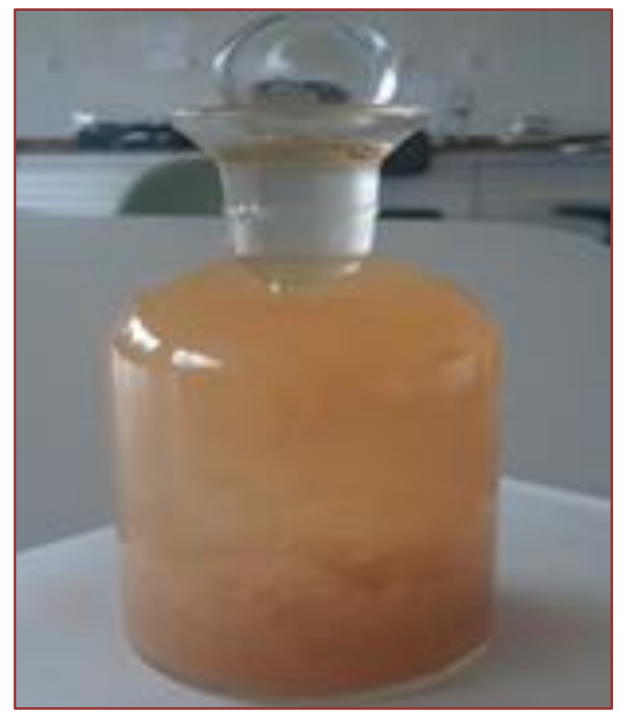

A azida sódica foi incorporada a análise para remover os nitritos presentes que são interferentes na reação, conforme equação 2,3 ;

$$
\begin{aligned}
& \mathrm{NaN}_{3}+\mathrm{H}^{+} \rightarrow \mathrm{HN}_{3}+\mathrm{Na}^{+} \\
& \mathrm{HN}_{3}+\mathrm{NO}_{2}^{--}+\mathrm{H}^{+} \rightarrow \mathrm{N}_{2}+\mathrm{N}_{2} \mathrm{O}+\mathrm{H}_{2} \mathrm{O}
\end{aligned}
$$

A liberação da amostra para a titulação (última etapa da análise) é realizada pela adição de ácido sulfúrico concentrado (Equação 4), que quebra os flocos formados e causa o aparecimento de uma coloração amarelada, que é proporcional a concentração de oxigênio dissolvido contido na amostra.

$$
\mathrm{MnO}_{2}+2 \mathrm{I}^{-}+4 \mathrm{H}^{+} \rightarrow \mathrm{Mn}^{+2}+\mathrm{I}_{2}+2 \mathrm{H}_{2} \mathrm{O}
$$

Nesta etapa da análise o íon iodeto anteriormente formado, é oxidado a iodo molecular em quantidade proporcional ao óxido de manganês presente na amostra, que é também proporcional à concentração de oxigênio dissolvido presente.

A última etapa da análise é a titulação do iodo liberado na amostra, com o reagente tiossulfato de sódio (Na2S406) (Equação 5). Esta etapa é também conhecida como iodometria.

$$
2 \mathrm{Na}_{2} \mathrm{~S}_{2} \mathrm{O}_{3}+\mathrm{I}_{2} \rightarrow \mathrm{Na}_{2} \mathrm{~S}_{4} \mathrm{O} 6+2 \mathrm{NaI}+10 \mathrm{H}_{2} \mathrm{O}
$$


A amostra é titulada com Tiossulfato de sódio $\left(\mathrm{Na}_{2} \mathrm{~S}_{2} \mathrm{O}_{3}\right)$ 0,0125 N. Uma solução de amido é utilizada como um indicador de viragem nessa titulação. 0 ponto final da titulação é a viragem da coloração azul para incolor.

\subsection{PRÁTICA EM LABORATÓRIO}

Nossa aula prática acontecerá no laboratório ou em campo (com adequação de local para as titulações), com medições reais e na sequência de etapas do método e ao final da titulação o cálculo do resultado com possibilidade de comparação com os valores permitidos pela legislação ambiental vigente para o parâmetro analisado.

É interessante ressaltar que a titulação para a determinação do oxigênio dissolvido em amostras de água tem um prazo definido para ser realizada, que é de até $8 \mathrm{~h}$ após a etapa de fixação (etapa que preserva a amostra de alterações de suas características iniciais) (CETESB, 2011). E é por esse motivo, que em algumas situações é necessário realizar a titulação em campo. Nesse sentido, é possível levar até o local de coleta o material necessário a realização da análise, organizando uma bancada com as vidrarias e reagentes necessários para a análise com os mesmos cuidados, atenção, organização como no laboratório.

\subsubsection{SELEÇÃO DO LOCAL}

O local escolhido deve atender aos critérios apresentados em sala de aula. Para determinação da quantidade de oxigênio presente em um corpo d'água é necessário observar in loco um local onde é possível realizar a coleta de forma segura e com representatividade; observar dentro do objetivo do estudo, se as amostras são de águas superficiais ou subterrâneas e utilizar o equipamento indicado para a realização da coleta. Para executar as etapas já mencionadas anteriormente de forma adequada é importante organizar a bancada com todo material necessário ao desenvolvimento da metodologia. $\mathrm{Na}$ etapa de laboratório, a utilização de EPI (Equipamentos de Proteção Individual) é indicada, além de vestimenta adequada, como jalecos de mangas compridas, calça jeans, sapato fechado. Após o procedimento de coleta, acondicionamento e preservação das amostras segundo Guia de coleta e preservação de amostras de água (CETESB, 2011) separar o material necessário para análise.

\subsubsection{MATERIAIS/ REAGENTES; VIDRARIAS UTILIZADOS NA ANÁLISE}

\subsubsection{REAGENTE UTILIZADOS NA ANÁLISE}

Solução de sulfato de Manganês;

Solução alcalina de iodeto e azida sódica;

Ácido sulfúrico concentrado;

Solução indicadora de amido 1\%;

Solução padronizada de tiossulfato de sódio $(0,0125 \mathrm{~N})$;

\subsubsection{MATERIAIS E EQUIPAMENTOS}

Batiscafo;

Garrafa hidrológica;

Frascos de DBO de capacidade de $300 \mathrm{ml}$;

Buretas de $25 \mathrm{ml}$;

Proveta de $100 \mathrm{ml}$;

Pipeta graduada de $10 \mathrm{ml}$;

Erlenmeyer de $250 \mathrm{ml}$; 


\subsubsection{PROCEDIMENTO ANALÍTICO}

1. Encher o frasco de OD com a amostra coletada, deixar extravasar um pouco (evitar aeração);

2. Tampar o frasco tendo o cuidado de não deixar bolhas de ar no interior da amostra;

3. Adicionar nesta ordem:

$1 \mathrm{ml} \mathrm{de} \mathrm{MnSO}_{4}$

$1 \mathrm{ml}$ de Iodeto alcalino;

Tampar e agitar por inversão por 3 vezes;

Deixar decantar por cerca de 3 minutos;

$1 \mathrm{ml} \mathrm{de} \mathrm{H}_{2} \mathrm{SO}_{4}$ concentrado.

4. Tampar e agitar por inversão (a coloração amarelada indica a presença de oxigênio na amostra (Figura 6), a presença de um precipitado branco, é indicativo da ausência de oxigênio dissolvido na amostra (Figura 7);

Figura 6 - Presença da coloração amarelada indica a presença de oxigênio na amostra de água

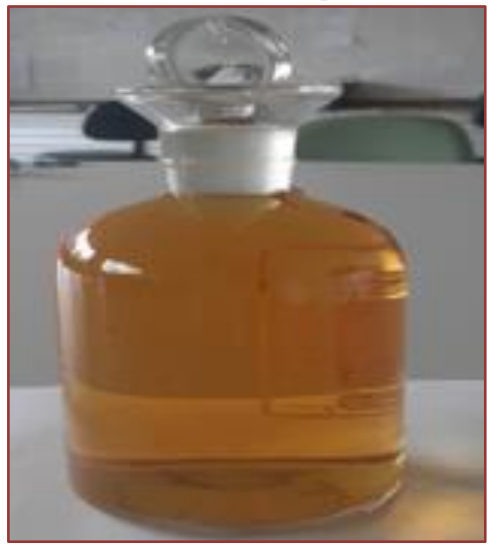

Fonte: Autora

Figura 7 - Precipitado branco indicando ausência de oxigênio na amostra de água

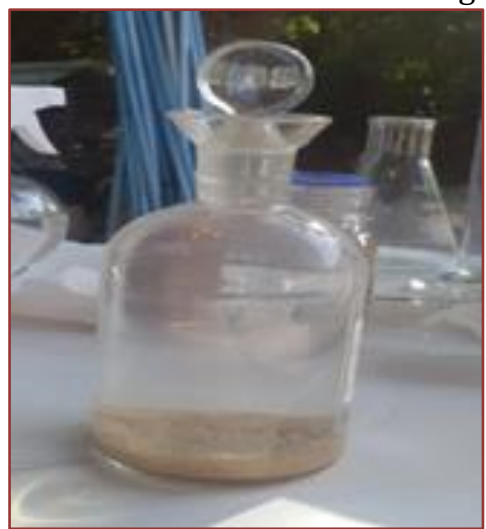

Fonte: Autora

5. Passar $100 \mathrm{ml}$ da solução que indica a presença de OD para um erlenmeyer de $250 \mathrm{ml}$ (esta etapa é realizada em triplicata);

6. Titular com $\mathrm{Na}_{2} \mathrm{~S}_{2} \mathrm{O}_{3}(0,0125 \mathrm{~N})$ até que a solução fique amarelo pálido;

7. Adicionar então $1 \mathrm{ml}$ de indicador amido à solução;

8. Continuar a titulação com o $\mathrm{Na}_{2} \mathrm{~S}_{2} \mathrm{O}_{3}$ até ponto final de viragem de azul para incolor; anotar o volume total de $\mathrm{Na}_{2} \mathrm{~S}_{2} \mathrm{O}_{3}$ gasto na titulação. 


\subsection{CÁLCULO DOS RESULTADOS APÓS A FINALIZAÇÃO DA ANÁLISE;}

A expressão dos resultados para a análise de oxigênio dissolvido é dada em mg02/L e é obtido pela fórmula abaixo;

$$
O_{2}(m g / L)=\frac{V_{1} \times \mathrm{N}\left(\mathrm{Na}_{2} S_{2} O_{3}\right) \times \mathrm{f} \times 8000}{V_{2}}
$$

Onde:

$$
\begin{aligned}
& V_{1}=\text { volume de Tiossulfato }\left(\mathrm{Na}_{2} \mathrm{~S}_{2} \mathrm{O}_{3}\right) \text { gasto na titulação; } \\
& N=\text { concentração da solução de Tiossulfato }\left(\mathrm{Na}_{2} \mathrm{~S}_{2} \mathrm{O}_{3}=0,0125 \mathrm{~N}\right) ; \\
& F=\text { fator de correção (obtido na padronização do Tiossulfato); } \\
& V_{2}=\text { volume da amostra titulada. }
\end{aligned}
$$

\subsection{INTERPRETAÇÃO DOS RESULTADOS OBTIDOS, APLICANDO AS LEGISLAÇÕES AMBIENTAIS VIGENTES}

As resoluções que estabelecem valores máximos permitidos (VMP) para parâmetros ambientais em mananciais superficiais, são as resoluções do Conselho Nacional de Meio Ambiente - CONAMA. Em se tratando de água doces, classe 2, aplica-se o valor de $5 \mathrm{mg} / \mathrm{L}$ de $\mathrm{O}_{2}$, como valor mínimo necessário a manutenção dos ecossistemas aquáticos (CONAMA 357/05). Assim, ambientes aquáticos com valores inferiores a $5 \mathrm{mg} / \mathrm{L}$ de $\mathrm{O}_{2}$, podem indicar aporte de matéria orgânica no corpo hídrico, o que provoca o consumo de oxigênio, causando desequilíbrio no ecossistema. É importante ressaltar que uma única análise não é suficiente para diagnosticar impactos em determinado corpo hídrico. 0 monitoramento ambiental, com uma malha amostral bem definida e em períodos que seja possível verificar a variação sazonal do parâmetro ambiental estudado é importante para se ter uma avaliação mais segura e com isso interpretações mais corretas do ambiente estudado.

\section{BIBLIOGRAFIA}

[1] APHA, AWWA, WEF, "Standard Methods for the Examination of Water and Wastewater", 18th ed. Washington, 1992.

[2] BRASIL. FUNDAÇÃO NACIONAL DE SAÚDE. Manual prático de análise de água. 1a. ed. Brasília: Fundação Nacional de Saúde, 2004.

[3] CETESB (2011) Guia nacional de coleta e preservação de amostras: água, sedimento, comunidades aquáticas e efluentes líquidos/Companhia Ambiental do Estado de São Paulo; Organizadores: Carlos Jesus Brandão... [et al.]. -São Paulo: CETESB; Brasília, 2011.

[4] CONSELHO NACIONAL DE MEIO AMBIENTE - CONAMA. Dispõe sobre a classificação dos Corpos de água e diretrizes ambientais para seu enquadramento, bem como estabelece as condições e padrões de lançamentos de efluentes, e dá outras providências. Resoluções no 357, de 17 de março de 2005.

[5] NBR 9898 - Preservação e técnicas de amostragem de efluentes líquidos e corpos receptores - 1987.

[6] NBR 9897 - Planejamento de amostragem de efluentes líquidos e corpos receptores - junho 1987. 
